NBER WORKING PAPER SERIES

\title{
DOES HAZARDOUS WASTE MATTER? EVIDENCE FROM THE HOUSING MARKET AND THE SUPERFUND PROGRAM
}

\author{
Michael Greenstone \\ Justin Gallagher \\ Working Paper 11790 \\ http://www.nber.org/papers/w11790 \\ NATIONAL BUREAU OF ECONOMIC RESEARCH \\ 1050 Massachusetts Avenue \\ Cambridge, MA 02138 \\ November 2005
}

We thank Daron Acemoglu, David Autor, Maureen Cropper, Esther Duflo, Dick Eckhaus, Alex Farrell, Don Fullerton, Ted Gayer, Jon Gruber, Jon Guryan, Joe Gyourko, Paul Joskow, Matthew Kahn, David Lee, Jim Poterba, Katherine Probst, Bernard Salanie, Randall Walsh, Rob Williams, and especially Ted Gayer for insightful comments. The paper also benefited from the comments of seminar participants at ASSA, BYU, UC-Berkeley, UC-Davis, UC-Santa Barbara, CEMFI, Colorado, Columbia, HEC Montreal, Kentucky, LSE, MIT, NBER, Rand, Resources for the Future, SITE, Stanford, Syracuse, Texas, and UCLA. Leila Agha, Brian Goodness, Elizabeth Greenwood, Rose Kontak, William Li, and Jonathan Ursprung provided outstanding research assistance. We especially thank Katherine Probst for generously sharing data on the costs of Superfund clean-ups. Funding from the Center for Integrating Statistical and Environmental Science at the University of Chicago and the Center for Energy and Environmental Policy Research at MIT is gratefully acknowledged. The views expressed herein are those of the author(s) and do not necessarily reflect the views of the National Bureau of Economic Research.

(C2005 by Michael Greenstone and Justin Gallagher. All rights reserved. Short sections of text, not to exceed two paragraphs, may be quoted without explicit permission provided that full credit, including $\odot$ notice, is given to the source. 
Does Hazardous Waste Matter? Evidence from the Housing Market and the Superfund Program Michael Greenstone and Justin Gallagher

NBER Working Paper No. 11790

November 2005

JEL No. H4, Q51, Q53, R5, R2, I18

\section{ABSTRACT}

Approximately $\$ 30$ billion (2000\$) has been spent on Superfund clean-ups of hazardous waste sites, and remediation efforts are incomplete at roughly half of the 1,500 Superfund sites. This study estimates the effect of Superfund clean-ups on local housing price appreciation. We compare housing price growth in the areas surrounding the first 400 hazardous waste sites to be cleaned up through the Superfund program to the areas surrounding the 290 sites that narrowly missed qualifying for these clean-ups. We cannot reject that the clean-ups had no effect on local housing price growth, nearly two decades after these sites became eligible for them. This finding is robust to a series of specification checks, including the application of a quasi-experimental regression discontinuity design based on knowledge of the selection rule. Overall, the preferred estimates suggest that the benefits of Superfund clean-ups as measured through the housing market are substantially lower than the $\$ 43$ million mean cost of Superfund clean-ups.

Michael Greenstone

MIT, Department of Economics

50 Memorial Drive, E52-359

Cambridge, MA 02142-1347

and NBER

mgreenst@mit.edu

Justin Gallagher

Department of Economics

549 Evans Hall, MC 3880

UC Berkeley

Berkeley, CA 94720-3880

justing@econ.berkeley.edu 


\section{Introduction}

The estimation of individuals' valuations of environmental amenities with revealed preference methods has been an active area of research for more than three decades. Numerous theoretical models outlining revealed preference methods to recover economically well defined measures of willingness to pay have been developed. In principle, these methods can be used in a variety of settings, including housing markets, recreational choices, health outcomes, and the consumption of goods designed to protect individuals against adverse environmentally-induced outcomes. ${ }^{1}$ The application of these approaches, however, is often accompanied by seemingly valid concerns about misspecification that undermine the credibility of any findings. Consequently, many are skeptical that markets can be used to determine individuals' valuation of environmental amenities. Further, the increasing reliance on stated preference techniques to value environmental amenities is surely related to dissatisfaction with the performance of revealed preference techniques. ${ }^{2}$

Hazardous waste sites are an example of an environmental disamenity that provokes great public concern. The 1980 Comprehensive Environmental Response, Compensation, and Liability Act, which became known as Superfund, aims to address this concern. The Act gave the EPA the right to initiate remedial clean-ups at sites where a release or significant threat of a release of a hazardous substance poses an imminent and substantial danger to public welfare and the environment. Since the passage of the Superfund legislation, more than 1,500 sites have been placed on the National Priorities List (NPL), qualifying those sites for federally financed remediation. As of 2000, approximately $\$ 30$ billion (2000\$) has been spent on clean-ups, and remediation efforts are incomplete at roughly half of the sites. Despite these past and future expenditures, there has not been a systematic accounting of the benefits of Superfund clean-ups of hazardous waste sites. As a result, Superfund is a controversial program. ${ }^{3}$

This paper estimates the effect of Superfund sponsored clean-ups of hazardous waste sites on

\footnotetext{
${ }^{1}$ See Freeman (2003) and Champ, Boyle, and Brown (2003) for reviews.

${ }^{2}$ See Hanemann (1994)) and Diamond and Hausman (1994) for discussions of stated preference techniques.

${ }^{3}$ In March 1995 in Congressional testimony, Katherine Probst of Resources for the Future said, "Although the program has been in existence for over 14 years, we still know very little about the benefits of site cleanup or about the associated costs." At the same hearing, John Shanahan of the Heritage Foundation said, "Superfund...is widely regarded as a wasteful and ineffective program in dire need of substantive reform."
} 
housing price appreciation in areas surrounding the sites. The empirical challenge is that the evolution of housing prices proximate to the Superfund sites in the absence of the clean-ups is unknown. The development of a valid counterfactual is likely to be especially challenging, because the sites assigned to the NPL are the most polluted ones in the US. Thus, it seems reasonable to assume that prices in these areas are determined by a different process than prices in the remainder of the country for reasons unrelated to the clean-ups. For example, what would have happened to housing prices in Love Canal, NY, in the absence of the famous clean-up there?

To solve this problem, we implement a quasi-experiment based on knowledge of the selection rule that the EPA used to develop the first NPL. Nearly 15,000 sites were referred to the EPA as potential NPL sites in 1980-1, but the EPA's budget could only accommodate 400 clean-ups. Consequently, they initially winnowed the list to the 690 worst sites and then developed the Hazardous Ranking System (HRS). The HRS was used to assign each site a score from 0 to 100 based on the risk it posed, with 100 being the most dangerous. The EPA placed the 400 sites with HRS scores exceeding 28.5 on the initial NPL in 1983, making them eligible for Superfund remedial clean-ups.

Our empirical strategy exploits this selection process by focusing on the areas surrounding the 690 hazardous waste sites that were finalists for the initial NPL. We compare the evolution of residential property values in the areas near sites that had initial HRS scores exceeding 28.5 to the areas proximate to sites that had HRS scores below the 28.5 threshold. The assumption is that the evolution of housing prices in the areas surrounding the sites with scores below 28.5 form a valid counterfactual for price appreciation in areas near sites with HRS scores above the threshold. We also implement a quasiexperimental regression discontinuity design (Cook and Campbell 1979) to focus the comparisons in the "neighborhood" of the cut-off.

The implementation of this HRS based research design suggests that the placement of a hazardous waste site on the NPL is associated with economically small and statistically indistinguishable from zero gains in residential property values. This finding holds whether the growth in housing prices is measured 7 or 17 years after the sites' placement on the NP. Moreover, it is robust to a variety of specification checks, including the regression discontinuity approach. The validity of these results is 
further supported by the finding that observable ex-ante determinants of housing price appreciation are well balanced among census tracts containing sites with HRS scores above and below 28.5, especially near the cut-off. Overall, these findings suggest that the mean benefits of a Superfund clean-up as measured through the housing market are substantially lower than the $\$ 43$ million mean cost of a Superfund clean-up.

A few other results from the HRS research design are noteworthy. There is little evidence that a site's placement on the NPL causes an immediate decline in rental rates or housing prices, which undermines the popular stigma hypothesis (e.g., Harris 1999). Additionally, we cannot reject that the clean-ups fail to cause changes in the fractions of minorities, children or other demographic characteristics of the population in the areas surrounding the sites. ${ }^{4}$ Finally, there is modest evidence that the clean-ups are associated with population increases in the census tracts containing the sites.

The conventional hedonic approach uses ordinary least squares to estimate the effect of a site's placement on the NPL on housing price appreciation. The basis of this approach is a comparison of the areas surrounding NPL sites with the remainder of the US. In contrast to the HRS research design, the conventional approach produces estimates that suggest that gains in property values exceed the mean costs of clean-up. However, these regressions also produce a number of puzzling results that undermine confidence in the approach's validity. Further, the ex-ante determinants of changes in housing prices differ dramatically between areas surrounding NPL sites and the rest of the country. These latter findings underscore the importance of the HRS research design as a potential solution to the misspecification problems that have plagued the conventional implementation of the hedonic approach in other settings and appear to undermine it here.

In addition to the availability of the HRS research design, this study has two other appealing features. First to conduct the study, we assembled the most comprehensive data file ever compiled by the EPA or other researchers on the Superfund program and its effects. The resulting database has

\footnotetext{
${ }^{4}$ See Banzhaf and Walsh (2005) and Cameron and McConnaha (2005) for evidence of migration induced by environmental changes in other contexts.
} 
information on all Superfund hazardous waste sites, the sites that narrowly missed placement on the initial NPL, and census-tract level housing prices for 1980, 1990, and 2000. The data file also contains a wealth of information about the hazardous waste sites, including their precise location, HRS scores, expected and actual (when remediation is complete) costs of clean-up, size in acres, and dates they achieved various milestones (including completion of remediation). Consequently, this study is a substantial departure from the previous Superfund/hazardous waste site hedonic literature, which is entirely comprised of examinations of a single site or handful of them. ${ }^{5}$

Second, we utilize consumers' reveled preferences and assume that they transmit their valuations of the clean-ups through the housing market. If the housing market is operating correctly, price changes will capture the health and aesthetic benefits of clean-ups. Further, hedonic theory can be used to relate the results to the theoretically correct welfare measure of willingness to pay. Thus, this approach frees us from a relying on state preference techniques or the notoriously poor laboratory estimates of risk to human health associated with the thousands of chemicals present at the sites and assumptions about the correct value of a statistical life. $^{6}$

The paper proceeds as follows. Section I provides background on the Superfund program and how its initial implementation provides a research design that may allow for credible estimation of the effects of Superfund clean-ups on price appreciation. Section II reviews the hedonic method theoretically and empirically and uses it to provide an economic interpretation for the results from the HRS research design. Section III details the data sources and provides some summary statistics. Sections IV and V reports on the econometric methods and empirical findings, respectively. Section VI interprets the results and discusses the policy implications, while VII concludes.

\section{The Superfund Program and a New Research Design}

\footnotetext{
${ }^{5}$ A partial list of previous Superfund/hazardous waste site hedonic studies includes Schmalensee et al. (1975), Smith and Michael (1990), Kohlhase (1991), Kiel (1995), Gayer Hamilton, and Viscusi (2000, 2002), Kiel and Zabel (2001), McCluskey and Rausser (2003), Ihlanfeldt and Taylor (2004), Messer et al. (2004), and Farrell (2004).

${ }^{6}$ Viscusi and Hamilton (1999) use EPA provided estimates of the probability of cancer cases at a subsample of sites and find that at the median site expenditure the average cost per cancer case averted by the clean-up exceeds $\$ 6$ billion.
} 


\section{A. History and Broad Program Goals}

Before the regulation of the disposal of hazardous wastes by the Toxic Substances Control and Resource Conservation and Recovery Acts of 1976, industrial firms frequently disposed of wastes by burying them in the ground. Love Canal, NY is perhaps the most infamous example of these disposal practices. Throughout the 1940s and 1950s, this area was a landfill for industrial waste and more than 21,000 tons of chemical wastes were ultimately deposited there. The landfill closed in the early $1950 \mathrm{~s}$ and over the next two decades a community developed in that area. In the 1970s, Love Canal residents began to complain of high rates of health problems, such as cancer, birth defects, miscarriages, and skin ailments. $^{7}$ After New York state investigators found high concentrations of dangerous chemicals in the air and soil, concerns about the safety of this area prompted President Carter to declare a state of emergency that led to the relocation of the 900 residents of this area. The Love Canal incident helped to galvanize support for addressing the legacy of industrial waste and this led to the creation of the Superfund program in 1980.

The centerpiece of the Superfund program, and this paper's focus, is the long-run remediation of hazardous waste sites. ${ }^{8}$ These multi-year remediation efforts aim to reduce permanently the serious, but not imminently life-threatening, dangers caused by hazardous substances. As of 2000, roughly 1,500 sites have been placed on the NPL and thereby chosen for these long-run clean-ups. The next subsection describes the selection process, which forms the basis of our research design.

\section{B. Site Assessment \& Superfund Clean-Ups Processes}

As of 1996, more than 40,000 hazardous waste sites had been referred to the EPA for possible inclusion on the NPL. The EPA follows a multi-step process to determine which of these sites pose the greatest danger to humans and the environment. The assessment process involves determining which

\footnotetext{
${ }^{7}$ EPA (2000) claims that $56 \%$ of the children born in Love Canal between 1974 and 1978 had birth defects.

8 The Superfund program also funds immediate removals. These clean-ups are responses to environmental emergencies and are generally short-term actions aimed at diminishing an immediate threat. Examples of such actions including cleaning up waste spilled from containers and constructing fences around dangerous sites. These actions are not intended to remediate the underlying environmental problem and account for a small proportion of Superfund activities. Importantly, they are administered at hazardous waste sites that are and are not on the NPL.
} 
hazardous chemicals are present at the site and the overall risk level.

The final step of the assessment process is the application of the Hazardous Ranking System (HRS), which is reserved for the most dangerous sites. The EPA developed the HRS in 1982 as a standardized approach to quantify and compare the human health and environmental risk among sites to identify the ones that pose the greatest threat. The original HRS evaluated the risk for exposure to chemical pollutants along three migration 'pathways': groundwater, surface water, and air.' ${ }^{9}$ The toxicity and concentration of chemicals, the likelihood of exposure and proximity to humans, and the population that could be affected are the major determinants of risk along each pathway. The non-human impact that chemicals may have is considered during the process of evaluating the site but plays a minor role in determining the HRS score.

The HRS produces a score for each site that ranges from 0 to 100 , with 100 being the highest level of risk. From 1982-1995, the EPA assigned all hazardous waste sites with a HRS score of 28.5 or greater to the NPL. ${ }^{10}$ These sites are the only ones that are eligible for Superfund remedial clean-up. The Data Appendix provides further details on the determination of HRS test scores.

Once a site is placed on the NPL, it generally takes many years until clean-up is complete. The first step is a further study of the extent of the environmental problem and how best to remedy it. This assessment is summarized in the Record of Decision (ROD), which also outlines the clean-up actions that are planned for the site. The site receives the "construction complete" designation once the physical construction of all clean-up remedies is complete, the immediate threats to health have been removed, and the long-run threats are "under control." The final step is the site's deletion from the NPL.

\footnotetext{
${ }^{9}$ In 1990, the EPA revised the HRS test so that it also considers soil as an additional pathway.

${ }^{10}$ In 1980 every state received the right to place one site on the NPL without the site having to score at or above 28.5 on the HRS test. As of 2003, 38 states have used their exception. It is unknown whether these sites would have received a HRS score above 28.5 .

In 1995 the criteria for placement on the NPL were altered so that a site must have a HRS score greater than 28.5 and the governor of the state in which the site is located must approve the placement. There are currently a number of potential NPL sites with HRS scores greater than 28.5 that have not been proposed for NPL placement due to known state political opposition. We do not know the precise number of these sites because our Freedom of Information Act request for information about these sites was denied by the EPA.
} 


\section{1982 HRS Scores as the Basis of a New Research Design}

This paper's goal is to obtain reliable estimates of the effect of Superfund sponsored clean-ups of hazardous waste sites on housing price appreciation in areas surrounding the sites. The empirical challenge is that NPL sites are the most polluted in the US, so the evolution of housing prices near these sites may not be comparable to that of the remainder of the US, even conditional on observable covariates. To avoid confounding the effects of the clean-ups with unobserved variables, it is necessary to develop a valid counterfactual for the evolution of property values at Superfund sites in the absence of those sites' placement on the NPL and eventual clean-up.

A feature of the initial NPL assignment process that has not been noted previously by researchers may provide a credible solution to the likely omitted variables problem. In the first year after the legislation's passage in 1980, 14,697 sites were referred to the EPA and investigated as potential candidates for remedial action. Through the assessment process, the EPA winnowed this list to the 690 most dangerous sites. Although the Superfund legislation directed the EPA to develop a NPL of "at least" 400 sites (Section 105(8)(B) of CERCLA), budgetary considerations caused the EPA to set a goal of placing exactly 400 sites on the NPL.

The EPA developed the HRS to determine scientifically the 400 out of the 690 sites that posed the greatest risk. Pressured to initiate the clean-ups quickly, the EPA developed the HRS in about a year. The HRS test was applied to the 690 worst sites, and their scores were ordered from highest to lowest. A score of 28.5 divided numbers 400 and 401, so the initial NPL published in September 1983 was limited to sites with HRS scores exceeding 28.5. ${ }^{11}$

The central role of the HRS score provides a compelling basis for a research design that compares outcomes at sites with initial scores above and below the 28.5 cut-off for at least three reasons. First, it is unlikely that sites' HRS scores were manipulated to affect their placement on the NPL, because the 28.5 threshold was established after the testing of the 690 sites was completed. The HRS scores therefore

\footnotetext{
${ }^{11}$ Exactly 400 of the sites on the initial NPL had HRS scores exceeding 28.5. The original Superfund legislation gave each state the right to place one site on the NPL without going through the usual evaluation process. Six of these "state priority sites" were included on the original NPL released in 1983. Thus, the original list contained the 400 sites with HRS scores exceeding 28.5 and the 6 state exceptions. See the Data Appendix for further details.
} 
reflected the EPA's assessment of the human health and environmental risks posed by each site and were not based on the expected costs or benefits of clean-up.

Second, the HRS scores were noisy measures of risk, so it is possible that true risks were similar above and below the threshold. This noisiness was a consequence of the scientific uncertainty about the health consequences of exposure to the tens of thousands of chemicals present at these sites. ${ }^{12}$ Further, the threshold was not selected based on evidence that HRS scores below 28.5 sites posed little risk to health. In fact, the Federal Register specifically reported that the "EPA has not made a determination that sites scoring less than 28.50 do not present a significant risk to human health, welfare, or the environment" (Federal Register 1984, Section IV) and that a more informative test would require "greater time and funds" (EPA 1982). ${ }^{13}$

Third, the selection rule that determined the placement on the NPL is a highly nonlinear function of the HRS score. This naturally lends itself to a comparison of outcomes at sites "near" the 28.5 cut-off. If the unobservables are similar around the regulatory threshold, then a comparison of these sites will control for all omitted factors correlated with the outcomes. This test has the features of a quasiexperimental regression-discontinuity design (Cook and Campbell 1979). ${ }^{14}$

An additional feature of the analysis is that an initial score above 28.5 is highly correlated with eventual NPL status but is not a perfect predictor of it. This is because some sites were rescored, with the

\footnotetext{
${ }^{12}$ A recent summary of Superfund's history makes this point. "At the inception of EPA's Superfund program, there was much to be learned about industrial wastes and their potential for causing public health problems. Before this problem could be addressed on the program level, the types of wastes most often found at sites needed to be determined, and their health effects studied. Identifying and quantifying risks to health and the environment for the extremely broad range of conditions, chemicals, and threats at uncontrolled hazardous wastes sites posed formidable problems. Many of these problems stemmed from the lack of information concerning the toxicities of the over 65,000 different industrial chemicals listed as having been in commercial production since 1945" (EPA 2000, p. 32).

${ }^{13}$ One way to measure the crude nature of the initial HRS test is by the detail of the guidelines used for determining the HRS score. The guidelines used to develop the initial HRS sites were collected in a 30 page manual. Today, the analogous manual is more than 500 pages.

${ }^{14}$ The research design of comparing sites with HRS scores "near" the 28.5 is unlikely to be valid for sites that received an initial HRS score after 1982. This is because once the 28.5 cut-off was set, the HRS testers were encouraged to minimize testing costs and simply determine whether a site exceeded the threshold. Consequently, testers generally stop scoring pathways once enough pathways are scored to produce a score above the threshold. When only some of the pathways are scored, the full HRS score is unknown and the quasi-experimental regression discontinuity design is inappropriate.
} 
later scores determining whether they ended up on the NPL. ${ }^{15}$ The subsequent analysis uses an indicator variable for whether a site's initial (i.e., 1982) HRS score was above 28.5 as an instrumental variable for whether a site was on the NPL in to purge the potentially endogenous variation in NPL status.

Finally, it important to emphasize that sites that failed to qualify for the NPL were ineligible for Superfund remediations. We investigated whether these sites were cleaned-up under state or local programs and found that they were frequently left untouched. Among the sites that were targeted by these programs, a typical solution was to put a fence around the site and place signs indicating the presence of health hazards. The point is that the remediation activities at NPL sites drastically exceeded the clean-up activities at non-NPL sites both in scope and cost.

\section{The Hedonic Method and How It Can Be Used to Interpret the HRS Research Design Results}

\section{A. The Hedonic Method and Its Econometric Identification Problems}

An explicit market for a clean local environment does not exist. The hedonic price method is commonly used to estimate the economic value of non-market amenities like environmental quality to individuals. It is based on the insight that the utility associated with the consumption of a differentiated product, such as housing, is determined by the utility associated with the good's characteristics. For example, hedonic theory predicts that an economic bad, such as proximity to a hazardous waste site, will be negatively correlated with housing prices, holding all other characteristics constant. This section reviews the hedonic method and describes the econometric identification problems associated with its implementation.

Economists have estimated the association between housing prices and environmental amenities at least since Ridker (1967) and Ridker and Henning (1967). However, Rosen (1974) and Freeman (1974) were the first to give this correlation an economic interpretation. In the Rosen formulation, a differentiated good can be described by a vector of its characteristics, $Q=\left(\mathrm{q}_{1}, \mathrm{q}_{2}, \ldots, \mathrm{q}_{\mathrm{n}}\right)$. In the case of a

\footnotetext{
${ }^{15}$ As an example, 144 sites with initial scores above 28.5 were rescored and this led to 7 sites receiving revised scores below the cut-off. Further, complaints by citizens and others led to rescoring at a number of sites below the cut-off. Although there has been substantial research on the question of which sites on the NPL are cleaned-up first (see, e.g., Sigman 2001), we are unaware of any research on the determinants of a site being rescored.
} 
house, these characteristics may include structural attributes (e.g., number of bedrooms), neighborhood public services (e.g., local school quality), and local environmental amenities (e.g., distance from a hazardous waste site). Thus, the price of the $\mathrm{i}^{\text {th }}$ house can be written as:

(1) $\quad P_{i}=P\left(q_{1}, q_{2}, \ldots, q_{n}\right)$.

The partial derivative of $\mathrm{P}(\bullet)$ with respect to the $\mathrm{n}^{\text {th }}$ characteristic, $\partial \mathrm{P} / \partial \mathrm{q}_{\mathrm{n}}$, is referred to as the marginal implicit price. It is the marginal price of the $\mathrm{n}^{\text {th }}$ characteristic implicit in the overall price of the house.

In a competitive market, the locus between housing prices and a characteristic, or the hedonic price schedule (HPS), is determined by the equilibrium interactions of consumers and producers. ${ }^{16}$ In the hedonic model, the HPS is formed by tangencies between consumers' bid and suppliers' offer functions. The gradient of the implicit price function with respect to the health risk associated with proximity to hazardous waste sites gives the equilibrium differential that compensates individuals for accepting the increased health risk. Put another way, areas with elevated health risks must have lower housing prices to attract potential homeowners and the HPS reveals the price that allocates individuals across locations. In principle, the price differential associated with proximity to hazardous waste sites reflects both individuals' valuations of the greater health risk and any effect on neighborhood aesthetics. ${ }^{17}$

At each point on the HPS, the marginal price of a housing characteristic is equal to an individual's marginal willingness to pay (MWTP) for that characteristic and an individual supplier's marginal cost of producing it. Since the HPS reveals the MWTP at a given point, it can be used to infer the welfare effects of a marginal change in a characteristic. The overall slope of the HPS provides an estimate of the average MWTP across all consumers. In principle, the hedonic method can also be used to recover individuals' demand or MWTP functions, which would be of tremendous practical importance because these functions allow for the calculation of the welfare effects of nonmarginal changes. ${ }^{18}$

Our focus is limited to the successful estimation of equation (1), which is the foundation for

\footnotetext{
${ }^{16}$ See Rosen (1974), Freeman (1993), and Palmquist (1991) for details.

${ }^{17}$ The hedonic approach cannot account for aesthetic benefits that accrue to nonresidents that, for example, engage in recreational activities near the site. The health effects approach has this same limitation.

${ }^{18}$ Rosen (1974) proposed a 2-step approach for estimating the MWTP function, as well as the supply curve. In recent work, Ekeland, Heckman and Nesheim (2004) outline the assumptions necessary to identify the demand (and supply) functions in an additive version of the hedonic model with data from a single market.
} 
welfare calculations of both marginal and non-marginal changes. Consistent estimation may be difficult since it is likely that there are unobserved factors that covary with both proximity to hazardous waste sites and housing prices. Although this possibility cannot be directly tested, it is notable that proximity to a hazardous waste site is associated with a number of important observable predictors of housing prices. For example compared to the rest of the country, areas with hazardous waste sites nearby tend to have lower population densities and mobile homes comprise a higher proportion of the housing stock.

Consequently, cross-sectional estimates of the association between housing prices and proximity to a hazardous waste site may be severely biased due to omitted variables. ${ }^{19}$ In fact, the cross-sectional estimation of the HPS has exhibited signs of misspecification in a number of other settings, including the relationships between land prices and school quality, total suspended particulates air pollution, and climate variables (Black 1999; Deschenes and Greenstone 2004; Chay and Greenstone 2005). ${ }^{20}$ Small (1975) recognized the consequences of the misspecification of equation (1) just one year after publication

of the Rosen and Freeman papers:

I have entirely avoided...the important question of whether the empirical difficulties, especially correlation between pollution and unmeasured neighborhood characteristics, are so overwhelming as to render the entire method useless. I hope that...future work can proceed to solving these practical problems....The degree of attention devoted to this [problem]...is what will really determine whether the method stands or falls..." [p. 107].

Rosen himself recognized the problem and expressed skepticism that the hedonic method could be implemented successfully in a cross-sectional setting. ${ }^{21}$ Yet, in the intervening years, this problem of misspecification has received little attention from empirical researchers. One of this paper's aims is to demonstrate that it may be possible to obtain reliable hedonic estimates with a credible research design.

\section{B. Using Hedonic Theory to Interpret the Results from the 1982 HRS Research Design}

\footnotetext{
${ }^{19}$ Incorrect choice of functional form is an alternative source of misspecification of the HPS. See Halvorsen and Pollakowski (1981) and Cropper et al. (1988) for discussions of this issue.

${ }^{20}$ Similar problems arise when estimating compensating wage differentials for job characteristics, such as the risk of injury or death. The regression-adjusted association between wages and many job amenities is weak and often has a counterintuitive sign (Smith 1979; Black and Kneisner 2003).

${ }^{21}$ Rosen (1986) wrote, "It is clear that nothing can be learned about the structure of preferences in a single crosssection..." (p. 658), and "On the empirical side of these questions, the greatest potential for further progress rests in developing more suitable sources of data on the nature of selection and matching..." (p. 688).
} 
The hedonic model describes a market in equilibrium and is most readily conceived of in a crosssectional setting. However, our research design assesses the effect of Superfund remediations of hazardous waste sites nearly two decades after the release of the NPL. Consequently, this subsection discusses the interpretation of the estimable parameters from the HRS research design. ${ }^{22}$

To fix thoughts, define $\mathrm{R}$ as the monetary value of the stream of services provided by a house over a period of time, or the rental rate. We assume $\mathrm{R}$ is a function of an index of individuals' disutility associated with living near a hazardous waste site. The index is denoted as $\mathrm{H}$ and is a function of the expected health risks and any aesthetic disamenities. $\partial \mathrm{R} / \partial \mathrm{H}<0$, because, for example, individuals' willingness to pay to rent a house is decreasing in the health risk associated with residing in it.

Now, consider how $\mathrm{H}$ changes for individuals that live near a hazardous waste site placed on the initial NPL as the site progresses through the different stages of the Superfund process:

(2) $\quad \mathrm{H}_{0}=$ Index Before Superfund Program Initiated (e.g., 1980)

$\mathrm{H}_{1}=$ Index After Site Placed on the NPL

$\mathrm{H}_{2}=$ Index Once ROD Published/Clean-Up is Initiated

$\mathrm{H}_{3}=$ Index Once "Construction Complete" or Deleted from NPL.

Notably, the clean-up process is slow. For example, the median time between NPL listing and achievement of the construction complete milestone is more than 12 years.

It seems reasonable to presume that $\mathrm{H}_{0}>\mathrm{H}_{3}$ so that $\mathrm{R}\left(\mathrm{H}_{3}\right)>\mathrm{R}\left(\mathrm{H}_{0}\right)$, because clean-ups reduce the health risks and likely increase the aesthetic value of proximity to the site. It is not evident whether $\mathrm{H}_{1}$ and $\mathrm{H}_{2}$ are greater than, less than, or equal to $\mathrm{H}_{0}$. It is frequently argued that the announcement that a site is eligible for Superfund remediation causes $\mathrm{H}$ to increase, because placement on the NPL may cause residents to revise upwards their expectation of the health risk. ${ }^{23} 24$

\footnotetext{
${ }^{22}$ An alternative valuation approach is to place a monetary value on any health improvements associated with the cleaning-up of a hazardous waste site. This approach involves four non-trivial steps. Specifically, it entails the determination of: the toxics present at each site and the pathways where they are found (e.g., air, soil, ground water); the health risks associated with toxic and pathway pair (this is especially difficult because there have been more than 65,000 chemicals in production in the US since World War II and due to the infeasibility of testing of humans due to valid ethical concerns); knowledge about the size of the affected population and their pathway-specific exposure (see Hamilton and Viscusi 1999 on the associated challenges); and willingness to pay to avoid mortality (Viscusi 1993; Ashenfelter and Greenstone 2004a, 2004b). In light of the substantial scientific, empirical, and data quality concerns with each of these steps, our view is that at present this approach is unlikely to produce credible estimates of the benefits of Superfund clean-ups. Further by its very nature, it cannot account for any aesthetic benefits.

${ }^{23}$ The stigma hypothesis is a related idea. It states that even after remediation individuals will assume incorrectly that properties near Superfund sites have an elevated health risk, relative to risk beliefs before its placement on the
} 
We can now write the constant dollar mean price of houses in the vicinity of the hazardous waste sites considered for placement on the initial NPL. We begin with the price of houses with HRS scores exceeding 28.5 (measured after the NPL listing):

$$
\text { (3) } \mathrm{P}_{t}^{H R S>28.5}=\sum_{t=0}^{\infty} 1\left(\mathrm{H}_{\mathrm{t}}=\mathrm{H}_{1}\right) \delta^{\mathrm{t}} \mathrm{R}\left(\mathrm{H}_{1}\right)+1\left(\mathrm{H}_{\mathrm{t}}=\mathrm{H}_{2}\right) \delta^{\mathrm{t}} \mathrm{R}\left(\mathrm{H}_{2}\right)+1\left(\mathrm{H}_{\mathrm{t}}=\mathrm{H}_{3}\right) \delta^{\mathrm{t}} \mathrm{R}\left(\mathrm{H}_{3}\right) \text {. }
$$

In this equation, the indicator variables $1\left(\cdot^{\cdot}\right)$ equal 1 when the enclosed statement is true in period $\mathrm{t}$ and $\delta$ is a discount factor based on the rate of time preference. The equation demonstrates that upon placement on the NPL, $\mathrm{P}_{t}^{H R S>28.5}$ reflects the expected evolution of $\mathrm{H}$ throughout the clean-up process. Further, it is evident that it varies with the stage of the Superfund clean-up at the time (i.e., t) that it is observed. For example, $\left[\mathrm{P}_{t}^{H R S>28.5} \mid \mathrm{H}_{\mathrm{t}}=\mathrm{H}_{3}\right]>\left[\mathrm{P}_{t}^{H R S>28.5} \mid \mathrm{H}_{\mathrm{t}}=\mathrm{H}_{1}\right]$ because the years of relatively low rental rates have passed.

The constant dollar mean price of houses located near the hazardous waste sites with HRS scores below 28.5 is:

(4) $\mathrm{P}_{t}^{H R S<28.5}=\sum_{t=0}^{\infty} \delta^{t} \mathrm{R}\left(\mathrm{H}_{0}\right)$.

We assume that $\mathrm{H}$ is unchanged for the sites that narrowly missed being placed on the NPL due to HRS scores below 28.5. If this assumption is valid (if, for example, these sites are never cleaned up), then $\mathrm{P}_{t}^{H R S<28.5}$ is identical in all periods.

It is now possible to define local residents' mean willingness to pay for the listing of an existing hazardous waste site on the initial NPL. This quantity is the difference between (3) and (4). It should be measured immediately after the sites are placed on the NPL so that measurement is among a fixed set of individuals' bid functions. Further, this timing of the measurement will ensure that it will account for the influence of the NPL listing on the value of housing services in all potentially affected years. Formally, we define the theoretically correct measure of willingness to pay (WTP) as:

NPL. Thus, there is a permanent negative effect on property values. Harris (1999) provides a review of the stigma literature.

${ }^{24}$ McCluskey and Rausser (2003) and Messer, Schulze, Hackett, Cameron, and McClelland (2004) provide evidence that prices decline immediately after the announcement that a local site has been placed on the NPL. The intuition is that residents knew that proximity to the site was undesirable but had underestimated the risks. 
(5) $\Delta_{\mathrm{WTP}}=\left[\mathrm{P}_{t}^{H R S>28.5}-\mathrm{P}_{t}^{H R S<28.5} \mid \mathrm{t}=\right.$ October 1983].

$\Delta_{\text {WTP }}$ must be measured in October 1983 , because this is immediately subsequent to the release of the initial NPL. Notice, $\Delta_{\text {WTP }}$ depends on the time required to complete each stage of the clean-up, the discount rate, and the change in $\mathrm{H}$ at each stage. If $\mathrm{H}_{1}, \mathrm{H}_{2}<\mathrm{H}_{0}$, then the sign of $\Delta_{\text {WTP }}$ is ambiguous.

Since data from 1983 are unavailable and our data on housing prices come from the decennial censuses, we estimate:

(6) $\Delta_{1990 \text { or } 2000}=\left[\mathrm{P}_{t}^{H R S>28.5}-\mathrm{P}_{t}^{H R S<28.5} \mid \mathrm{t}=1990\right.$ or 2000].

This is the mean difference in housing prices near NPL and non-NPL sites measured in either 1990 or 2000. The difference between (5) and (6) is that the latter is measured either 7 or 17 years later than the former.

This delay in measuring the difference in housing prices is likely to causes $\Delta_{1990}$ or 2000 to exceed the preferred measure of $\Delta_{\text {WTP }}$ for two reasons. First, many of the low rental rate years where $H_{t}=H_{1}$ have passed by 1990 and 2000. Second, enough time has elapsed between NPL listing and the observation on prices so that individuals can sort in response to the NPL listing and/or clean-up. Thus, efforts to estimate willingness to pay functions are unlikely to be convincing, leaving successful estimation of the HPS as the empirical goal. Further, Superfund remediations intend to cause large changes in environmental quality. The fact that the HPS is weakly greater than each individual's relevant bid function combined with the non-marginal nature of the clean-ups is another reason that $\Delta_{1990}$ or 2000 is likely to be an overestimate of $\Delta_{\mathrm{WTP}}$.

\section{Data Sources and Summary Statistics}

\section{A. Data Sources}

To implement the analysis, we constructed the most comprehensive data file ever compiled on the Superfund program. The data file contains detailed information on all hazardous waste sites placed on the NPL by 2000, as well as the hazardous waste sites with 1982 HRS scores below 28.5. We also compiled housing price, housing characteristic, and neighborhood demographic information for the areas surrounding these sites. 
These data come from Geolytics's Neighborhood Change Database, which includes information from the 1970, 1980, 1990, and 2000 Censuses. Importantly, the 1980 data predate the publication of the first NPL in 1983. We use these data to form a panel of census tracts based on 2000 census tract boundaries, which are drawn so that they include approximately 4,000 people in 2000 . Census tracts are the smallest geographic unit that can be matched across the 1970-2000 Censuses. ${ }^{25}$ We restrict the analysis to the 48,246 out of the 65,4432000 census tracts that have non-missing housing price data in 1980 (before the Superfund legislation was passed), 1990, and 2000.

We spent considerable effort collecting precise location data (e.g., longitude and latitude) for each of the NPL sites and hazardous waste sites with initial HRS scores below 28.5. This information was used to place these sites in unique census tracts. We also used GIS software to identify the census tracts that share a border with the tracts with the sites. Additionally, we create separate observations for the portion of tracts that fall within circles of varying radii (e.g., 1, 2, and 3 miles) around the sites. The subsequent analysis tests for price effects in all three of these groupings of tracts. The Data Appendix provides further details on how we defined these groups of tracts.

The 1982 HRS composite scores are a crucial component of the analysis. We collected these scores for the 690 hazardous waste sites considered for placement on the initial NPL from various issues of the Federal Register. We also obtained the groundwater, surface water, and air pathway scores from the same source.

We collected a number of other variables for the NPL sites. Various issues of the Federal Register were used to determine the dates of NPL listing. The EPA provided us with a data file that reports the dates of release of the ROD, initiation of clean-up, completion of remediation (i.e., construction complete), and deletion from the NPL for sites that achieved these milestones. We also collected data on the expected costs of clean-up before remediation was initiated and estimates of the actual costs for the sites that reached the construction complete stage. ${ }^{26}{ }^{27}$ We obtained information on

\footnotetext{
${ }^{25}$ See the Data Appendix for a description of how 1980 and 1990 census tracts were adjusted to fit 2000 census tract boundaries.

${ }^{26}$ The EPA divides some sites into separate operating units and issues separate RODs for them. We calculated the cost variables as the sum across all operating units. Further, we reserved the construction complete designation for
} 
the on the size (measured in acres) of the NPL hazardous waste sites from the RODs. See the Data Appendix for more details on these variables and our sources.

\section{B. Summary Statistics}

The analysis is conducted with two data samples. We refer to the first as the "All NPL Sample," and it includes the 1,398 hazardous waste sites in the 50 US states and the District of Columbia that were placed on the NPL by January 1, 2000. The second is labeled the "1982 HRS Sample," and it is comprised of the hazardous waste sites tested for inclusion on the initial NPL, regardless of their eventual NPL status. ${ }^{28}$

Table 1 presents summary statistics on the hazardous waste sites in these samples. The entries in column (1) are from the All NPL Sample and are limited to sites in a census tract for which there is nonmissing housing price data in 1980, 1990, and 2000. After these sample restrictions, there are 985 sites, which is more than $70 \%$ of the sites placed on the NPL by 2000 . Columns (2) and (3) report data from the 1982 HRS Sample. The column (2) entries are based on the 487 sites that we placed in a census tract with complete housing price data. Column (3) reports on the remaining 189 sites located in census tracts with incomplete housing price data (generally due to missing 1980 data). The 14 sites located outside of the continental United States were dropped from the sample.

Panel A reports on the timing of the sites' placement on the NPL. Column (1) reveals that about $75 \%$ of all NPL sites received this designation in the $1980 \mathrm{~s}$. Together, columns (2) and (3) demonstrate that 443 of the 676 sites in the 1982 HRS sample eventually were placed on the NPL. This number exceeds the 400 sites that Congress set as an explicit goal, because, as we have discussed, some sites with initial scores below 28.5 were rescored and then received scores above the threshold. Most of this

sites where the EPA declared remediation to be complete at all operating units.

${ }^{27}$ We measure actual cost as the sum of government outlays and estimates of the costs of the remediation that were paid for by non-governmental responsible parties across. The actual outlays by these parties are unavailable to the public and the EPA, so these parties' estimated outlays come from EPA engineers' estimates of the costs of completing the required remediation. See the Data Appendix for further details. Probst and Konisky (2001) provide a comprehensive accounting of past costs on Superfund remediations and detailed projections about future costs.

${ }^{28}$ Federal facilities were prohibited from inclusion on the NPL until 1984. Consequently, the 1982 HRS sample does not contain any federal facilities. 
rescoring occurred in the 1986-1989 period. Panel B provides mean HRS scores, conditioned on scores above and below 28.5. Notably, the means are similar across the columns.

Panel $\mathrm{C}$ reports on the size of the hazardous waste sites measured in acres. This variable is only available for NPL sites since it is derived from the RODs. In the three columns, the median site size ranges between 25 and 35 acres. The means are substantially larger due to a few very large sites. The modest size of most sites suggests that any expected effects on property values may be confined to relatively small geographic areas.

Panel D provides evidence on the time required for the achievement of the clean-up milestones. The median time until the different milestones are achieved is reported, rather than the mean, because many sites have not reached all of the milestones yet. As an example, only 16 of the NPL sites in column (2) received either the construction complete or deleted designation by 1990 . Thus, when we measure the effect of NPL status on 1990 housing prices, this effect will almost entirely be driven by sites where remediation activities are unfinished. By 2000, the number of sites in the construction complete/deleted category in this column had increased dramatically to 198. In column (1), the numbers of sites that were construction complete by 2000 (1990) is 478 (22).

Panel E reports the expected costs of clean-up for NPL sites. This information was obtained from the sites' RODs and provides a measure of the expected costs (2000 \$'s) of the clean-up before any remediation activities have begun. ${ }^{29}$ They include all costs expected to be incurred during the active clean-up phase, as well as the expected costs during the operation and maintenance phase that is subsequent to the assignment of the construction complete designation.

In the All NPL Sample, the estimated cost data is available for 753 of the 985 NPL sites. The mean and median expected costs of clean-up are \$28.3 million and \$11 million. The larger mean reflects the high cost of a few clean-ups - for example, the $95^{\text {th }}$ percentile expected cost is $\$ 89.6$ million. In the 1982 HRS Sample in column (2), the mean and median are \$27.5 million and \$15.0 million.

The final panel reports estimated and actual costs for the subsample of construction complete

\footnotetext{
${ }^{29}$ All monetary figures are reported in 2000 \$'s, unless otherwise noted.
} 
sites where both cost measures are available. To the best of our knowledge, the estimated and actual cost data have not been brought together before. The conventional wisdom is that the actual costs greatly exceed the estimated costs of clean-up, and this table provides the first opportunity to test this view. The data support the conventional wisdom as the mean actual costs are $35 \%-55 \%$ higher than the mean expected costs across the three columns. The findings are similar for median actual and expected costs.

A comparison of columns (2) and (3) across the panels reveals that the sites with and without complete housing price data are similar on a number of dimensions. For example, the mean HRS scores conditional on scoring above and below 28.5 are remarkably similar. Further, the median size and various cost variables are comparable in the two columns. Consequently, it seems reasonable to conclude that the sites without complete housing price data are similar to the column (2) sites, suggesting the subsequent results may be representative for the entire 1982 HRS Sample.

Additionally, the sites in column (1) are similar to the sites in column (2) and (3) in size and the two cost variables. The mean HRS scores are a few points lower, but this comparison is not meaningful due to the changes in the test over time and changes in the how the scoring was conducted. ${ }^{30}$ Overall, the similarity of the column (1) sites with the other sites suggests that it may be reasonable to assume that the results from the application of the HRS research design to the 1982 HRS sample are informative about the effects of the other Superfund clean-ups.

We now graphically summarize some other features of the two samples. Figure 1 displays the geographic distribution of the 985 hazardous waste sites in the All NPL Sample. There are NPL sites in 45 of the 48 continental states, demonstrating that Superfund is genuinely a national program. The highest proportion of sites, however, is in the Northeast and Midwest (i.e., the "Rust Belt") that reflects the historical concentration of heavy industry in these regions.

Figures 2A and 2B present the geographic distribution of the 1982 HRS sample. Figure 2A displays the distribution of sites with 1982 HRS scores exceeding 28.5, while those with scores below this

\footnotetext{
${ }^{30}$ Further once the 28.5 cut-off was set, the HRS testers were encouraged to minimize testing costs and simply determine whether a site exceeded the threshold. Consequently, testers generally stop scoring pathways once enough pathways are scored to produce a score above the threshold.
} 
threshold are depicted in $2 \mathrm{~B}$. The sites in both categories are spread throughout the United States, but the below 28.5 sites are in fewer states. For example, there are not any below 28.5 sites in Minnesota, Florida, and Delaware. The unequal distribution of sites across the country in these two groups is a potential problem for identification in the presence of local shocks, which are a major feature of the housing market. To mitigate concerns about these shocks, we emphasize econometric models that include state fixed effects for changes in housing prices.

Figure 3 reports the distribution of HRS scores among the 487 sites in the 1982 HRS Sample. The figure is a histogram where the bins are 4 HRS points wide. The distribution looks approximately normal, with the modal bin covering the 36.5-40.5 range. Importantly, 227 sites have HRS scores between 16.5 and 40.5 . This set is centered on the regulatory threshold of 28.5 that determines placement on the NPL and constitutes the regression discontinuity sample that we exploit in the subsequent analysis.

Figure 4 plots the mean estimated costs of remediation by 4-unit intervals (solid line), along with the fraction of sites in each interval with non-missing cost data (dotted line). The vertical line denotes the 28.5 threshold. The non-zero mean costs below the threshold are calculated from the sites that received a score greater than 28.5 upon rescoring and later made it onto the NPL. The estimated costs of remediation appear to be increasing in the HRS score. This finding suggests that despite its widely acknowledged noisiness, the 1982 HRS scores may be informative about relative risks. In the neighborhood of 28.5, however, estimated costs are roughly constant, providing some evidence that risks are roughly equal among the sites in the regression discontinuity sample.

\section{Econometric Methods}

\section{A. Least Squares Estimation with Data from the Entire U.S.}

Here, we discuss a conventional econometric approach to estimating the relationship between housing prices and NPL listing. This approach is laid out in the following system of equations:

$$
\mathrm{y}_{\mathrm{c} 2000}=\theta 1\left(\mathrm{NPL}_{\mathrm{c} 2000}\right)+\mathrm{X}_{\mathrm{c} 1980^{\prime}} \beta+\varepsilon_{\mathrm{c} 2000}
$$

$$
1\left(\mathrm{NPL}_{\mathrm{c} 2000}\right)=\mathrm{X}_{\mathrm{c} 1980}{ }^{\prime} \Pi+\eta_{\mathrm{c} 2000},
$$

where $\mathrm{y}_{\mathrm{c} 2000}$ is the $\log$ of the median property value in census tract $\mathrm{c}$ in 2000 . The indicator 
variable $1\left(\mathrm{NPL}_{\mathrm{c} 2000}\right)$ equals 1 only for observations from census tracts that contain a hazardous waste site that has been placed on the NPL by 2000. Thus, this variable takes on a value of 1 for any of the Superfund sites in column (1) of Table 1, not just those that were on the initial NPL list. The vector $\mathrm{X}_{\mathrm{c} 1980}$ includes determinants of housing prices measured in 1980, and $\varepsilon_{\mathrm{c} 2000}$ and $\eta_{\mathrm{c} 2000}$ are the unobservable determinants of housing prices and NPL status, respectively. We are also interested in the effect of NPL status in 1990, and the year 1990 versions of these equations are directly analogous.

A few features of the $X$ vector are noteworthy. First, we restrict this vector to 1980 values of the variables to avoid confounding the effect of NPL status with "post-treatment" changes in these variables that may be due to NPL status. Second, we include the 1980 value of the dependent variable, $\mathrm{y}_{\mathrm{c} 80}$ in

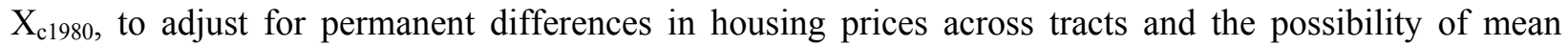
reversion in housing prices. See the Data Appendix for the full set of covariates.

Third in many applications of Rosen's model, the vector of controls, denoted by $\mathrm{X}$, is limited to housing and neighborhood characteristics (e.g., number of bedrooms, school quality, and air quality). Income and other similar variables are generally excluded on the grounds that they are "demand shifters" and are needed to obtain consistent estimates of the MWTP function. The exclusion restriction is invalid however if individuals treat wealthy neighbors as an amenity (or disamenity). In the subsequent analysis, we are agnostic about which variables belong in the $\mathrm{X}$ vector and report estimates that are adjusted for different combinations of the variables available in the Census data.

The coefficient $\theta$ measures the effect of NPL status on 2000 property values after controlling for 1980 mean property values and the other covariates. It tests for differential housing price appreciation in census tracts with sites placed on the NPL. If there are unobserved permanent or transitory determinants of housing prices that covary with NPL status, then the least squares estimator of $\theta$ will be biased. More formally, consistent estimation of $\theta$ requires $\mathrm{E}\left[\varepsilon_{\mathrm{c} 2000} \eta_{\mathrm{c} 2000}\right]=0$. To account for local shocks to housing markets, we emphasize results from specifications that include a full set of state fixed effects.

Ultimately, the conventional approach described in this subsection relies on a comparison of NPL sites to the rest of the country. Its validity rests on the assumption that linear adjustment controls for all determinants of housing price growth between census tracts with and without a NPL site, besides the 
effect of the site's placement on the NPL.

\section{B. A Quasi-Experimental Approach based on the 1982 HRS Research Design}

Here, we discuss our preferred identification strategy that has two key differences with the one described above. First, we limit the sample to the subset of census tracts containing the 487 sites that were considered for placement on the initial NPL and have complete housing price data. Thus, all observations are from census tracts with hazardous waste sites that were judged to be among the nation's most dangerous by the EPA in 1982. If, for example, the $\beta$ 's differ across tracts with and without hazardous waste sites or there are differential trends in housing prices in tracts with and without these sites, then this approach is more likely to produce consistent estimates. Second, we use a two-stage least squares (2SLS) strategy to account for the possibility of endogenous rescoring of sites.

More formally, we replace equation (8) with:

$$
1\left(\mathrm{NPL}_{\mathrm{c} 2000}\right)=\mathrm{X}_{\mathrm{c} 1980}{ }^{\prime} \Pi+\delta 1\left(\mathrm{HRS}_{\mathrm{c} 82}>28.5\right)+\eta_{\mathrm{c} 2000}
$$

where $1\left(\mathrm{HRS}_{\mathrm{c} 82}>28.5\right)$ serves as an instrumental variable. This indicator function equals 1 for census tracts with a site that has a 1982 HRS score exceeding the 28.5 threshold. We then substitute the predicted value of $1\left(\mathrm{NPL}_{\mathrm{c} 2000}\right)$ from the estimation of equation (9) in the fitting of (7) to obtain $\theta_{2 \mathrm{SLS}}$. In this 2SLS framework, $\theta_{2 \text { SLS }}$ is identified from the variation in NPL status that is due to a site having a 1982 HRS score that exceeds 28.5.

For $\theta_{2 \text { SLS }}$ to provide a consistent estimate of the HPS gradient, the instrumental variable must affect the probability of NPL listing, without having a direct effect on housing prices. The next section will demonstrate that the first condition clearly holds. The second condition requires that the unobserved determinants of 2000 housing prices are orthogonal to the portion of the nonlinear function of the 1982

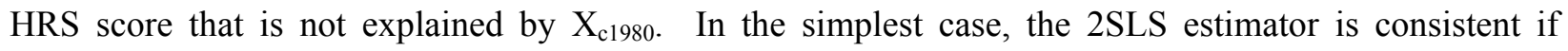
$\mathrm{E}\left[1\left(\mathrm{HRS}_{\mathrm{c} 82}>28.5\right) \varepsilon_{\mathrm{c} 2000}\right]=0$.

We also obtain 2 SLS estimates another way that allows for the possibility that $\mathrm{E}\left[1\left(\mathrm{HRS}_{\mathrm{c} 82}>\right.\right.$ 28.5) $\left.\varepsilon_{\mathrm{c} 2000}\right] \neq 0$ over the entire 1982 HRS sample. In particular, we exploit the regression discontinuity design implicit in the $1(\bullet)$ function that determines NPL eligibility in three separate ways. In the first 
approach, a quadratic in the $1982 \mathrm{HRS}$ score is included in $\mathrm{X}_{\mathrm{c} 1980}$ to partial out any correlation between residual housing prices and the indicator for a 1982 HRS score exceeding 28.5. This approach does not require that the determinants of housing prices are constant across the range of 1982 HRS scores. Instead, it relies on the plausible assumption that residual determinants of housing price growth do not change discontinuously at HRS scores just above 28.5.

The second regression discontinuity approach involves implementing our 2SLS estimator on the regression discontinuity sample of 227 census tracts. Recall, this sample is limited to tracts with sites that have 1982 HRS scores between 16.5 and 40.5. Here, the identifying assumption is that all else is held equal in the "neighborhood" of the regulatory threshold. More formally, it is $E\left[1\left(\mathrm{HRS}_{\mathrm{c} 82}>28.5\right)\right.$ $\left.\varepsilon_{\mathrm{c} 2000} \mid 16.5<1982 \mathrm{HRS}<40.5\right]=0$. Recall, the HRS score is a nonlinear function of the ground water, surface water, and air migration pathway scores. The third regression discontinuity method exploits

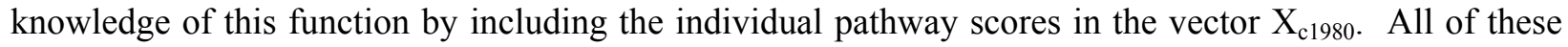
regression discontinuity approaches are demanding of the data and this will be reflected in the sampling errors.

\section{Empirical Results}

\section{A. Balancing of Observable Covariates}

This subsection examines the quality of the comparisons that underlie the subsequent least squares and quasi-experimental 2SLS estimates of the effect of NPL status on housing price growth. We begin by examining whether NPL status and the $1\left(\mathrm{HRS}_{\mathrm{c} 82}>28.5\right)$ instrumental variable are orthogonal to the observable predictors of housing prices. Formal tests for the presence of omitted variables bias are as always unavailable, but it seems reasonable to presume that research designs that balance the observable covariates across NPL status or $1\left(\mathrm{HRS}_{\mathrm{c} 82}>28.5\right)$ may suffer from smaller omitted variables bias. First, these designs may be more likely to balance the unobservables (Altonji, Elder, and Taber 2000). Second if the observables are balanced, then consistent inference does not depend on functional form assumptions on the relations between the observable confounders and housing prices. Estimators that misspecify these functional forms (e.g., linear regression adjustment when the conditional expectations function is 
nonlinear) will be biased.

Table 2 shows the association of NPL status and $1\left(\mathrm{HRS}_{\mathrm{c} 82}>28.5\right)$ with potential determinants of housing price growth measured in 1980. Column (1) reports the means of the variables listed in the row headings in the 985 census tracts with NPL hazardous waste sites and complete housing price data. Column (2) displays the means in the 41,989 census tracts that neither contain a NPL site nor share a border with a tract containing one. Columns (3) and (4) report on the means in the 181 and 306 census tracts with hazardous waste sites with 1982 HRS scores below and above the 28.5 threshold, respectively. Columns (5) and (6) repeat this exercise for the 90 and 137 tracts below and above the regulatory threshold in the regression discontinuity sample. The remaining columns report p-values from tests that the means in pairs of the first six columns are equal. P-values less than 0.01 are denoted in bold.

Column (7) compares the means in columns (1) and (2) to explore the possibility of confounding in the least square approach. The entries indicate that 1980 housing prices are more than $20 \%$ lower in tracts with a NPL site. Among the potential determinants of housing prices, the hypothesis of equal means can be rejected at the $1 \%$ level for 9 of the 11 demographic and economic variables, 7 of 11 of the housing characteristics, and 3 of the 4 geographic regions. Specifically, the tracts with NPL sites are less densely populated (e.g., due to locations in industrial parts of urban areas and rural areas) and have lower household incomes. One variable that seems to capture this is that the fraction of the housing stock that is comprised of mobile homes is more than $80 \%$ greater $(0.0862$ versus 0.0473$)$ in these tracts. Additionally, the fraction of Blacks and Hispanics is greater in tracts without NPL sites, which undermines "environmental justice" claims in this context. Due to the confounding of NPL status with these other determinants of housing price growth, it may be reasonable to assume that least squares estimation of equation (7) will produce biased estimates of the effect of NPL status.

Column (8) compares the tracts with hazardous wastes that have 1982 HRS scores below and above the 28.5 regulatory threshold. It is immediately evident that by narrowing the focus to these tracts, the differences in the potential determinants of housing prices are greatly mitigated. For example, the population density and percentage of mobile homes are well balanced. One important difference that remains is that the mean housing price in 1980 is roughly $16 \%$ higher in tracts with HRS scores above 
28.5. Overall, the entries suggest that the above and below 28.5 comparison reduces the confounding of NPL status.

Column (9) repeats this analysis in the regression discontinuity sample. Notably, the difference in 1980 housing prices is reduced to $10 \%$ and is no longer statistically significant at conventional levels (p-value $=0.084)$. With respect to the other determinants of 2000 housing prices, the findings are remarkable in that the hypothesis of equal means cannot be rejected at the $1 \%$ level for any of these variables. The differences in the means are substantially reduced for many of the variables, so this result is not simply due to the smaller sample (and larger sampling errors). This finding suggests that estimates of the effect of NPL status on housing price growth from the regression discontinuity sample may be of especial interest.

There is not enough room to present the results here, but there are substantial differences in the geographic distribution of sites across states in both the above and below 28.5 (i.e., columns 3 and 4 ) and regression discontinuity (i.e., columns 5 and 6) comparisons. It is likely that this is due to the small samples in each state. The dramatic differences in state-level trends in housing prices in the 1980s and 1990s suggest that this is a potential source of bias. Consequently, we will emphasize specifications that include state fixed effects to control for state-level shocks to housing prices.

\section{B. Least Squares Estimates from the All NPL Sample}

Table 3 presents the first large-scale effort to test the effect of Superfund clean-ups on property value appreciation rates. Specifically, it reports the regression results from fitting 4 least squares versions of equation (7) for both 1990 and 2000 housing prices. The sample size is 42,974 in all regressions. In Panel A, 746 (985) observations in 1990 (2000) are from census tracts that contain a hazardous waste site that had been on the NPL at any time prior to 1990 (2000). ${ }^{31}$ In addition to tracts with incomplete housing price data from 1980 - 2000, tracts that share a border with tracts containing NPL sites (unless

\footnotetext{
${ }^{31}$ For tracts that include multiple NPL sites, the observation from that tract is repeated in the data file for each site. Thus, there would be 2 identical observations for a tract that contains two NPL sites. The 746 (985) NPL sites in 1990 (2000) are located in 682 (892) individual tracts.
} 
they also contain a NPL site) are dropped from the sample since Superfund clean-ups may affect housing prices in adjacent tracts.

The possibility of price effects in adjacent tracts is investigated in Panel B. Here, the observation from each tract with a NPL site is replaced with the average of all variables across the census tracts that share a border with the tract containing the NPL site and have complete housing price data. Further, the individual observations on the adjacent tracts are excluded from the sample as in Panel A. The remainder of the sample is comprised of observations on the 41,989 tracts with complete housing price data that neither have a NPL site nor are adjacent to a tract with a NPL site.

In principle, the price effects in adjacent tracts could be positive or negative. The most straightforward possibilities are that a site's remediation would cause property values in adjacent tracts to increase or leave them unaffected (if, for example, any health benefits are limited to the tract containing the site). If housing markets are small and segmented, however, it is possible that a Superfund clean-up would induce migration from the adjacent tracts to the tract containing the sites and that this dynamic would lead to lower housing prices in the adjacent tracts. In the polar case, the NPL designation and subsequent clean-up would reallocate housing values within the segmented market and have no overall effect on housing values.

The dependent variables are underlined in the first column. The entries report the coefficient and heteroskedastic-consistent standard error on the NPL indicator. All specifications control for the natural $\log$ of the mean housing price in 1980 , so the reported parameter should be interpreted as the growth in housing prices in tracts with a NPL site (or its neighbors), relative to tracts without NPL sites. The exact covariates in each specification are noted in the row headings at the bottom of the table and are described in more detail in the Data Appendix.

The Panel A results show that this least squares approach finds a positive association between NPL listing and housing price increases. Specifically, the estimates in the first row indicate that median housing prices grew by $9.8 \%$ to $16.4 \%$ (measured in $\ln$ points) more in tracts with a site placed on the NPL from 1980 to 1990 . All of these estimates would easily be judged statistically significant by conventional criteria. The column (4) estimate of $9.8 \%$ is the most reliable one, because it is adjusted for 
all unobserved state-level determinants of price growth. Recall, Table 1 demonstrated that remediation activities had been initiated at less than half of these sites and only 22 sites were construction complete by 1990. Thus, these findings appear to contradict the popular "stigma" hypothesis (see, e.g., Harris 1999) that a site's placement on the NPL causes housing prices to decline. We investigate this issue further below.

The next row repeats this exercise for the period from 1980 to 2000. Here, the estimated effect of the presence of a NPL site within a tract's boundaries is associated with a $4.0 \%$ to $7.3 \%$ increase in the growth of house prices depending on the specification. Notably, the standard errors on the 2000 estimates are about half the size of the 1990 ones.

Panel B explores the growth of housing prices in the census tracts that are adjacent to the tracts containing the NPL sites. All of the estimates are statistically different from zero and imply that the placement of a site on the NPL is associated with a positive effect on the growth of housing prices in neighboring tracts. The column (4) specification indicates $10.8 \%$ and $8.8 \%$ gains by 1990 and 2000 , respectively. ${ }^{32}$

It is possible to use the Table 3 estimates to do a crude cost-benefit calculation. The 1980 mean of aggregate property values in tracts with NPL sites is roughly $\$ 77$ million. The multiplication of this value by the 2000 own tract, column (4) point estimate of 0.066 implies that housing prices were roughly \$5 million higher in these tracts in 2000 due to the NPL designation. The 1980 mean of aggregate property values in adjacent tracts is $\$ 638$ million and an analogous calculation suggests that the NPL designation led to a mean increase in property values of roughly $\$ 56$ million. Setting aside the legal costs associated with collecting the funds from private parties and deadweight loss of public funds, the $\$ 61$ million mean increase in property values per site appears larger than our estimate of the mean actual costs

\footnotetext{
${ }^{32}$ The subsequent sections are focused on the subset of hazardous waste sites that were tested in 1982 for inclusion on the initial NPL. Consequently, it is relevant to contrast the subsequent estimates with those from the Table 3 approach. When the set of tracts with NPL sites is limited to those that were tested in 1982, the column 4 specification in Table 3 produces point estimates (standard errors) of $0.063(0.025)$ and $0.057(0.013)$ for 1990 and 2000. The analogous 1990 and 2000 adjacent census tract results are $0.080(0.016)$ and 0.073 (0.012). Overall, these estimates are quite similar to those in Table 3 for the full set of NPL sites.
} 
of clean-ups of about $\$ 40$ million per site. ${ }^{33}$

Before drawing any definitive conclusions or policy implications, however, it is worth emphasizing that three features of the evidence presented so far suggest that the Table 3 estimates may be unreliable. First, Table 2 demonstrated that NPL status is confounded by many variables. Second, 7 of the 8 adjacent tract point estimates exceed the own census tract estimates. In light of these tracts' small size (recall, the median size of a site is 29 acres), it seems unlikely that NPL status would have a larger effect in the adjacent tracts. Third, all of the 2000 own tract and adjacent point estimates are smaller than the 1990 point estimates from the same specifications. This finding is puzzling, because remediation was complete at only 22 of the NPL sites by 1990. In contrast, the clean-ups had been completed at nearly half of the sites by 2000 .

The next section begins our presentation of the results from the 1982 HRS research design. This design mitigates many of the concerns about omitted variables bias that plague the least squares approach.

\section{Is the $1\left(\mathrm{HRS}_{c 82}>\right.$ 28.5) a Valid Instrumental Variable for NPL Status?}

This section presents evidence on the first-stage relationship between the $1\left(\mathrm{HRS}_{\mathrm{c} 82}>28.5\right)$ indicator and NPL status, as well as some suggestive evidence on the validity of the exclusion restriction. Figure 5 plots the bivariate relation between the probability of 1990 (Panel A) and 2000 (Panel B) NPL status and the 1982 HRS score among the 487 sites in the 1982 HRS sample. The plots are done separately for sites above and below the 28.5 threshold and come from the estimation of nonparametric regressions that use Cleveland's (1979) tricube weighting function and a bandwidth of 0.5. ${ }^{34}$ Thus, they represent a moving average of the probability of NPL status across 1982 HRS scores. The data points represent the mean probabilities in the same 4-unit intervals of the HRS score as in Figures 3 and 4.

\footnotetext{
${ }^{33}$ Our estimates of the mean actual costs of clean-ups are calculated in the following manner. Panel F of Table 1 indicates that among fully remediated sites the actual costs of clean-up exceed the expected costs by roughly $40 \%$ among all NPL sites. We then multiply the mean expected costs of clean (calculated among all sites) of $\$ 28.3$ million by 1.4, which gives our estimated mean actual cost of $\$ 40$ million. The comparable figure for the column (2) NPL sites, which are the focus of the subsequent analysis, is $\$ 43$ million.

${ }^{34}$ The smoothed scatterplots are qualitatively similar with a rectangular weighting function (i.e., equal weighting) and alternative bandwidths.
} 
The figures present dramatic evidence that a HRS score above 28.5 is a powerful predictor of NPL status in 1990 and 2000. Virtually all sites with initial scores greater than 28.5 are on the NPL. The figures also reveal that some sites below 28.5 made it on to the NPL (due to rescoring) and that this probability is increasing in the initial HRS score and over time.

Panel A of Table 4 reports on the statistical analog to these figures from the estimation of linear probability versions of equation (9) for NPL status in 1990 and 2000. This is a test of the "first-stage" relationship in our two-stage least squares approach. In the first five columns, the sample is comprised of the full 1982 HRS Sample. The controls in the first four columns are identical to those in the four specifications in Table 3. In the fifth column, the 1982 HRS score and its square are added to the column (4) specification so that the estimates are adjusted for a smooth function of the "running" variable. Thus, the specification tests for a discontinuity in the probability of NPL status at the regulatory threshold of 28.5. In column (6), the controls are the same as in column (4), and the sample is the regression discontinuity sample that is comprised of the 227 sites with 1982 HRS scores between 16.5 and 40.5 . These specifications and samples are repeated throughout the remainder of paper.

The results confirm the visual impression that a 1982 HRS score above 28.5 increases the probability that a site is placed on the NPL. The point estimates imply a higher probability ranging between $61 \%$ and $86 \%$, depending on the year and specification. Overall, these findings reveal a powerful first-stage relationship suggesting that weak instrument concerns are not relevant here (Staiger and Stock 1997).

Panel B of Table 4 presents an informal test of the validity of the research design. In the first row of the panel, the dependent variable is the natural log of 1980 mean housing prices and the sample is again comprised of the 1982 HRS sample. In the second row, the dependent variable and the covariates for each observation are calculated as the mean across the census tracts that share a border with the tract containing the hazardous waste site. The specifications are identical to those in the upper panel (except, of course, they do not control for 1980 prices). The table reports the coefficient and standard error on $1\left(\mathrm{HRS}_{\mathrm{c} 82}>28.5\right)$ from five regressions.

These Panel B regressions test for differential 1980 housing prices above and below the threshold 
after adjustment for observed covariates. This is an important test, because 1980 housing prices are not balanced across the values of $1\left(\mathrm{HRS}_{\mathrm{c} 82}>28.5\right)$ in the full $1982 \mathrm{HRS}$ sample and residual housing prices may be an important predictor of the growth in housing prices. Evidence of significant differences would undermine the validity of this research design.

After adjustment for the housing characteristics, the point estimate on the above 28.5 indicator is small both economically and statistically in the own census tract regressions. In columns (3) - (6), the estimates range from -0.010 to 0.001 and the largest t-statistic is 0.55 . The adjacent census tract results suggest that a HRS score exceeding 28.5 is virtually uncorrelated with adjusted 1980 housing prices.

Figure 6 allows for a graphical investigation of this test. It plots the results from nonparametric regressions between 1980 residual housing prices after adjustment for the column (4) covariates (except the indicator for a HRS score above 28.5) and the 1982 HRS scores. These plots are done separately for sites above and below the threshold and again use Cleveland's (1979) tricube weighting function and a bandwidth of 0.5 . The qualitative findings are unaffected by reasonable alternatives for the weighting function and the bandwidth. In Panel A, the 1982 HRS sample is used, whereas Panel B employs the regression discontinuity sample. ${ }^{35}$

There is little evidence of a relationship between the 1982 HRS score and 1980 residual housing prices in either figure. Importantly, there are only modest differences in residual housing prices just above and below the regulatory threshold. Along with the findings in Tables 2 and 4, these plots support the validity of this paper's quasi-experimental approach.

\section{Quasi-Experimental Estimates of NPL Status on Housing Prices}

Table 5 presents 2SLS estimates of the effect of NPL status on housing prices in 1990 and 2000. In Panel A the observations are from the census tracts containing the 487 hazardous waste sites in the

\footnotetext{
${ }^{35}$ Figure 6 is intended to provide a qualitative graphical exploration of the regression results. The relationship between housing prices and 1982 HRS scores cannot be exactly inferred from this graph, because the HRS score has not been adjusted for the column (4) covariates. This same caveat applies to the subsequent Figures 7, 8, and 9. However, the meaningfulness of this graph is supported by Table 2's finding that the covariates are well balanced among sites with 1982 HRS scores above and below the regulatory threshold, especially in the regression discontinuity sample.
} 
1982 HRS sample. In Panel B each observation is comprised of the average of all variables across tracts that share a border with these tracts. The 6 combinations of samples and control variables are identical to those in Panel A of Table 4.

These Panel A results suggest that a site's placement on the NPL has little impact on the growth of property values in its own census tract, relative to tracts with sites that narrowly missed placement on the NPL. The 1990 and 2000 point estimates range from $-0.6 \%$ to $6.6 \%$. However, they all have associated t-statistics less than 2 .

The most reliable specifications are presented in columns (4) - (6). The column (4) specification controls for state fixed effects in housing price growth and produces smaller point estimates than the identical specification in Table 3. However, the imprecision of the estimates means that the 95\% confidence intervals of these estimates overlap. The regression discontinuity specifications in columns (5) and (6) may be the least subject to omitted variables bias concerns, so it is notable that they produce the smallest point estimates. These two specifications are demanding of the data and this is reflected in the larger standard errors. ${ }^{36}$

Panel B presents the adjacent tract results. The column (4) specification produces economically small point estimates that are estimated more precisely. Specifically, the 1990 and 2000 point estimates (standard errors) are $-0.006(0.027)$ and $0.012(0.022)$, respectively. Notably, the $95 \%$ confidence intervals of these estimates do not overlap with the Table 3 estimates from the identical specification. The regression discontinuity estimates are also small and the null of zero cannot be rejected at anything approaching conventional levels. Overall, these quasi-experimental results suggest that a site's placement on the NPL does not affect housing prices in neighboring census tracts either positively or negatively. In this respect they contrast sharply with the adjacent tract results from the least squares approach in Table 3.

\footnotetext{
${ }^{36}$ Probst and Konisky (2001) find that approximately $14.5 \%$ of RODs ultimately receive a "no further action" classification from the EPA. This classification was applied when removal activities were sufficient to remove the environmental risk and/or the risk naturally dissipated. This is potentially relevant for our analysis for the sites where the EPA classified every ROD for every operating unit as "no further action," because these sites are not standard NPL sites in that no remediation activities took place at them. There are 11 of these sites in the 1982 HRS sample. The own census tract regression results are virtually identical to those in Panel A of Table 5 when the tracts containing these 11 sites are dropped from the sample.
} 
Figures 7 and 8 provide an opportunity to better understand the source of these regression results. They are constructed identically to Figure 6 and plot the nonparametric regressions of 2000 residual housing prices (after adjustment for the column (4) covariates) against the 1982 HRS Score in the 1982 HRS (Panel A) and Regression Discontinuity (Panel B) samples. The figures are for the own and adjacent census tract housing prices, respectively, and are the graphical version of the reduced form relationship between housing price growth and the instrument.

These graphs confirm that there is little association between 2000 residual housing prices and the 1982 HRS score. A comparison of the plots at the regulatory threshold is of especial interest in light of the large jump in the probability of placement on the NPL there. In all four of these plots the moving averages from the left and right are virtually equal at the threshold.

One potentially troublesome issue with the approach thus far is the arbitrary nature of census tract boundaries with respect to the location of the hazardous waste sites. Although there is no a priori reason to believe that it is likely, it is possible that the houses affected by the clean-ups fall predominantly outside the sites' tracts and the adjacent tracts. To explore this possibility, we obtained the exact longitude and latitude of all the hazardous waste sites in the 1982 HRS sample and used GIS software to draw circles around them with radii of 1,2 , and 3 miles. We then calculated the means of all variables as the weighted average across the portion of tracts that fall within the relevant circle around the hazardous waste sites. The weight is the fraction of the tract's area within the relevant circle multiplied by the tract's 1980 population. To place the size of these circles in some context, the 1980 aggregate values of the housing stock in the three circles are roughly $\$ 300, \$ 755$, and $\$ 1,410$ million (2000 \$'s).

Appendix Table 1 reports results from the application of the 6 2SLS specifications used in Table 5 to these data sets. None of the 36 point estimates presented would be judged to be statistically different from zero by conventional criteria. In both the 1 and 2 mile panels, the $95 \%$ confidence interval of the column (4) estimate lies below the housing price appreciation rate necessary for the clean-ups to surpass our estimated cost of the clean-ups of $\$ 43$ million in this sample. Overall, this table confirms that 
a site's receipt of the NPL designation appears to have little effect on the growth of local housing prices. ${ }^{37}$

Table 6 presents the results from a series of other specification checks, all of which return to using census tracts, rather than circles around a site, as the unit of observation. For conciseness, we only present estimates from the column (1) specification and the three most robust specifications (i.e., columns 4, 5, and 6) from Table 5. We also limit the table to the 2000 own census tract results. We focus on the 2000 own census tract data, because it is more likely that we will find an effect with them since more clean-ups are completed in 2000 and the data come from the houses in closest proximity to the sites. Consequently, a continued failure to find an effect of NPL status will further undermine the view that NPL status affects local property values.

Each of the specification checks is reported in a separate panel. Panel A reports the results from the addition of the individual pathway scores to the vector $\mathrm{X}_{\mathrm{c} 1980}$ of controls in all six specifications. This is the third regression discontinuity style approach. In Panel B, we add the 1970 values of the covariates (including the natural log of 1970 housing prices) to the Table 5 specification to adjust for mean reversion or pre-existing trends. The 1970 data is available for a subset of counties, so the sample sizes decline to 353 in columns (1) - (3) and 157 in (4). Panel $\mathrm{C}$ adds the 2000 value of the covariates. These variables are potentially endogenous, because they may be affected by the clean-ups. To isolate the effect of NPL status on land values (rather than housing values), however, it may be appropriate to adjust for these variables.

The results in the first three panels of Table 6 continue to suggest that the NPL designation has little effect on the growth of property values between 1980 and 2000. The adjustment for the individual pathway scores generally reduces the point estimates and causes the standard errors to increase. The addition of the 1970 and 2000 covariates also tends to reduce the point estimates. All 12 of these estimates have an associated t-statistic less than $1.1 .^{38}$

\footnotetext{
37 A limitation of this GIS approach is that street address level data on housing prices and the covariates is unavailable. Consequently, we assign a census tract's average to the portion of the tract that falls within the circle, which is equivalent to assuming that there is no heterogeneity in housing prices or other variables within a tract.

${ }^{38}$ It is possible that the least expensive houses within a tract are the ones closest to the NPL site. If this is the case, the site's remediation could lead to zero growth in median house prices but substantial growth in mean prices. A test of this possibility by using mean housing prices as the dependent variable does not affect our qualitative
} 
Panel D tests whether the effect of the NPL designation differs in census tracts with a population density exceeding 1,588 per square mile, which is the top quartile among tracts in this sample. The intuition is that the price response to clean-ups may be greater in higher density tracts where there are fewer undeveloped plots of land to build new houses. ${ }^{39}$ Specifically, the specification now includes an indicator for these tracts and the additional variable of interest, which is the interaction of this indicator and the indicator for 2000 NPL status. The latter variable is treated as endogenous and instrumented with the interaction of indicators for tracts with a population density exceeding 1,588 and sites with a HRS score exceeding 28.5. Two of the estimates of the interaction are positive and two are negative. None of them would be judged to be statistically different from zero by conventional criteria. ${ }^{40}$

Panel E follows a similar approach, except that its focus is on tracts where it is most likely that the hazardous waste site has contaminated local drinking water supplies. These tracts are defined as those where the site's groundwater pathway score exceeds 28.5 and the tract is in the top half of the distribution of mean household well water usage (i.e., more than $11.8 \%$ of households use well water). It seems reasonable to suppose that tracts where households rely on contaminated water may place a higher value on clean-ups. Here, the point estimates on the interaction are in the relatively narrow range of -0.007 to 0.024 , although individually they are poorly determined. ${ }^{41} 42$

conclusions. In fact, the results from the most reliable specifications (i.e., those reported in Table 6) are virtually identical to those for models for median house prices. Similarly, the results are practically unchanged when the dependent variable is the difference between the ln of 2000 (or 1990) and 1980 housing prices.

${ }^{39}$ Davis (2004) finds a $13 \%$ house price response to the outbreak of a cancer cluster in Churchill County, Nevada, which has a population density of 5 people per square mile. The relevance for this paper is that it clearly contradicts the view that the house prices do not respond to changes in environmental goods (or other public goods) in regions with plentiful undeveloped land. This is consistent with the notion that there is a fixed amount of land (i.e., a vertical supply curve of land). Nevertheless, we present the Panel D results to explore this issue in our setting.

${ }^{40}$ The results are qualitatively similar when we test whether the effect of the NPL designation differs in tracts located in counties in the top quartile of county population density.

${ }^{41}$ Of the 122 tracts with a population density exceeding 1,588, 72 have a HRS score exceeding 28.5 and 79 have sites placed on the NPL by 2000 . Among the 204 tracts that qualify as potentially having contaminated drinking water, 164 have HRS scores exceeding 28.5 and 170 have sites that had been placed on the NPL by 2000 .

${ }^{42}$ We would have liked to test whether the effects of clean-ups differed for large sites or ones where the estimated costs of clean-up are high (so called "mega" sites). The size and estimated cost data are only available for NPL sites, so it is impossible to include a main effect for these characteristics. Since these characteristics are likely to have a direct effect on housing price appreciation, we cannot conduct meaningful tests of these hypotheses. 


\section{E. Quasi-Experimental Estimates of Stages of Superfund Clean-Ups on Rental Rates}

We now turn to using the 1990 and $2000 \ln$ median rental rates as the outcome variable. Rental units account for roughly $20 \%$ of all housing units and generally differ on observable characteristics from owner occupied homes, so the results may not be indicative of the overall housing market. The appeal of this outcome is that rental rates are a flow measure, so we can abstract from the problem that individuals' expectations about the length of time until the completion of the clean-up are unknown. Consequently, we can test whether the impact of the clean-ups on the value of local housing services varies at different stages of Superfund clean-ups. ${ }^{43}$

Table 7 presents separate 2SLS estimates of the effect of the different stages of the remediation process on 1990 and 2000 rental rates. The three endogenous variables are independent indicator variables for tracts that contain a site that by 1990/2000: is on the NPL but a ROD has not been issued; has a ROD and/or clean-up has been initiated but not completed; or, has been designated construction complete or deleted from the NPL. The three instruments are the interaction of the $1\left(\mathrm{HRS}_{\mathrm{c} 82}>28.5\right)$ variable with the indicators for these three stages of the NPL process. The table reports the point estimates and their standard errors, along with the p-value from a F-test that the three point estimates are equal. The number of sites in each category and the mean HRS score is also listed in brackets.

The sites in the "NPL Only" category have been on the NPL for 7 (17) years by 1990 (2000), but the EPA had not developed a remediation plan yet. It seems reasonable to presume that individuals have had enough time to use the NPL listing to update their expectation of the risk associated with proximity to the site. In both the 1990 (2000) regressions, 3 (2) of the 4 point estimates are positive for this group. The large standard errors, especially in the regression discontinuity specifications, make definitive conclusions unjustified. However, the results in this table (along with results from analogous housing price regressions ${ }^{44}$ ) fail to lend much credence to the conventional wisdom that a site's placement on the

\footnotetext{
43 Viscusi and Hamilton (1999) find evidence that decisions about the timing of clean-ups of NPL sites are associated with local measures of political activism. Other researchers have found less decisive evidence on the relationship between local community's characteristics and EPA decisions on the timing of clean-ups (Hird 1993, 1994; Zimmerman 1993; Gupta et al., 1995 and 1996).

${ }^{44}$ We also estimated a version of these models for housing prices. The column (2) "NPL Only" parameter estimates (standard errors) for 1990 and 2000 are 0.018 (0.067) and $0.015(0.065)$, respectively.
} 
NPL leads to an immediate reduction in the value of housing services near the site.

The 2000 results for the "Construction Complete or NPL Deletion" category are noteworthy. The point estimates from the more reliable specifications range from -0.043 to 0.046 and zero cannot be rejected for any of them. This finding is telling, because these sites have been fully remediated and yet there seems to be little effect on the growth of rental rates. ${ }^{45}$

The null hypothesis of equality of the three parameters cannot be rejected at conventional levels in any of the specifications. The imprecision of the estimates helps to explain this finding, but their rank ordering is also surprising. In three of the four 2000 specifications, the point estimate on the "NPL Only" indicator is either equal to or exceeds the "Construction Complete or NPL Deletion" one.

A possible explanation for the small housing price effects in Tables 5 and 6 is that gains near sites where clean-ups are complete are obscured by declines at sites where the clean-ups are not complete or have not been initiated. The Table 7 findings undermine this explanation. Overall, this table lends further support to the view that Superfund clean-ups had small effects on the value of local housing services.

\section{F. Quasi-Experimental Estimates of the Effect of NPL Status on Total Population and Demographics}

Table 8 presents 2SLS estimates for a series of housing supply, population, and demographic variables measured in 2000. We continue to focus on the tracts containing the hazardous waste sites. The intent is to determine whether individuals sort in response to changes in local environmental amenities, or specifically the Superfund clean-ups. We report the parameter estimate and standard errors on the dummy for NPL status by 2000. As in the earlier analysis, this variable is instrumented with an indicator for a HRS score above 28.5.

The first specification simply adjusts for the 1980 value of the dependent variable. The column (2) specification adds state fixed effects. The column (3) specification adds a quadratic in the 1982 HRS score and in column (4) the smaller regression discontinuity sample is used. To keep the interpretation

\footnotetext{
45 The point estimates (standard errors) for the "Construction Complete or NPL Deletion" indicator from the columns (2), (3), and (4) specifications in the 2000 housing price analogs to the Table 7 regressions are 0.063 $(0.029), 0.016(0.060)$, and $0.038(0.040)$. Thus, these regressions also fail to provide much evidence that Superfund clean-ups have a substantial impact on housing prices.
} 
simple, the estimates are not adjusted for the wide range of housing characteristics, economic conditions and demographics as was done in the price and rental rate regressions.

Panel A tests for an association between NPL status and growth in the total number of housing units and population. The results provide mixed evidence on total housing units. There is modest evidence of a relative increase in population in the tracts with NPL sites. The estimates in the regression discontinuity specifications are poorly determined, but the point estimates are similar to those in the other specifications. Figure 9 provides an opportunity to examine the population results graphically. It is evident that tracts with HRS scores exceeding 28.5 have higher population growth but there is only weak evidence of a discontinuous jump in population growth at the regulatory threshold.

Panels B and C examine whether the NPL designation is associated with sorting or migration that leads to changes in the income and demographic characteristics of local residents. The first two specifications suggest that household income increased more in NPL tracts and that the fraction of households receiving public assistance declined. The regression discontinuity specifications, however, are less supportive of this conclusion. It appears that the fraction of Blacks or Hispanics did not change in a meaningful way. Although the clean-up of Superfund sites is intended to reduce environmental risks for local residents, especially children, the fraction of the population under the age of 6 is unchanged.

\section{Interpretation and Policy Implications}

This paper's primary finding is that the NPL designation and eventual clean-up of hazardous waste sites have small effects on the value of housing services in the areas proximate to these sites. In light of the substantial resources devoted to these clean-ups and the claims of large health benefits, this finding may be considered surprising. Here, we review two explanations both of which are consistent with the results.

First, there may be heterogeneity in individuals' valuations of the risks associated with proximity to hazardous waste sites and the individuals that choose to live near these sites may have a low willingness to pay to avoid the associated health risks. This could be the case either because of differences in income or heterogeneity in preferences. In this case, the paper's estimate would be 
uninformative about the population average willingness to pay. It is important to note, however, that from a policy perspective the crucial parameter is the willingness to pay of the population that lives near these sites and this is the parameter that the paper has estimated.

Second, individuals may have imperfect information. This imperfect information could take the form of ignorance about proximity to sites or unawareness of the reduction in health risks associated with clean-ups. It is unlikely that individuals are unaware of the sites, because local newspapers often provide extensive coverage when a site is placed on the NPL (or even considered for placement) and/or when remediation is completed. Further, at least a few states (e.g., Alaska and Arizona) require home sellers to disclose whether there are hazardous waste sites in close proximity.

Alternatively, it seems plausible that individuals do not perfectly understand the health benefits of Superfund clean-ups. As discussed above, scientists are actively studying the health consequences of exposure to the thousands of toxics present at Superfund sites, but laboratory evidence on the human (rather than mouse or rat) health effects of these toxics will not be available any time soon since scientific review boards reasonably place many safeguards on the study of human health. Put another way, the scientific uncertainty surrounding the toxics at many Superfund sites makes it difficult for individuals to correctly assess the health benefits of clean-ups. ${ }^{46}$ A related possibility is that regardless of the clean-ups' effectiveness at reducing health risks, individuals do not believe that they mitigate risk.

These two explanations have very different policy implications. The former suggests that society devotes too many resources to these clean-ups and that it may be prudent to consider less expensive options. For example, a policy of erecting fences around the sites and posting signs that warn about the potential health risks would be cheaper. Alternatively if the goal is to transfer resources to the people that live in polluted parts of the country, the results suggest that society should identify projects that are more

\footnotetext{
${ }^{46}$ One caveat to this line of reasoning is that although there is uncertainty about the magnitude of the benefits of clean-ups, it is not evident why individuals would incorrectly assume they are small rather than large. It is possible that some individuals have difficulty assessing low probability events (e.g., a small increase in the probability of contracting cancer) and just assume that the clean-ups induce no change in risk. However, if this is a mistake, it is unclear why all individuals would make it. Markets allow for heterogeneity in beliefs and presumably the individuals that believe that clean-ups have large health benefits would purchase houses from the individuals that believe the opposite.
} 
valuable to individuals living in these areas. Of course, cash transfers are one such option, although they may not be politically desirable or feasible. ${ }^{47}$

The latter explanation suggests that the benefits of these clean-ups may be substantially larger than suggested by this paper's results. However, this possibility cannot be assessed without reliable estimates on the health benefits of these clean-ups. This is an important area for future research.

\section{Conclusions}

This study has estimated the effect of Superfund clean-ups of hazardous waste sites on local housing price appreciation. The basis of the analysis is a comparison of housing price growth in the areas surrounding the first 400 hazardous waste sites to be cleaned up through the Superfund program to the areas surrounding the 290 sites that narrowly missed qualifying for the initial Superfund clean-ups. Using the most comprehensive data file on Superfund ever compiled by the EPA or other researchers, we cannot reject that the clean-ups had no effect on housing price growth, nearly two decades after these sites became eligible for them. This finding is robust to a series of specification checks, including the application of a quasi-experimental regression discontinuity design based on knowledge of the exact selection rule. Overall, the preferred quasi-experimental estimates suggest that the benefits of Superfund clean-ups as measured through the housing market are substantially lower than $\$ 43$ million, which is our best estimate of the mean costs of a Superfund clean-up.

More broadly, this paper contributes to a growing body of research (Black 1999; Chay and Greenstone 2005) which suggests that it is possible to identify research designs that mitigate the confounding that has historically undermined the credibility of conventional hedonic approaches to valuing non-market goods. In this respect, it suggests that there may be more opportunities to use markets to value environmental goods than is commonly accepted.

\footnotetext{
${ }^{47}$ If the paper's estimates that housing prices are unaffected by the NPL designation are correct and there aren't any health benefits, then the social cost of the Superfund program is simply the deadweight loss associated with the collection of public funds. In this case, the program could be viewed as primarily consisting of a transfer from taxpayers to EPA personnel, lawyers, environmental engineers, and other individuals and companies involved in the remediation of Superfund hazardous waste sites. Whether transfers to these groups are more preferable than transfers to individuals that live near hazardous waste sites is a political decision.
} 


\section{DATA APPENDIX}

\section{Covariates in Housing Price and Rental Rate Regressions}

The following are the control variables used in the housing price and rental rate regressions. They are listed by the categories indicated in the row headings at the bottom of these tables. All of the variables are measured in 1980 and are measured at the census tract level (or are the mean across sets of census tracts, for example tracts that share a border with a tract containing a hazardous waste site).

1980 Ln House Price

In mean value of owner occupied housing units in 1980 (note: the median is unavailable in 1980)

\section{Housing Characteristics}

total housing units

$\%$ of total housing units (rental and owner occupied) that are occupied

\# housing units owner occupied

$\%$ of owner occupied housing units with 0 bedrooms

$\%$ of owner occupied housing units with 1 bedroom

$\%$ of owner occupied housing units with 2 bedrooms

$\%$ of owner occupied housing units with 3 bedrooms

$\%$ of owner occupied housing units with 4 bedrooms

$\%$ of owner occupied housing units with 5 or more bedrooms

$\%$ of owner occupied housing units that are detached

$\%$ of owner occupied housing units that are attached

$\%$ of owner occupied housing units that are mobile homes

$\%$ of owner occupied house built within last year

$\%$ of owner occupied house built 2 to 5 years ago

$\%$ of owner occupied house built 6 to 10 years ago

$\%$ of owner occupied house built 10 to 20 years ago

$\%$ of owner occupied house built 20 to 30 years ago

$\%$ of owner occupied house built 30 to 40 years ago

$\%$ of owner occupied house built more than 40 years ago

$\%$ of all housing units without a full kitchen

$\%$ of all housing units that have no heating or rely on a fire, stove, or portable heater

$\%$ of all housing units without air conditioning

$\%$ of all housing units without a full bathroom

Note: In the rental regressions in Table 7, the owner occupied variables are replaced with renter occupied versions of the variables. For example, the first variable is replaced with the "\% of renter occupied housing units with 0 bedrooms."

\section{Economic Conditions}

mean household income

$\%$ of households with income below poverty line

unemployment rate

$\%$ of households that receive some form of public assistance

1980 Demographics

population density

$\%$ of population Black

$\%$ of population Hispanic 
$\%$ of population under age 18

$\%$ of population 65 or older

$\%$ of population foreign born

$\%$ of households headed by females

$\%$ of households residing in same house as 5 years ago

$\%$ of individuals aged 16-19 that are high school drop outs

$\%$ of population over 25 that failed to complete high school

$\%$ of population over 25 that have a BA or better (i.e., at least 16 years of education)

\section{Assignment of HRS Scores}

The HRS test scores each pathway from 0 to 100 , where higher scores indicate greater risk. ${ }^{48} 49$ The individual pathway scores are calculated using a method that considers characteristics of the site as being included in one of three categories: waste characteristics, likelihood of release, and target characteristics. The final pathway score is a multiplicative function of the scores in these three categories. The logic is, for example, that if twice as many people are thought to be affected via a pathway then the pathway score should be twice as large.

The final HRS score is calculated using the following equation:

(1) HRS Score $=\left[\left(\mathrm{S}_{\mathrm{gw}}^{2}+\mathrm{S}_{\mathrm{sw}}^{2}+\mathrm{S}_{\mathrm{a}}^{2}\right) / 3\right]^{1 / 2}$,

where $S_{\mathrm{gw}}, \mathrm{S}_{\mathrm{sw}}$, and $\mathrm{S}_{\mathrm{a}}$, denote the ground water migration, surface water migration, and air migration pathway scores, respectively. As equation (1) indicates, the final score is the square root of the average of the squared individual pathway scores. It is evident that the effect of an individual pathway on the total HRS score is proportional to the pathway score.

It is important to note that HRS scores can't be interpreted as strict cardinal measures of risk. A number of EPA studies have tested how well the HRS represents the underlying risk levels based on cancer and non-cancer risks. ${ }^{50}$ The EPA has concluded that the HRS test (at least from the late 1980s version) is an ordinal test but sites with scores within 2 points of each pose roughly comparable risks to human health (EPA 1991). ${ }^{51}$

\section{Primary Samples}

We have two primary samples. The first sample includes sites that were placed on the National Priority List (NPL) before January 1, 2000. There are 1,398 sites in this sample. The second sample is all sites that were tested between 1980 and 1982 for inclusion on the initial National Priority List announced on September 8, 1983.

\section{A. All NPL Sample}

The All NPL sample includes NPL sites located in the 50 US states and the District of Columbia that were placed on the NPL before January 1, 2000. Although there are NPL sites located in US territories such as Puerto Rico, they are not included in the sample because the census data from these areas differs from the data for the remainder of the country. Further, the sample is limited to sites that

\footnotetext{
${ }^{48}$ See the EPA's Hazard Ranking System Guidance Manual for further details on the determination of the HRS score.

${ }^{49}$ The capping of individual pathways and of attributes within each pathway is one limiting characteristic of the test. There is a maximum value for most scores within each pathway category. Also, if the final pathway score is greater than 100 then this score is reduced to 100. The capping of individual pathways creates a loss of precision of the test since all pathway scores of 100 have the same effect on the final HRS score but may represent different magnitudes of risk.

${ }^{50}$ See Brody (1998) for a list of EPA studies that have examined this issue.

${ }^{51}$ The EPA states that the early 1980s version of the HRS test should not be viewed as a measure of "absolute risk", but that "the HRS does distinguish relative risks among sites and does identify sites that appear to present a significant risk to public health, welfare, or the environment" (Federal Register 1984).
} 
were listed on the NPL before January 1, 2000 to ensure that site listing occurred before any data collection for the 2000 census.

\section{B. 1982 HRS Sample}

The second sample consists of sites tested for inclusion on the initial NPL published on September 8, 1983. 690 sites were tested for inclusion on this list. As noted in the text, not all sites tested between 1980 and 1982 were placed on the first NPL list due to initial HRS scores below 28.5.

Additionally, 12 sites proposed for the NPL on December 30, 1982 were not listed on the first NPL which was issued on September 8, 1983. Specifically, 418 sites were proposed for the NPL, but 406 sites were listed. The difference between the proposed list and the final list is due mostly to the rescoring of sites. The EPA received 343 comments on 217 sites (all of which were proposed NPL sites) that led to score changes in 156 sites. Revised scores for 5 of these sites fell below 28.5. These sites were dropped from the proposed list. Also not included on the 1983 NPL are 7 more sites. These 7 sites were considered "still under consideration" and did not have final rescores available as of September 8, 1983.

Here is a detailed explanation of the difference between the 1982 proposed list and the first NPL issued in 1983:

(1) Included on the 1982 proposed list and not on 1983 final list

a. Sites with a revised HRS score below 28.5:

1. Crittenden County Landfill (Marion, AR)

2. Flynn Lumber (Caldwell, ID)

3. Parrot Road (New Haven, IN)

4. Phillips Chemical (Beatrice, NE)

5. Van Dale Junkyard (Marietta, $\mathrm{OH}$ )

b. Sites "still under consideration":

1. Clare Water Supply (Clare, MI)

2. Electravoice (Buchanan, MI)

3. Littlefield Township Dump (Oden, MI)

4. Whitehall Wells (Whitehall, MI)

5. Kingman Airport Industrial Area (Kingman, AZ)

6. Airco (Calvert City, KY)

7. Bayou Sorrel (Bayou Sorrel, LA)

c. State priority sites that were dropped:

1. Plastifax (Gulfport, MS)

d. Sites cleaned up by the responsible party before the 1983 NPL:

1. Gratiot Co Golf Course (St. Louis, MI)

e. Sites split into two separate sites:

1. Vestal Water Supply (Vestal, NY)

(2) Included on the 1983 final list but not on the 1982 proposed list

a. Two separate sites, formally Vestal Water Supply:

1. Vestal 1-1 (Vestal, NY)

2. Vestal 4-2 (Vestal, NY)

b. Site identified and tested after the 1982 proposed list:

1. Times Beach (Times Beach, MO)

Note that 5 of the 7 "still under consideration" sites (Airco, Bayou, Clare, Electravoice, and Whitehall Wells) were later added to the NPL. All five sites had score changes (3 revised upward, 2 revised downward). Two sites (Littlefield, Kingman) were never listed on the NPL. These sites would have had scores that dropped below 28.5.

Changes to site status for the sites in (1)c-(1)e, (2)a, and (2)b above did affect our sample. Gratiot Co Golf Course (1)d was remediated before publication of the final NPL and therefore dropped from our sample. The original Vestal Water Supply (1)e split into 2 sites, with Vestal 4-2 retaining all of the original attributes of the site. We therefore considered Vestal 4-2 as a continuation of the original site. 
Vestal 1-1 is not included in our sample as there is no 1982 score associated with this site. Likewise Times Beach (2)b is not included in our sample since there is no 1982 score. Plastifax (1)c received a 1982 score that would not have qualified the site for remediation. The site remains in the sample as would any other site that scored below 28.5.

As a reminder, we instrument for NPL status with 1982 HRS scores to purge the estimates of NPL status on housing price appreciation of the influence of the potentially endogenous decision to rescore sites.

\section{Site Size Variable}

The size of site is collected from EPA documentation on the site. Note, there are two sources for the "actual physical size" of a superfund site. Both sources are from the EPA's on-line Comprehensive Environmental Response, Compensation and Liability Information System (CERCLIS) Database. One is extracted from the Fact Sheet and the other from the Site Narrative. They differ for numerous sites and in these cases we used the average of the two sources. If only one was available we used that one.

In some cases the site size provided in CERCLIS refers to the area of source of the contamination and not the size of the site. There are relatively few sites that are described this way. To maintain consistency in how we interpret a site's size we excluded these data from our primary data file and indicated the 'actual-size' as missing. Further, there are some sites for which there is no size data available in CERCLIS. In some of these cases, we were able to obtain site size from the original HRS scoring sheets, which we obtained from the EPA docket center via a Freedom of Information Request.

Finally, sometimes the source of contamination is described as being just one part of the entire site. For example, the description for superfund site "NJD980505424" says that there is a 57 acre landfill on 144 acres of property. For this site and others described similarly, we considered the physical size of the site to be 57 acres.

\section{Details on the Determination of Construction Complete Status}

The Construction Complete variable was created by the EPA to gauge progress on remediating NPL sites. The EPA first began using this designation in 1990. However, it is evident from the remedial action site histories and a construction complete data file we received from the EPA that construction complete definitions were retroactively assigned to pre-1990 sites. Importantly, a site does not receive the construction complete designation until remediation is complete (besides operation and maintenance) at all of its operating units.

There are 4 sites in our samples which have been deleted but for which no Construction Complete dates are provided. The site ids for these sites are ARD059636456, KSD007241656, MND000686071, and WID990829475. These sites were all deleted between 1990 and 2000. Since construction complete is a precursor for deletion, we assign these sites a construction complete date 1 year prior to the deletion date. Table 1 reveals that on average deletions occur about 1 year before deletion.

\section{Measures of Expected and Actual Remediation Costs}

We collected data on the expected and actual costs of remediation at each Superfund site in our samples. Here, we describe the differences in these measures of costs and how they were calculated.

\section{A. Expected (Estimated) Costs}

Each site's expected cost is calculated as the sum of the "estimated costs" reported in the first Record of Decision (ROD) for each operating unit associated with the site. Each ROD evaluates possible remedial action plans and selects one that satisfies all relevant national and state requirements for human health and the natural environment. RODs are issued for NPL sites only, so expected costs are unavailable for sites that fail to make it onto the NPL. These data were unavailable in a few RODs and some sites were still without RODs by 2000.

Estimated costs include both the remedial action cost and where available the discounted operations and management cost for the selected remedy. The projected time period for these operation 
and management costs is usually $20-30$ years.

Many sites have multiple "operating units" or completely separate sections of the site with different RODs. We include estimated costs from each "operating unit" that has a separate ROD. Savannah Silver Site is the site with the greatest number of operating units in our sample with at least 73. Many of these operating units do not yet have a published ROD with an estimated cost. The vast majority of sites - approximately $90 \%$ - have 3 or less operating units.

Note that the Savannah Silver Site highlights a limitation of the expected cost data. Many sites listed on the National Priority List have Records of Decision and expected costs available for some, but not all of the operating units at the site. To guard against the possibility of under-estimating the expected costs at a site we emphasize expected cost data from those sites that are construction complete. It is clear that all Records of Decision would be published for these sites.

Occasionally the ROD(s) for a site are updated or amended and this frequently leads to revisions in the estimated costs field. These revisions are not included as part of the expected costs presented in this paper. Thus, this paper's reported expected costs are projections of the total costs of site remediation before any clean-up activities have been initiated. (Interestingly, the amended mean expected costs of remediation are nearly identical to the mean expected costs reported in the paper.)

\section{B. Actual Costs}

The actual cost data presented in this paper is our best effort to calculate the actual amount spent on remedial action at each site by the EPA, state governments, and responsible parties. As will be explained in greater detail below, the actual cost data comes from 2 sources. The first source is a complete history of all EPA costs summarized by year and site. These data are from the IFMS database and were provided to us by the financial/accounting department at the federal EPA office. The second source is a document called Enforcement 3, also obtained from the accounting department of the national EPA, which estimates all potential responsible party (i.e. private party) costs for each NPL site. These potential responsible party (PRP) costs are estimates by EPA engineers of remedial action expenses paid directly by companies and individuals. These costs are not reimbursements to the EPA or another party for work that was already completed. Note that private companies are not required to disclose the actual amount of money spent on remediation efforts. Thus, the actual cost data used in this paper is the sum of the EPA actual costs and the PRP estimated costs.

Before explaining in greater detail the data sources used, we note that we explored two other data sources for actual cost information but found both of them to be of unacceptably low quality. The first source was a data file sent to us by the National EPA office that reportedly included all available actual cost data on NPL sites. However, inspection of this file revealed numerous instances of sites with actual cost amounts of 1,0, and negative dollar amounts. Our hypothesis is that these data include money reimbursed to the EPA by states and potential responsible parties. This could account for the negative and zero dollar amounts for sites that clearly had remedial action. We are uncertain as to what might explain the arbitrarily low dollar amounts $(1,2$, etc.) other than data error. The second source of data we explored using is the "actual cost" figures listed for some NPL sites on the EPA's Superfund website (CERCLIS). On inspection of these cost figures we again found 1, 0, and negative dollar amounts.

Apart from the obvious concerns with the other potential actual cost data sources there are several advantages of the data provided to us by the financial office of the EPA. First, the costs are all listed by site by year. This allows us to convert all cost expenditures to year 2000 \$'s. Second, the EPA actual cost data include both 'direct' and 'indirect' costs for each site. Direct costs include remedial action and operations and management costs. Indirect costs are the EPA's estimate of the portion of the Superfund program costs (personnel wages, travel costs to inspect the sites, etc.) that are attributed to each site. Third, by including EPA estimates for additional Potential Responsible Party costs, we have a more complete accounting of the total costs to remediate each site.

A challenge regarding the actual cost data is to determine whether we have accounted for all costs

paid by state governments. Initial Superfund legislation required that state governments pay for at least $10 \%$ of the remedial costs and all of the operations and management costs for sites located in their state. 
The Federal EPA does not track state costs. Conversations with federal EPA personnel have indicated that it is often the case that the Federal EPA pays for the work done at the sites and that the states then reimburse the EPA. This interpretation would be consistent with the fact that the EPA actual cost data file tracks operations and management costs - costs technically supposed to be covered by the states. Although we are not convinced that we have accounted for all state costs, our conversations with individual states and the federal EPA have not identified an appealing alternative method to measure these costs.

\section{Matching of 2000 Census Tracts to 1980 and 1990 Censuses}

The census tract is used as the unit of analysis, because it is the smallest aggregation of data that is available in the 1980,1990 and 2000 US Census. As noted in the text, year 2000 census tract boundaries are fixed so that the size and location of the census tract is the same for the 1980 and 1990 census data. The fixed census tract data boundaries were provided by Geolytics, a private company. Information on how the 1980 and 1990 census tracts were adjusted to fit the 2000 census tract boundaries can be found on their website at: www.geolytics.com. An outline of their approach is as follows.

Geolytics mapped 1990 census tracts into 2000 census tracts using block level data. Their documentation states, "The basic methodology was to use the smaller blocks to determine the populationweighted proportion of a 1990 tract that was later redefined as part of a 2000 tract." ${ }^{, 52}$ A 1990 street coverage file was used to weight populations of 1990 blocks included in 2000 census tracts when the 1990 blocks were split among multiple census tracts. The assumption is that local streets and roads served as a proxy for where populations were located. Block level data for 1980 were unavailable. This complicated the mapping of 1980 tracts into 1990 tracts. However, the correspondence between 1980 tracts and 1990 blocks is "very good". As such "splitting a 1980 tract into 1990 tracts had to be done spatially, meaning based solely on the 1990 block to 1980 tract correspondence."

\section{Placement of Hazardous Waste Sites in 2000 Census Tracts}

There are 2 types of hazardous waste sites in our sample - those that were eventually listed on the National Priority List (NPL) and those that have never been listed on the NPL. Each of these hazardous waste sites was assigned to a single census tract. The remainder of this section describes the separate procedures we used to determine the year 2000 census tract of location for NPL and non-NPL hazardous waste sites.

For the NPL sites, latitude and longitude coordinates are available on the EPA's CERCLIS web site. These coordinates were spot checked against their addresses and site descriptive information. GIS Arc Map software was then used to place these sites in a single census tract.

It is more difficult to place the hazardous waste sites that have never been on the NPL in a single census tract. Our first attempt was to place these sites using a comprehensive file provided to us by the EPA that contained latitude and longitude coordinates for non-NPL sites. However, upon inspection of this file we found numerous errors. Many of our sample sites were placed in different cities, counties, states, or zip codes from the EPA address descriptions provided in CERCLIS and the Federal Register.

In light of the unreliable latitude and longitude data, we used several methods to place these sites. Those sites with complete street address information were placed using a program that converts street addresses to latitude and longitude coordinates. These coordinates were then placed in a census tract using GIS Arc Map software.

Those non-NPL sites with missing or incomplete addresses were the most difficult sites to place. We requested original Hazardous Ranking System (HRS) documents on all of these sites from the Federal Register. The HRS documents are the first comprehensive documents prepared for each site. These

\footnotetext{
52 Appendix J: Description of Tract Remapping Methodology of Geolytics Data Users' Guide for Neighborhood Change Database (1970-2000), page J3.

${ }^{53}$ Ibid, page J4.
} 
documents often contain more detailed descriptive information on the sites. Some HRS documents also contain maps showing a site's location in the surrounding community. Many of these sites could be placed by hand using the more detailed descriptive and location information contained in the HRS documents and an electronic US Census map.

We called regional and state EPA officials regarding all non-NPL sites that we were unable to place with certainty using either CERCLIS information or the HRS scoring packages. For each of these sites, we located someone with first hand knowledge of the site's location or who was able to provide us with either a map of the site, a more complete address, or more accurate latitude longitude coordinates. Through these efforts, we placed all non-NPL sites in individual census tracts.

\section{Neighbor Samples}

We use two approaches to define the set of houses outside each site's tract that may be affected by the clean-up. We refer to these sets of houses as "neighbors."

The first approach defines the neighbors as all census tracts that share a border with the tract that contains the site. GIS software was used to find each primary census tract and extract the identity of its adjacent neighbors. In the $1982 \mathrm{HRS}$ sample, the maximum number of neighboring census tracts is 21 and the median is 7 . The population of each adjacent census tract was used to weight the housing price, housing characteristics, and demographic variables for each tract when calculating the mean adjacent neighbor values.

The second approach defines neighbors based on circles of varying radii around the exact location of the site. GIS software is used to draw a circle around the point representing the site (generally the center of the site, but sometimes the point associated with the street address). For example in the 1 mile sample, the GIS program draws circles with radii of 1 mile around each of the sites. For a given site, data from all census tracts that fall within its 1-mile radius circle are used to calculate the mean housing values and housing and demographic characteristics. To calculate these weighted means, each census tract within the circle is weighted by the product of its population and the portion of its total area that falls within the circle. The maximum number of census tracts included in the 1 mile ring for a site is 37 and the median is 3 . For the 2 mile ring the maximum number of neighbor sites is 80 , with a median of 5 . 


\section{REFERENCES}

Altonji, Joseph G., Todd E. Elder, and Christopher R. Taber, "Selection on Observed and Unobserved Variables: Assessing the Effectiveness of Catholic Schools," NBER Working Paper No. 7831, 2000.

Ashenfelter, Orley and Michael Greenstone, "Using Mandated Speed Limits to Measure the Value of a Statistical Life," Journal of Political Economy, CXII (Feb. 2004), S226-S268.

----, "Estimating the Value of a Statistical Life: The Importance of Omitted Variables and Publication Bias," American Economic Review, XCIV (May 2004), 454-60.

Banzhaf, H. Spencer and Randall P. Walsh, "Do People Vote with Their Feet: An Empirical Test of Environmental Gentrification,” Mimeograph, 2005.

Black, Dan A. and Thomas J. Kneisner, "On the Measurement of Job Risk in Hedonic Wage Models," Journal of Risk and Uncertainty, XXVII (Dec. 2003), 205-20.

Black, Sandra, "Do Better Schools Matter? Parental Valuation of Elementary Education," Quarterly Journal of Economics, CXIV (May 1999), 577-99.

Brody, Thomas M., "Investing in Cleanup: A New Look at Decision Criteria for the Comparison and Management of Risk," Dissertation, Northwestern University, 1998.

Cameron, Trudy Ann and Ian T. McConnaha, "Evidence of Environmental Migration," Mimeograph, 2005.

Champ, Patricia A., Kevin J. Boyle and Thomas C. Brown, eds., A Primer on Nonmarket Valuation, (Dordrecht, The Netherlands: Kluwer Academic Publishers, 2003).

Chay, Kenneth Y., and Michael Greenstone, "Does Air Quality Matter? Evidence from the Housing Market," Journal of Political Economy, CXIII (Apr. 2005), 376-424.

Cleveland, William S., "Robust Locally Weighted Regression and Smoothing Scatterplots," Journal of the American Statistical Association, LXXIV (Dec. 1979), 829-36.

Cook, Thomas D., and Donald T. Campbell, Quasi-Experimentation: Design and Analysis Issues for Field Settings, (Boston, MA: Houghton Mifflin, 1979).

Cropper, Maureen L., Leland B. Deck, and Kenneth E. McConnell, "On the Choice of Functional Form for Hedonic Price Functions," Review of Economics and Statistics, LXX (Nov. 1988), 668-75.

Davis, Lucas, "The Effect of Health Risk on Housing Values: Evidence from a Cancer Cluster," American Economics Review, XCIV (Dec. 2004), 1693-1704.

Deschenes, Olivier and Michael Greenstone, "The Economic Impacts of Climate Change: Evidence from Agricultural Profits and Random Fluctuations in Weather,” NBER Working Paper No. 10663, 2004.

Diamond, Peter A. and Jerry A. Hausman, "Contingent Valuation: Is Some Number Better Than No Number?” Journal of Economic Perspectives, VIII (Autumn 1994), 45-64.

Ekeland, Ivar, James J. Heckman, and Lars Nesheim, "Identification and Estimation of Hedonic Models," 
Journal of Political Economy, CXII (Feb. 2004), S60-S109.

Environmental Protection Agency, Superfund: 20 Years of Protecting Human Health and the Environment, "http://www.epa.gov/superfund/action/20years/index.htm," 2000.

Farrell, Alex, "A Partial Benefit-Cost Test of NPL Site Remediation: Benefit Transfer with Met-Analytic Hedonic Data,” Mimeograph, University of California, Berkeley, 2004.

Federal Register Rules and Regulations, National Oil and Hazardous Substance Contingency Plan; The National Priorities List; Amendment, Various Issues.

Federal Register Rules and Regulations, Section IV, "Process for Establishing the National Priorities List,” XLIX (September 21, 1984), 37070-82.

Freeman, A Myrick, III, “On Estimating Air Pollution Control Benefits from Land Value Studies, Journal of Environmental Economics and Management, I (May 1974), 74-83.

----, The Measurement of Environmental and Resource Values, (Washington, DC: Resources for the Future, 2003).

Gayer, Ted, James T. Hamilton, and W. Kip Viscusi, "Private Values of Risk Tradeoffs at Superfund Sites: Housing Market Evidence on Learning about Risk," The Review of Economics and Statistics, LXXXII (Aug. 2000), 439-51.

----, "The Market Value of Reducing Cancer Risk: Hedonic Housing Prices with Changing Information," Southern Economic Journal, LXIX (Oct. 2002), 266-89.

Gupta, Shreekant, George Van Houtven, and Maureen Cropper, "Do Benefits and Costs Matter in Environmental Regulation? An Analysis of EPA Decisions under Superfund," Analyzing Superfund: Economics, Science, Law, Richard L. Revesz and Richard B. Stewart eds., (Washington, DC: Resources for the Future, 1995).

----, "Paying for Permanence: An Economic Analysis of EPA's Cleanup Decisions at Superfund Sites," RAND Journal of Economics, XXVII (Autumn 1996), 563-82.

Halvorsen, Robert and Henry O. Pollakowski, "Choice of Functional Form for Hedonic Price Equations," Journal of Urban Economics, X (Jul. 1981), 37-49.

Hamilton, James T. and W. Kip Viscusi, Calculating Risks: The Spatial and Political Dimensions of Hazardous Waste Policy, (Cambridge, MA: The MIT Press, 1999).

Hanemann, W. Michael, "Valuing the Environment through Contingent Valuation," Journal of Economic Perspectives, VIII (Autumn 1994), 19-43.

Harris, John D., "Property Values, Stigma, and Superfund," Environmental Protection Agency, "http://www.epa.gov/superfund/programs/recycle/property.htm," 1999.

Hird, John, "Environmental Policy and Equity: The Case of Superfund," Journal of Policy Analysis and Management, XII (Spring 1993), 323-43.

----, Superfund: the Political Economy of Environmental Risk, (Baltimore, MD: Johns Hopkins University 
Press, 1994).

Ihlanfeldt, Keith R. and Laura O. Taylor, "Externality Effects of Small-Scale Hazardous Waste Sites: Evidence from Urban Commercial Property Markets,” XLVII (January 2004), 117-39.

Kiel, Katherine A., "Measuring the Impact of the Discovery and Cleaning of Identified Hazardous Waste Sites on House Values," Land Economics, LXXI (Nov. 1995), 428-35.

Kiel, Katherine A. and Jeffery Zabel, "Estimating the Economic Benefits of Cleaning Up Superfund Sites: The Case of Woburn, Massachusetts," The Journal of Real Estate Finance \& Economics, XXII (Mar. 2001), 163-84.

Kohlhase, Janet E., "The Impact of Toxic Waste Sites on Housing Values," Journal of Urban Economics, XXX (Jul. 1991), 1-26.

McCluskey, Jill J. and Gordon C. Rausser, "Hazardous Waste Sites and Housing Appreciation Rates," Journal of Environmental Economics and Management, XLV (Jul. 2003), 166-176.

Messer, Kent, William Schulze, Katherine Hackett, Trudy Cameron, and Gary McClelland, "Stigma: The Psychology and Economics of Superfund," Working Paper, 2004.

Michaels, R. Gregory and V. Kerry Smith, "Market Segmentation and Valuing Amenities with Hedonic Models: The Case of Hazardous Waste Sites," Journal of Urban Economics, XXVIII (Sep. 1990), 223-42.

Palmquist, Raymond B., "Hedonic Methods," Measuring the Demand for Environmental Quality, John Bardon and Charles Kolstad eds., (Amsterdam: Elsevier Science Publishers, 1991).

Probst, Katherine N. and David M. Konisky, Superfund's Future: What Will It Cost?, (Washington, DC: Resources for the Future, 2001).

Ridker, Ronald, The Economic Cost of Air Pollution, (New York, NY: Prager, 1967).

---- and J.A. Henning, "The Determinants of Residential Property Values with Special Reference to Air Pollution," Review of Economics and Statistics, XLIX (May 1967), 246-57.

Rosen, Sherwin, "Hedonic Prices and Implicit Markets: Product Differentiation in Pure Competition," Journal of Political Economy, LXXXII (Jan. 1974), 34-55.

----, "The Theory of Equalizing Differences," Handbook of Labor Economics, Orley Ashenfelter and Richard Layard, eds., (Amsterdam: North-Holland, 1986).

Schmalensee, Richard, Ramachandra Ramanathan, Wolfhard Ramm, and Dennis Smallwood, Measuring External Effects of Solid Waste Management, (Washington DC: Environmental Protection Agency, 1975).

Sigman, Hilary, "The Pace of Progress at Superfund Sites: Policy Goals and Interest Group Influence," Journal of Law and Economics, XLIV (Apr. 2001), 315-44.

Small, Kenneth A., "Air Pollution and Property Values: A Further Comment," Review of Economics and Statistics, LVII (Feb. 1975), 105-7. 
Smith, Robert S., "Compensating Wage Differentials and Public Policy: A Review," Industrial and Labor Relations Review, XXXII (Apr. 1979), 339-52.

Staiger, Douglas and James H. Stock, "Instrumental Variables with Weak Instruments," Econometrica, LXV (May 1997), 557-86.

Viscusi, W. Kip, "The Value of Risks to Life and Health," Journal of Economic Literature, XXXI (Dec. 1993), $1912-46$.

---- and James T. Hamilton, "Are Risk Regulators Rational? Evidence from Hazardous Waste Cleanup Decisions," American Economic Review, LXXXIX (Sep. 1999), 1010-27.

Zimmerman, Rae, “Social Equality and Environmental Risk,” Risk Analysis, XIII (Dec. 1993), 649-66. 
Table 1: Summary Statistics on the Superfund Program

\begin{tabular}{|c|c|c|c|}
\hline & $\begin{array}{l}\text { All NPL Sites w/ } \\
\text { non-Missing House } \\
\text { Price Data } \\
\text { (1) }\end{array}$ & $\begin{array}{c}1982 \text { HRS Sites w/ } \\
\text { non-Missing } \\
\text { House Price Data } \\
\text { (2) }\end{array}$ & $\begin{array}{l}1982 \text { HRS Sites w/ } \\
\text { Missing House } \\
\text { Price Data } \\
\text { (3) }\end{array}$ \\
\hline Number of Sites & 985 & 487 & 189 \\
\hline 1982 HRS Score Above 28.5 & ------ & 306 & 95 \\
\hline \multicolumn{4}{|c|}{ A. Timing of Placement on NPL } \\
\hline Total & 985 & 332 & 111 \\
\hline \# 1981-1985 & 406 & 312 & 97 \\
\hline \# 1986-1989 & 340 & 14 & 9 \\
\hline \# 1990-1994 & 166 & 4 & 3 \\
\hline \# 1995-1999 & 73 & 2 & 2 \\
\hline \multicolumn{4}{|c|}{ B. HRS Information } \\
\hline Mean Scores $\mid$ HRS $\geq 28.5$ & 41.89 & 44.47 & 43.23 \\
\hline Mean Scores $\mid$ HRS $<28.5$ & ----- & 15.54 & 16.50 \\
\hline \multicolumn{4}{|c|}{ C. Size of Site (in acres) } \\
\hline Number of sites with size data & 920 & 310 & 97 \\
\hline Mean (Median) & $1,186(29)$ & $334(25)$ & $10,507(35)$ \\
\hline Maximum & 195,200 & 42,560 & 405,760 \\
\hline \multicolumn{4}{|c|}{ D. Stages of Clean-Up for NPL Sites } \\
\hline \multicolumn{4}{|c|}{ Median Years from NPL Listing Until: } \\
\hline ROD Issued & ------ & 4.3 & 4.3 \\
\hline Clean-Up Initiated & ------ & 5.8 & 6.8 \\
\hline Construction Complete & ------ & 12.1 & 11.5 \\
\hline Deleted from NPL & ------ & 12.8 & 12.5 \\
\hline \multicolumn{4}{|c|}{1990 Status Among Sites NPL by 1990} \\
\hline NPL Only & 394 & 100 & 31 \\
\hline ROD Issued or Clean-up Initiated & 335 & 210 & 68 \\
\hline \multicolumn{4}{|c|}{2000 Status Among Sites NPL by 2000} \\
\hline NPL Only & 137 & 15 & 3 \\
\hline ROD Issued or Clean-up Initiated & 370 & 119 & 33 \\
\hline Construction Complete or Deleted & 478 & 198 & 75 \\
\hline \multicolumn{4}{|c|}{ E. Expected Costs of Remediation (Millions of 2000 \$'s) } \\
\hline \# Sites with Nonmissing Costs & 753 & 293 & 95 \\
\hline Mean (Median) & $\$ 28.3(\$ 11.0)$ & $\$ 27.5(\$ 15.0)$ & $\$ 29.6(\$ 11.5)$ \\
\hline $95^{\text {th }}$ Percentile & $\$ 89.6$ & $\$ 95.3$ & $\$ 146.0$ \\
\hline \multicolumn{4}{|c|}{ F. Actual and Expected Costs Conditional on Construction Complete (Millions of 2000 \$'s) } \\
\hline Sites w/ Both Costs Nonmissing & 477 & 203 & 69 \\
\hline Mean (Median) Expected Costs & $\$ 15.5(\$ 7.8)$ & $\$ 20.6(\$ 9.7)$ & $\$ 17.3(\$ 7.3)$ \\
\hline Mean (Median) Actual Costs & $\$ 21.6(\$ 11.6)$ & $\$ 32.0(\$ 16.2)$ & $\$ 23.3(\$ 8.9)$ \\
\hline
\end{tabular}

Notes: All dollar figures are in 2000 \$'s. Column (1) includes information for sites placed on the NPL before 12/31/99. The estimated cost information is calculated as the sum across the first Record of Decisions for each operating unit associated with a site. See the Data Appendix for further details. 
Table 2: Mean Census Tract Characteristics by Categories of the 1982 HRS Score

\begin{tabular}{|c|c|c|c|c|c|c|c|c|c|}
\hline & $\begin{array}{c}\text { NPL Site } \\
\text { by } 2000 \\
(1)\end{array}$ & $\begin{array}{c}\text { No NPL Site } \\
\text { by } 2000 \\
(2)\end{array}$ & $\begin{array}{c}\text { HRS }<28.5 \\
\text { (3) }\end{array}$ & $\begin{array}{c}\text { HRS }>28.5 \\
(4)\end{array}$ & $\begin{array}{c}\text { HRS }>16.5 \\
\&<28.5 \\
(5) \\
\end{array}$ & $\begin{array}{c}\text { HRS }>28.5 \\
\&<40.5 \\
(6) \\
\end{array}$ & $\begin{array}{c}\text { P-Value } \\
\text { (1) vs. (2) } \\
(7) \\
\end{array}$ & $\begin{array}{c}\text { P-Value } \\
\text { (3) vs. (4) } \\
(8) \\
\end{array}$ & $\begin{array}{c}\text { P-Value } \\
\text { (5) vs. (6) } \\
(9) \\
\end{array}$ \\
\hline \# Census Tracts & 985 & 41,989 & 181 & 306 & 90 & 137 & ----- & ----- & ----- \\
\hline \multicolumn{10}{|c|}{ Superfund Clean-up Activities } \\
\hline Ever NPL by 1990 & 0.7576 & ----- & 0.1271 & 0.9902 & 0.2222 & 0.9854 & ----- & 0.000 & 0.000 \\
\hline Ever NPL by 2000 & 1.0000 & ----- & 0.1602 & 0.9902 & 0.2667 & 0.9854 & ----- & 0.000 & 0.000 \\
\hline \multicolumn{10}{|l|}{ Housing Prices } \\
\hline 1980 Mean & 58,058 & 69,904 & 45,027 & 52,137 & 46,135 & 50,648 & 0.000 & 0.000 & 0.084 \\
\hline 1990 Median & 100,102 & 99,552 & 80,185 & 96,752 & 84,461 & 91,611 & 0.839 & 0.005 & 0.433 \\
\hline 2000 Median & 139,066 & 151,712 & 115,479 & 135,436 & 117,528 & 123,503 & 0.000 & 0.001 & 0.449 \\
\hline \multicolumn{10}{|l|}{ Neighbor Housing Prices } \\
\hline 1980 Mean & 61,124 & ----- & 49,324 & 62,711 & 48,735 & 54,078 & ----- & 0.038 & 0.047 \\
\hline 1990 Median & 101,011 & ----- & 85,476 & 98,743 & 85,793 & 88,743 & ----- & 0.009 & 0.653 \\
\hline 2000 Median & 143,805 & ----- & 122,337 & 140,841 & 122,776 & 131,125 & ----- & 0.002 & 0.277 \\
\hline \multicolumn{10}{|c|}{ Demographics \& Economic Characteristics } \\
\hline Population Density & 1,406 & 5,786 & 1,670 & 1,157 & 1,361 & 1,151 & 0.000 & 0.067 & 0.570 \\
\hline$\%$ Black & 0.0914 & 0.1207 & 0.1126 & 0.0713 & 0.0819 & 0.0844 & 0.000 & 0.037 & 0.926 \\
\hline \% Hispanic & 0.0515 & 0.0739 & 0.0443 & 0.0424 & 0.0309 & 0.0300 & 0.000 & 0.841 & 0.928 \\
\hline \% Under 18 & 0.2940 & 0.2779 & 0.2932 & 0.2936 & 0.2885 & 0.2934 & 0.000 & 0.958 & 0.568 \\
\hline \% Female Head HH & 0.1617 & 0.1934 & 0.1879 & 0.1576 & 0.1639 & 0.1664 & 0.000 & 0.017 & 0.862 \\
\hline \% Same House 5 Yrs Ago & 0.5442 & 0.5127 & 0.6025 & 0.5623 & 0.5854 & 0.5655 & 0.000 & 0.001 & 0.244 \\
\hline \% > 25 No HS Diploma & 0.3425 & 0.3144 & 0.4053 & 0.3429 & 0.3881 & 0.3533 & 0.000 & 0.000 & 0.060 \\
\hline$\%>25$ BA or Better & 0.1390 & 0.1767 & 0.1003 & 0.1377 & 0.1092 & 0.1343 & 0.000 & 0.000 & 0.036 \\
\hline$\%<$ Poverty Line & 0.1056 & 0.1141 & 0.1139 & 0.1005 & 0.1072 & 0.1115 & 0.003 & 0.109 & 0.716 \\
\hline \% Public Assistance & 0.0736 & 0.0773 & 0.0885 & 0.0745 & 0.0805 & 0.0755 & 0.083 & 0.041 & 0.578 \\
\hline Household Income & 20,344 & 21,526 & 19,635 & 20,869 & 19,812 & 20,301 & 0.000 & 0.013 & 0.486 \\
\hline \multicolumn{10}{|l|}{ Housing Characteristics } \\
\hline Total Housing Units & 1,392 & 1,350 & 1,357 & 1,353 & 1,367 & 1,319 & 0.040 & 0.951 & 0.575 \\
\hline \% Mobile Homes & 0.0862 & 0.0473 & 0.0813 & 0.0785 & 0.0944 & 0.0787 & 0.000 & 0.792 & 0.285 \\
\hline \% Owner Occupied & 0.6821 & 0.6125 & 0.6792 & 0.6800 & 0.6942 & 0.6730 & 0.000 & 0.959 & 0.344 \\
\hline \% 0-2 Bedrooms & 0.4480 & 0.4722 & 0.4691 & 0.4439 & 0.4671 & 0.4496 & 0.000 & 0.103 & 0.417 \\
\hline \% 3-4 Bedrooms & 0.5246 & 0.5015 & 0.5098 & 0.5284 & 0.5089 & 0.5199 & 0.000 & 0.209 & 0.586 \\
\hline \% Built Last 5 Years & 0.1434 & 0.1543 & 0.1185 & 0.1404 & 0.1366 & 0.1397 & 0.006 & 0.050 & 0.844 \\
\hline \% Built Last 10 Years & 0.2833 & 0.2874 & 0.2370 & 0.2814 & 0.2673 & 0.2758 & 0.501 & 0.012 & 0.723 \\
\hline
\end{tabular}




\begin{tabular}{|c|c|c|c|c|c|c|c|c|c|}
\hline \% No Air Conditioning & 0.4904 & 0.4220 & 0.5058 & 0.4800 & 0.5157 & 0.5103 & 0.000 & 0.253 & 0.870 \\
\hline \% with Zero Full Baths & 0.0254 & 0.0229 & 0.0315 & 0.0259 & 0.0339 & 0.0290 & 0.011 & 0.089 & 0.386 \\
\hline \% Units Detached & 0.8764 & 0.8773 & 0.8585 & 0.8908 & 0.8545 & 0.8897 & 0.868 & 0.050 & 0.107 \\
\hline \% Units Attached & 0.0374 & 0.0754 & 0.0603 & 0.0307 & 0.0511 & 0.0317 & 0.000 & 0.040 & 0.297 \\
\hline \multicolumn{10}{|c|}{ Geographic Distribution Across Census Regions } \\
\hline \% Northeast & 0.3797 & 0.2116 & 0.3315 & 0.4771 & 0.3889 & 0.4234 & 0.0000 & 0.0014 & 0.6063 \\
\hline \% Midwest & 0.2183 & 0.2320 & 0.3481 & 0.2255 & 0.3222 & 0.2847 & 0.3016 & 0.0044 & 0.5507 \\
\hline$\%$ South & 0.2355 & 0.3227 & 0.2155 & 0.1928 & 0.1889 & 0.2044 & 0.0000 & 0.5519 & 0.7744 \\
\hline \% West & 0.1665 & 0.2337 & 0.1050 & 0.1046 & 0.1000 & 0.0876 & 0.0000 & 0.9890 & 0.7565 \\
\hline
\end{tabular}

Notes: Columns (1) - (6) report the means of the variables listed in the row headings across the groups of census tracts listed at the top of the columns. In all of these columns, the sample restriction that the census tract must have nonmissing house price data in 1980, 1990, and 2000 is added. Columns (7)-(9) report the p-values from tests that the means in different sets of the subsamples are equal. The Panel title "Neighbor Housing Price" reports the mean housing prices in all tracts that share a border with the tract containing the hazardous waste site. All other entries in the table refer to characteristics of the tract where the site is located. P-values less than .01 are denoted in bold. For the air conditioning and bath questions, the numerator is year round housing units and the denominator is all housing units. For all other variables in the "Housing Characteristics" category, the denominator is all housing units. 
Table 3: Estimates of the Association Between the Presence of a NPL Hazardous Waste Site and the ln of Median Census Tract Housing Prices, 1990 and 2000

\begin{tabular}{|c|c|c|c|c|}
\hline & $(1)$ & $(2)$ & (3) & $(4)$ \\
\hline \multicolumn{5}{|c|}{ A. Own Census Tract } \\
\hline \multicolumn{5}{|l|}{$\underline{\ln (1990 \text { Median Price) }}$} \\
\hline 1(NPL Status by 1990) & $\begin{array}{c}0.123 \\
(0.023)\end{array}$ & $\begin{array}{c}0.155 \\
(0.021)\end{array}$ & $\begin{array}{c}0.164 \\
(0.020)\end{array}$ & $\begin{array}{c}0.098 \\
(0.018)\end{array}$ \\
\hline \multicolumn{5}{|l|}{$\underline{\ln (2000 \text { Median Price) }}$} \\
\hline 1(NPL Status by 2000) & $\begin{array}{c}0.040 \\
(0.012)\end{array}$ & $\begin{array}{c}0.046 \\
(0.011)\end{array}$ & $\begin{array}{c}0.073 \\
(0.010)\end{array}$ & $\begin{array}{c}0.066 \\
(0.009)\end{array}$ \\
\hline \multicolumn{5}{|c|}{ B. Adjacent Census Tracts } \\
\hline$\underline{\ln (1990 \text { Median Price) }}$ & 0.157 & 0.149 & 0.173 & 0.108 \\
\hline 1(NPL Status by 1990) & $(0.018)$ & $(0.016)$ & $(0.014)$ & $(0.011)$ \\
\hline$\underline{\ln (2000 \text { Median Price) }}$ & 0.041 & 0.061 & 0.092 & 0.088 \\
\hline 1(NPL Status by 2000) & $(0.011)$ & $(0.010)$ & $(0.009)$ & $(0.008)$ \\
\hline 1980 Prices & Yes & Yes & Yes & Yes \\
\hline 1980 Housing Char’s & No & Yes & Yes & Yes \\
\hline 1980 Economic Conditions & No & No & Yes & Yes \\
\hline 1980 Demographics & No & No & Yes & Yes \\
\hline State Fixed Effects & No & No & No & Yes \\
\hline
\end{tabular}

Notes: The table reports results from 16 separate regressions where the unit of observation is a census tract. The sample size is 42,974 in all regressions. In Panel A, 746 (985) observations in 1990 (2000) are from census tracts that contain a hazardous waste site that had been on the NPL at any time prior to observation on housing prices. In Panel $\mathrm{B}$, the observations from tracts containing the NPL sites are replaced with observations comprised of averages of all variables across the census tracts with complete housing price data that share a border with the tracts containing the sites. The dependent variables are underlined in the first column. The entries report the coefficient and heteroskedastic-consistent standard error (in parentheses) on the NPL indicator. The controls are listed in the row headings at the bottom of the table. See the text and Data Appendix for further details. 
Table 4: Estimates of the First-Stage Relationship and an Informal Validity Test

\begin{tabular}{|c|c|c|c|c|c|c|}
\hline & $(1)$ & $(2)$ & $(3)$ & $(4)$ & $(5)$ & $(6)$ \\
\hline \multicolumn{7}{|c|}{$\begin{array}{l}\text { A. First Stage: } \\
\text { Between Instrument and NPL Status }\end{array}$} \\
\hline \multicolumn{7}{|l|}{ 1(NPL Status by 1990) } \\
\hline 1(1982 HRS Score > 28.5) & $\begin{array}{c}0.864 \\
(0.026)\end{array}$ & $\begin{array}{c}0.859 \\
(0.027)\end{array}$ & $\begin{array}{c}0.849 \\
(0.028)\end{array}$ & $\begin{array}{c}0.843 \\
(0.031)\end{array}$ & $\begin{array}{c}0.670 \\
(0.063)\end{array}$ & $\begin{array}{c}0.728 \\
(0.057)\end{array}$ \\
\hline \multicolumn{7}{|l|}{ 1(NPL Status by 2000) } \\
\hline 1(1982 HRS Score > 28.5) & $\begin{array}{c}0.827 \\
(0.029)\end{array}$ & $\begin{array}{c}0.822 \\
(0.029)\end{array}$ & $\begin{array}{c}0.813 \\
(0.030)\end{array}$ & $\begin{array}{c}0.801 \\
(0.034)\end{array}$ & $\begin{array}{c}0.608 \\
(0.066)\end{array}$ & $\begin{array}{c}0.687 \\
(0.060)\end{array}$ \\
\hline \multicolumn{7}{|c|}{$\begin{array}{l}\text { B. Informal Validity Test: } \\
\text { Association Between Instrument and ln (1980 Mean House Price) }\end{array}$} \\
\hline \multicolumn{7}{|l|}{ Own Census Tract } \\
\hline 1(1982 HRS Score > 28.5) & ----- & $\begin{array}{c}0.035 \\
(0.027)\end{array}$ & $\begin{array}{c}0.001 \\
(0.021)\end{array}$ & $\begin{array}{l}-0.010 \\
(0.018)\end{array}$ & $\begin{array}{c}-0.004 \\
(0.029)\end{array}$ & $\begin{array}{l}-0.008 \\
(0.021)\end{array}$ \\
\hline \multicolumn{7}{|l|}{ Adjacent Census Tracts } \\
\hline 1(1982 HRS Score > 28.5) & ----- & $\begin{array}{c}0.039 \\
(0.031)\end{array}$ & $\begin{array}{c}0.016 \\
(0.026)\end{array}$ & $\begin{array}{c}0.010 \\
(0.022)\end{array}$ & $\begin{array}{l}-0.003 \\
(0.039)\end{array}$ & $\begin{array}{c}0.023 \\
(0.026)\end{array}$ \\
\hline 1980 Prices (Panel A only) & Yes & Yes & Yes & Yes & Yes & Yes \\
\hline 1980 Housing Char’s & No & Yes & Yes & Yes & Yes & Yes \\
\hline 1980 Economic Conditions & No & No & Yes & Yes & Yes & Yes \\
\hline 1980 Demographics & No & No & Yes & Yes & Yes & Yes \\
\hline State Fixed Effects & No & No & No & Yes & Yes & Yes \\
\hline Quadratic in 1982 HRS Score & No & No & No & No & Yes & No \\
\hline Regression Discontinuity Sample & No & No & No & No & No & Yes \\
\hline
\end{tabular}

Notes: The table reports results from 22 separate regressions. The sample size is 487 in all regressions in columns (1)-(5), which is the number of sites that received 1982 HRS scores and are located in census tracts with non-missing housing price data in 1980, 1990, and 2000. The regression discontinuity sample in column (6) limits the sample to tracts (or neighbors of tracts) with sites with initial HRS scores between 16.5 and 40.5 and totals 227 census tracts. In Panel A, the dependent variables are indicators for whether the hazardous waste sites had been placed on the NPL by 1990 and 2000, respectively. In Panel B, the dependent variables are the ln of 1980 mean housing prices in the tract with the hazardous waste site and the $\ln$ of the mean of the mean house price across the census tracts that share a border with the tract containing the NPL site, respectively. The dependent variables are underlined in the first column. The table reports the regression coefficient and heteroskedastic consistent standard error (in parentheses) associated with the indicator variable for whether the hazardous waste site received a 1982 HRS score exceeding 28.5. The controls are listed in the row headings at the bottom of the table. See the text and Data Appendix for further details. 
Table 5: Two-Stage Least Squares (2SLS) Estimates of the Effect of NPL Status on House Prices

\begin{tabular}{|c|c|c|c|c|c|c|}
\hline & $(1)$ & $(2)$ & $(3)$ & $(4)$ & $(5)$ & $(6)$ \\
\hline \multicolumn{7}{|c|}{ A. Own Census Tract } \\
\hline \multicolumn{7}{|l|}{1990} \\
\hline 1(NPL Status by 1990) & $\begin{array}{c}0.034 \\
(0.062)\end{array}$ & $\begin{array}{c}0.066 \\
(0.057)\end{array}$ & $\begin{array}{c}0.064 \\
(0.054)\end{array}$ & $\begin{array}{c}0.020 \\
(0.054)\end{array}$ & $\begin{array}{l}-0.006 \\
(0.122)\end{array}$ & $\begin{array}{l}-0.006 \\
(0.078)\end{array}$ \\
\hline \multicolumn{7}{|l|}{$\underline{2000}$} \\
\hline 1(NPL Status by 2000) & $\begin{array}{c}0.037 \\
(0.035)\end{array}$ & $\begin{array}{c}0.043 \\
(0.031)\end{array}$ & $\begin{array}{c}0.056 \\
(0.029)\end{array}$ & $\begin{array}{c}0.047 \\
(0.027)\end{array}$ & $\begin{array}{c}0.007 \\
(0.063)\end{array}$ & $\begin{array}{c}0.027 \\
(0.038)\end{array}$ \\
\hline \multicolumn{7}{|c|}{$\underline{\text { B. Adjacent Census Tracts }}$} \\
\hline 1990 & & & & & & \\
\hline 1(NPL Status by 1990) & $\begin{array}{c}0.068 \\
(0.048)\end{array}$ & $\begin{array}{c}0.060 \\
(0.039)\end{array}$ & $\begin{array}{c}0.012 \\
(0.033)\end{array}$ & $\begin{array}{l}-0.006 \\
(0.027)\end{array}$ & $\begin{array}{l}-0.005 \\
(0.059)\end{array}$ & $\begin{array}{l}-0.020 \\
(0.044)\end{array}$ \\
\hline \multicolumn{7}{|l|}{$\underline{2000}$} \\
\hline 1(NPL Status by 2000) & $\begin{array}{c}0.068 \\
(0.035)\end{array}$ & $\begin{array}{c}0.019 \\
(0.029)\end{array}$ & $\begin{array}{c}0.014 \\
(0.025)\end{array}$ & $\begin{array}{c}0.012 \\
(0.022)\end{array}$ & $\begin{array}{c}0.021 \\
(0.054)\end{array}$ & $\begin{array}{c}0.011 \\
(0.035)\end{array}$ \\
\hline 1980 Ln House Price & Yes & Yes & Yes & Yes & Yes & Yes \\
\hline 1980 Housing Char's & No & Yes & Yes & Yes & Yes & Yes \\
\hline 1980 Economic Conditions & No & No & Yes & Yes & Yes & Yes \\
\hline 1980 Demographics & No & No & Yes & Yes & Yes & Yes \\
\hline State Fixed Effects & No & No & No & Yes & Yes & Yes \\
\hline Quadratic in 1982 HRS Score & No & No & No & No & Yes & No \\
\hline Regression Discontinuity Sample & No & No & No & No & No & Yes \\
\hline
\end{tabular}

Notes: The entries report the results from 24 separate regressions, where a census tract is the unit of observation. The samples sizes are 487 in columns (1) through (5) and 227 in column (6). The 1990 and 2000 values of the $\ln$ (median house price) are the dependent variables. The variable of interest is an indicator for NPL status and this variable is instrumented with an indicator for whether the tract had a hazardous waste site with a 1982 HRS score exceeding 28.5. The entries are the regression coefficient and heteroskedastic consistent standard errors (in parentheses) associated with the NPL indicator. See the notes to Table 4, the text and the Data Appendix for further details. 
Table 6: Further 2SLS Estimates of the Effect of NPL Status on 2000 House Prices

\begin{tabular}{|c|c|c|c|c|}
\hline & $(1)$ & $(2)$ & $(3)$ & $(4)$ \\
\hline \multicolumn{5}{|c|}{ A. Add Controls for Ground Water, Surface Water, and Air Migration Pathway Scores } \\
\hline 1(NPL Status by 2000) & $\begin{array}{c}-0.010 \\
(0.053)\end{array}$ & $\begin{array}{l}-0.022 \\
(0.042)\end{array}$ & $\begin{array}{c}0.013 \\
(0.063)\end{array}$ & $\begin{array}{c}0.000 \\
(0.068)\end{array}$ \\
\hline \multicolumn{5}{|c|}{ B. Add Controls for 1970 Covariates } \\
\hline 1(NPL Status by 2000) & $\begin{array}{c}0.037 \\
(0.037)\end{array}$ & $\begin{array}{c}0.028 \\
(0.033)\end{array}$ & $\begin{array}{l}-0.036 \\
(0.072)\end{array}$ & $\begin{array}{c}0.037 \\
(0.056)\end{array}$ \\
\hline \multicolumn{5}{|c|}{ C. Add Controls for 2000 Covariates } \\
\hline 1(NPL Status by 2000) & $\begin{array}{c}0.037 \\
(0.035)\end{array}$ & $\begin{array}{c}0.022 \\
(0.022)\end{array}$ & $\begin{array}{c}-0.044 \\
(0.056)\end{array}$ & $\begin{array}{c}0.010 \\
(0.033)\end{array}$ \\
\hline \multicolumn{5}{|c|}{ D. Does Effect of NPL Status Differ in Tracts in Top Quartile of Population Density? } \\
\hline 1(NPL Status by 2000) & $\begin{array}{c}0.078 \\
(0.042)\end{array}$ & $\begin{array}{c}0.029 \\
(0.032)\end{array}$ & $\begin{array}{c}-0.001 \\
(0.066)\end{array}$ & $\begin{array}{c}0.045 \\
(0.048)\end{array}$ \\
\hline 1(2000 NPL)*1(Top Quartile Density) & $\begin{array}{l}-0.062 \\
(0.077)\end{array}$ & $\begin{array}{c}0.064 \\
(0.056)\end{array}$ & $\begin{array}{c}0.060 \\
(0.055)\end{array}$ & $\begin{array}{l}-0.084 \\
(0.097)\end{array}$ \\
\hline \multicolumn{5}{|c|}{$\begin{array}{c}\text { E. Does Effect of NPL Status Differ in Tracts where the Site has Substantially Polluted Ground } \\
\text { Water and Households Rely on Well Water? }\end{array}$} \\
\hline 1(NPL Status by 2000) & $\begin{array}{c}0.019 \\
(0.047)\end{array}$ & $\begin{array}{c}0.017 \\
(0.035)\end{array}$ & $\begin{array}{c}-0.002 \\
(0.079)\end{array}$ & $\begin{array}{c}0.018 \\
(0.053)\end{array}$ \\
\hline 1(2000 NPL)*1(Possible Contaminated Water Supply) & $\begin{array}{c}-0.007 \\
(0.065)\end{array}$ & $\begin{array}{c}0.016 \\
(0.057)\end{array}$ & $\begin{array}{c}0.024 \\
(0.063)\end{array}$ & $\begin{array}{c}0.011 \\
(0.078)\end{array}$ \\
\hline 1980 Ln House Price & Yes & Yes & Yes & Yes \\
\hline 1980 House Char’s, Econ Conditions, \& Demog’s & No & Yes & Yes & Yes \\
\hline State Fixed Effects & No & Yes & Yes & Yes \\
\hline Quadratic in 1982 HRS Score & No & No & Yes & No \\
\hline Regression Discontinuity Sample & No & No & No & Yes \\
\hline
\end{tabular}

Notes: Each panel reports parameter estimates and standard errors from 4 separate regressions for 2000 housing prices. The panels differ from the Table 5 specifications in the following ways: A. adds controls for the individual pathway scores that are used to calculate the HRS score; B. and C. add controls for the 1970 and 2000 values of the covariates, respectively; D. allows the effect of NPL status to differ in census tracts in the top quartile of population density; and E. allows the effect of NPL status to differ in census tracts where the site has substantially polluted groundwater (i.e., the groundwater pathway score exceeds 28.5) and well water is a significant source of water for households (i.e., the tract is in the top half of well water usage, which is defined as more than $11.8 \%$ of households). The sample sizes in Panel B are 353 (cols 1-3) and 157 (col 4) and otherwise are as in Table 5. See the Notes to Table 5 and the text for further details. 
Table 7: 2SLS Estimates of Stages of Superfund Clean-ups on Rental Rates

\begin{tabular}{|c|c|c|c|c|}
\hline & $(1)$ & $(2)$ & (3) & $(4)$ \\
\hline \multicolumn{5}{|l|}{ Ln (1990 Median Rental Rate) } \\
\hline 1(NPL Only) & 0.107 & 0.027 & -0.016 & 0.034 \\
\hline [100 Sites, Mean HRS = 40.8] & $(0.064)$ & $(0.063)$ & $(0.106)$ & $(0.113)$ \\
\hline 1(ROD \& Incomplete Remediation) & 0.036 & -0.013 & -0.063 & -0.063 \\
\hline [210 Sites, Mean HRS = 44.5] & $(0.048)$ & $(0.050)$ & $(0.094)$ & $(0.073)$ \\
\hline 1(Const Complete or NPL Deletion) & 0.176 & 0.087 & 0.053 & 0.047 \\
\hline [16 Sites, Mean HRS = 35.3] & $(0.111)$ & $(0.105)$ & $(0.132)$ & $(0.135)$ \\
\hline P-Value from F-Test of Equality & 0.23 & 0.48 & 0.38 & 0.45 \\
\hline \multicolumn{5}{|l|}{ Ln (2000 Median Rental Rate) } \\
\hline 1(NPL Only) & 0.234 & 0.040 & -0.044 & -0.020 \\
\hline [15 Sites, Mean HRS = 36.2] & $(0.133)$ & $(0.067)$ & $(0.088)$ & $(0.126)$ \\
\hline 1(ROD \& Incomplete Remediation) & 0.184 & 0.012 & -0.080 & -0.129 \\
\hline [119 Sites, Mean HRS = 44.0] & $(0.044)$ & $(0.035)$ & $(0.068)$ & $(0.058)$ \\
\hline 1(Const Complete or NPL Deletion) & 0.128 & 0.046 & -0.043 & -0.020 \\
\hline [198 Sites, Mean HRS = 42.1] & $(0.039)$ & $(0.032)$ & $(0.062)$ & $(0.049)$ \\
\hline P-Value from F-Test of Equality & 0.30 & 0.58 & 0.50 & 0.16 \\
\hline 1980 Prices/Rental Rate & Yes & Yes & Yes & Yes \\
\hline 1980 Housing Char’s & No & Yes & Yes & Yes \\
\hline 1980 Economic Conditions & No & Yes & Yes & Yes \\
\hline 1980 Demographics & No & Yes & Yes & Yes \\
\hline State Fixed Effects & No & Yes & Yes & Yes \\
\hline Quadratic in 1982 HRS Score & No & No & Yes & No \\
\hline Regression Discontinuity Sample & No & No & No & Yes \\
\hline
\end{tabular}

Notes: Here, the indicator variable for NPL status has been replaced by three independent indicator variables. They are equal to 1 for sites that by 1990 (2000) were placed on the NPL but no ROD had been issued, issued a ROD but remediation was incomplete, and were "construction complete" or deleted from the NPL, respectively. The instruments are the interactions of the indicator for a 1982 HRS score above 28.5 and these three independent indicators. The table reports the instrumental variables parameter estimates and heteroskedastic consistent standard errors for the three indicators of clean-up status. The table also reports the p-value associated with a F-test that the three parameters are equal. The sample sizes for 1990 (2000) are 484 (482), 480 (478), 480 (478), and 226 (224) in columns (1) - (4), respectively. See the text and notes to Table 5 for further details. 
Table 8: 2SLS Estimates of 2000 NPL Status on 2000 Population, Wealth, and Demographics

\begin{tabular}{|c|c|c|c|c|}
\hline & $(1)$ & $(2)$ & (3) & $(4)$ \\
\hline \multicolumn{5}{|c|}{ A. Housing Units and Population Outcomes } \\
\hline Total Housing Units & 238 & 213 & -154 & 64 \\
\hline [1980 Mean: 1,354; 2000 -1980 Mean: 463] & (69) & $(70)$ & $(186)$ & $(120)$ \\
\hline Population & 614 & 491 & 221 & 403 \\
\hline [1980 Mean: 3,756; 2000 -1980 Mean: 891] & $(188)$ & $(190)$ & $(497)$ & (333) \\
\hline \multicolumn{5}{|c|}{ B. Residents' Wealth Outcomes } \\
\hline Household Income & 4,923 & 3,736 & $-4,358$ & -90 \\
\hline [1980 Mean: 20,410; 2000 - 1980 Mean: 36,471] & $(1,757)$ & $(1,951)$ & $(4,151)$ & $(2,186)$ \\
\hline \% Public Assistance & -0.016 & -0.013 & 0.012 & 0.001 \\
\hline [1980 Mean: 0.080; 2000 -1980 Mean: -0.003] & $(0.005)$ & $(0.006)$ & $(0.013)$ & $(0.008)$ \\
\hline$\%$ BA or Better & 0.014 & 0.011 & -0.000 & 0.001 \\
\hline [1980 Mean: 0.124; 2000 -1980 Mean: 0.083] & $(0.011)$ & $(0.012)$ & $(0.026)$ & $(0.016)$ \\
\hline \multicolumn{5}{|c|}{ C. Demographic/Environmental Justice Outcomes } \\
\hline \% Black & -0.022 & -0.026 & 0.040 & 0.000 \\
\hline [1980 Mean: 0.087; 2000 -1980 Mean: 0.026] & $(0.012)$ & $(0.014)$ & $(0.031)$ & $(0.018)$ \\
\hline \% Hispanic & -0.001 & -0.011 & -0.018 & -0.011 \\
\hline [1980 Mean: 0.043; 2000 -1980 Mean: 0.036] & $(0.008)$ & $(0.009)$ & $(0.021)$ & $(0.014)$ \\
\hline \% Population Under Age 6 & -0.004 & -0.002 & 0.001 & 0.001 \\
\hline [1980 Mean: 0.086; 2000 -1980 Mean: -0.018] & $(0.002)$ & $(0.002)$ & $(0.006)$ & $(0.003)$ \\
\hline 1980 Dependent Variable & Yes & Yes & Yes & Yes \\
\hline State Fixed Effects & No & Yes & Yes & Yes \\
\hline Quadratic in 1982 HRS Score & No & No & No & No \\
\hline Reg Discontinuity Sample & No & No & Yes & Yes \\
\hline
\end{tabular}

Notes: The entries report the results from 32 separate instrumental variables regressions. The dependent variables are the underlined entries in the first column and are measured in 2000. The table reports the parameter and heteroskedastic consistent standard error associated with an indicator variable that equals 1 for observations from tracts with a hazardous waste site that was placed on the NPL by 2000. The indicator is instrumented with an indicator for whether the hazardous waste site had a 1982 HRS score exceeding 28.5. There are 487 observations in the columns (1) - (3) specifications and 227 in column (4). The entries in brackets are the mean of the dependent variable in 1980 and the mean of the difference between the 2000 and 1980 values. See the text and Notes to Table 5 for further details. 
Appendix Table 1: 2SLS Estimates of the Effect of NPL Status on House Prices

(1) (2)

(3)

(4)

(5)

(6)

A. Houses within 1 Mile of Hazardous Waste Site

$\underline{1990}$

1(NPL Status by 1990)

$\begin{array}{cccccc}0.035 & 0.086 & 0.069 & 0.010 & 0.101 & 0.028 \\ (0.053) & (0.048) & (0.044) & (0.042) & (0.087) & (0.070)\end{array}$

$\underline{2000}$

1(NPL Status by 2000)

$\begin{array}{cccccc}0.046 & 0.046 & 0.047 & 0.028 & 0.065 & 0.021 \\ (0.034) & (0.029) & (0.027) & (0.025) & (0.060) & (0.036)\end{array}$

B. Houses within 2 Miles of Hazardous Waste Site

1990

1(NPL Status by 1990)

$\begin{array}{cccccc}0.027 & 0.056 & 0.047 & -0.009 & 0.007 & -0.037 \\ (0.048) & (0.043) & (0.039) & (0.034) & (0.070) & (0.057)\end{array}$

$\underline{2000}$

1(NPL Status by 2000)

$\begin{array}{cccccc}0.023 & 0.005 & 0.020 & 0.007 & 0.015 & -0.007 \\ (0.032) & (0.029) & (0.026) & (0.023) & (0.052) & (0.033)\end{array}$

C. Houses within 3 Miles of Hazardous Waste Site

1990

1(NPL Status by 1990)

$\begin{array}{cccccc}0.063 & 0.060 & 0.038 & -0.018 & -0.033 & -0.037 \\ (0.049) & (0.041) & (0.036) & (0.029) & (0.061) & (0.049)\end{array}$

$\underline{2000}$

1(NPL Status by 2000)

$\begin{array}{cccccc}0.054 & 0.024 & 0.026 & 0.001 & -0.032 & -0.007 \\ (0.038) & (0.031) & (0.026) & (0.021) & (0.051) & (0.034)\end{array}$

1980 Ln House Price

Yes Yes Yes $\quad$ Yes $\quad$ Yes $\quad$ Yes

1980 House, Econ \& Demog Vars

No

Yes

Yes

Yes

Yes

Yes

State Fixed Effects

No No

No

Yes

Yes

Yes

Quadratic in 1982 HRS Score

No

No

No

No

Yes

No

Regression Discontinuity Sample

No No

No

No

No

Yes

Notes: The entries report the parameter estimate and heteroskedastic consistent standard error on NPL indicators from 36 separate regressions. Here, the dependent variable and all controls are calculated as the weighted average across the portion of tracts that fall within circles of radius 1 mile (Panel A), 2 miles (Panel B), and 3 miles (Panel C) around the hazardous waste sites with a 1982 HRS score. The weight is the portion of the census tract that falls within the relevant circle multiplied by the tract's 1980 population. The sample sizes are 483 (columns 1-5) and 226 (column 6) in all Panels. The 1980 aggregate values of the housing stock in the three circles are roughly $\$ 300, \$ 755$, and $\$ 1,410$ million (2000 \$'s). See the text for further details. 
Figure 1: Geographic Distribution of NPL Hazardous Waste Sites in the All NPL Sample

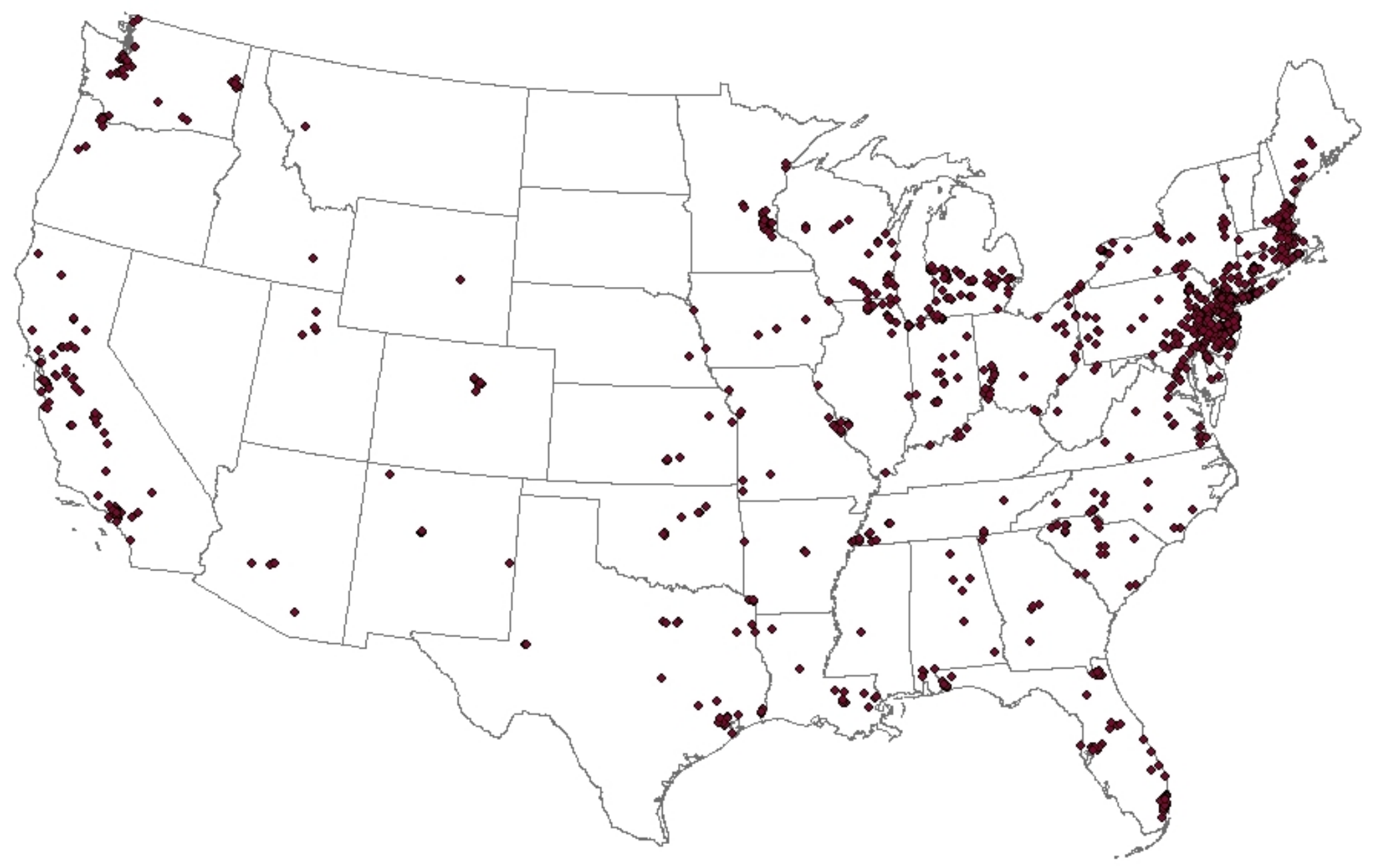

Notes: The All NPL sample is comprised of the 985 hazardous waste sites assigned to the NPL by January 1, 2000 that we placed in a census tract with nonmissing housing price data in 1980, 1990, and 2000. 
Figure 2: Geographic Distribution of Hazardous Waste Sites in the 1982 HRS Sample

A. Sites with 1982 HRS Scores Exceeding 28.5

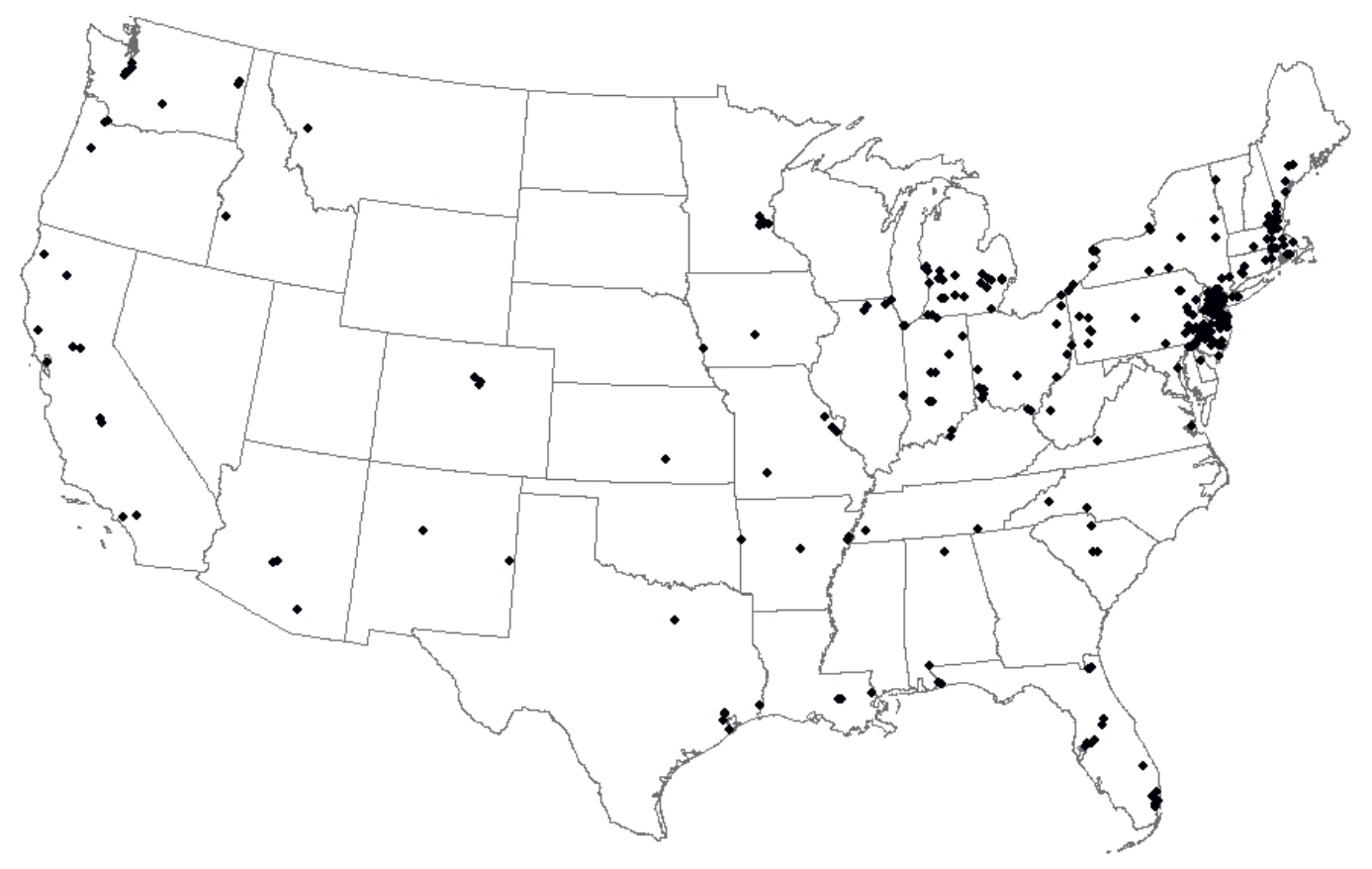

B. Sites with 1982 HRS Scores Below 28.5

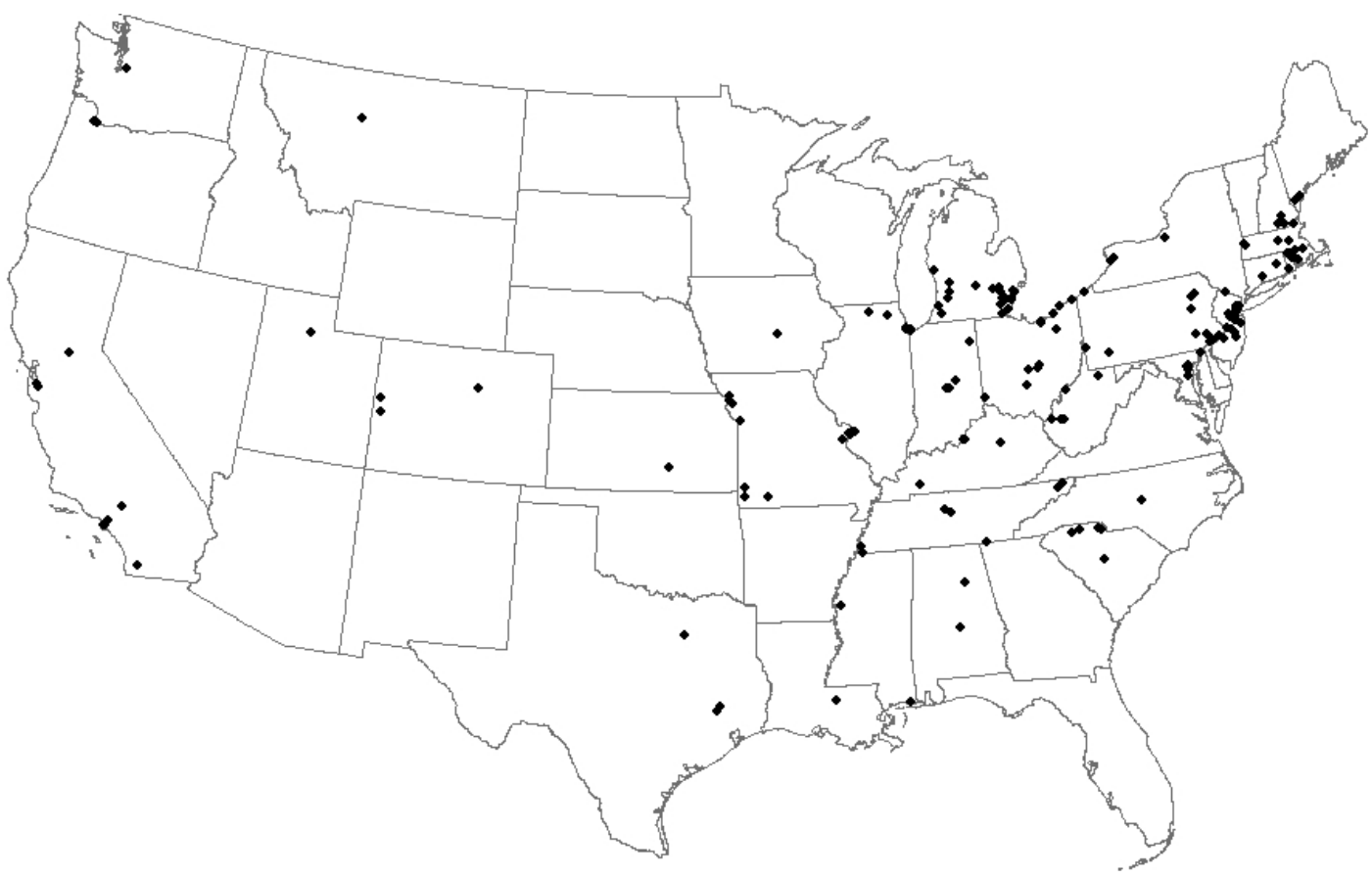

Notes: The 1982 HRS Sample is comprised of the 487 hazardous waste sites that were placed in a census tract with nonmissing housing price data in 1980, 1990, and 2000. 306 (181) of these sites had 1982 HRS scores above (below) 28.5. 
Figure 3: Distribution of 1982 HRS Scores

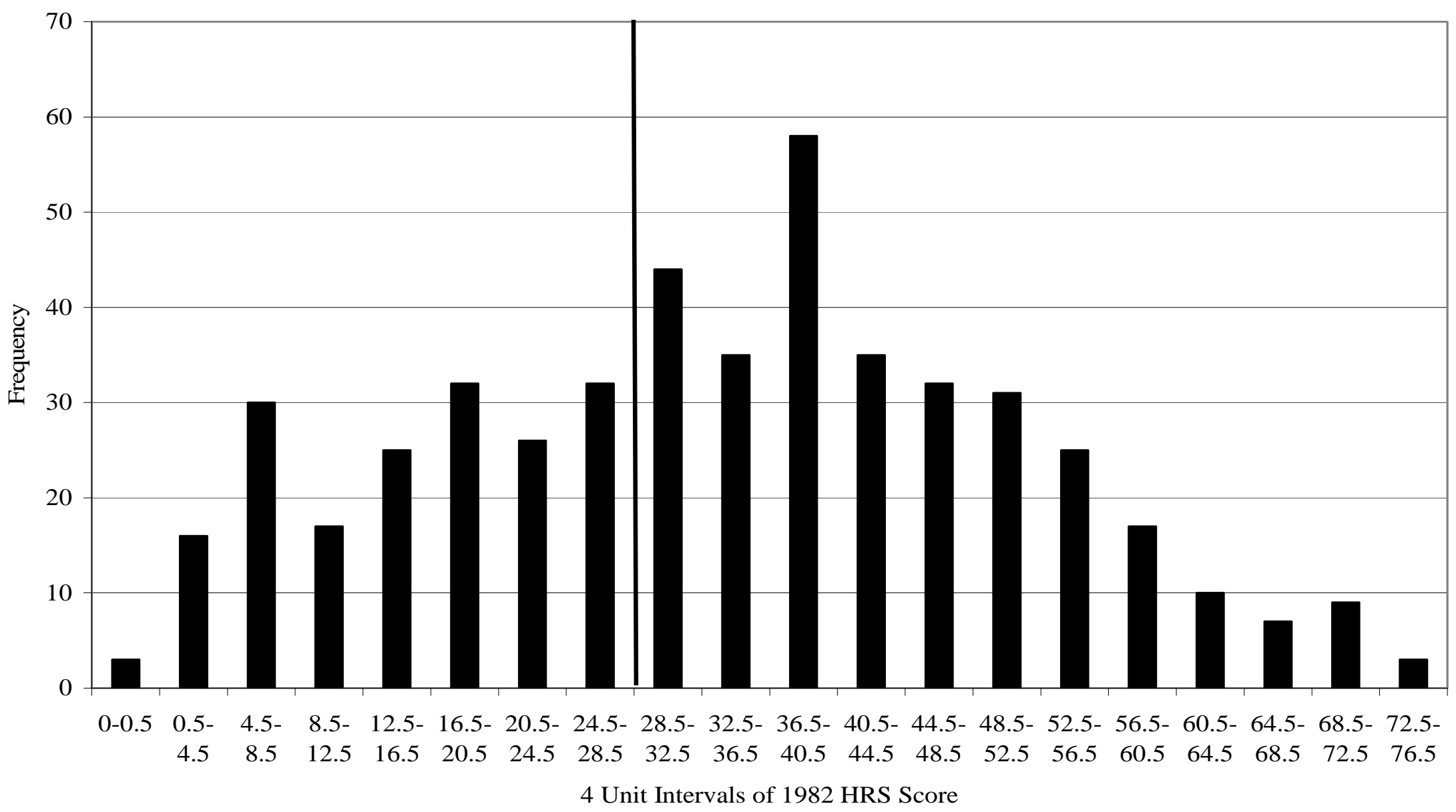

Notes: The figure displays the distribution of 1982 HRS scores among the 487 hazardous waste sites that were tested for placement on the NPL after the passage of the Superfund legislation but before the announcement of the first NPL in 1983. The 188 sites with missing housing data in 1980, 1990, or 2000 are not included in the subsequent analysis and hence are excluded from this figure. The vertical line at 28.5 represents the cut-off that determined eligibility for placement on the NPL. 
Figure 4: Estimated Costs of Remediation from Initial Record of Decision, by 4 Unit Intervals of the 1982 HRS Score

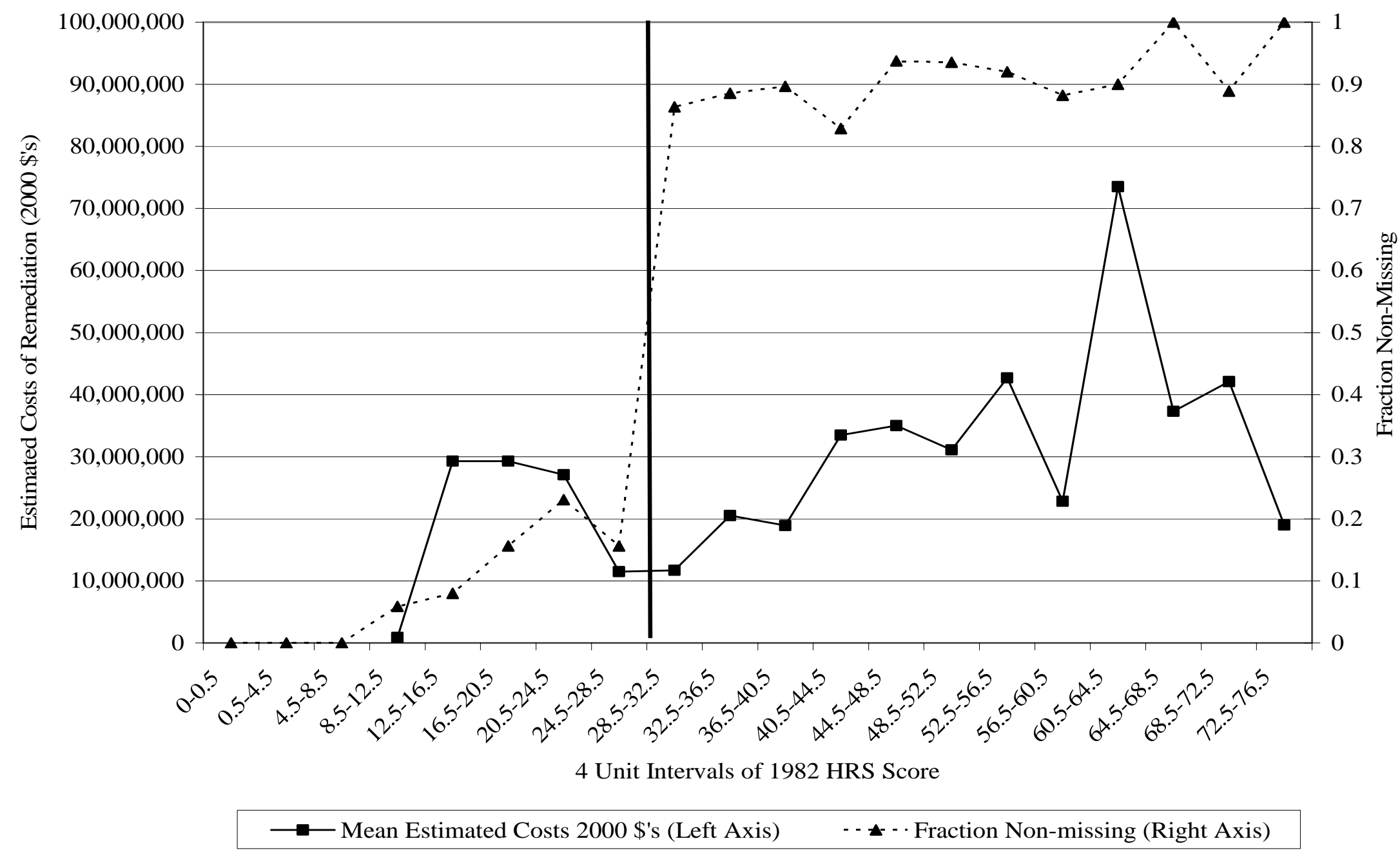

Notes: The figure plots the mean estimated costs (full line) for complete remediation by 4-unit intervals of the sites’ 1982 HRS score. The estimated costs are derived from each site's first ROD. The dotted line represents the fraction of sites in each 4-unit interval with non-missing cost data. The vertical line denotes the 28.5 threshold. See the text and Data Appendix for further details. 
Figure 5: Probability of Placement on the NPL by 1982 HRS Score

A. NPL Status by 1990

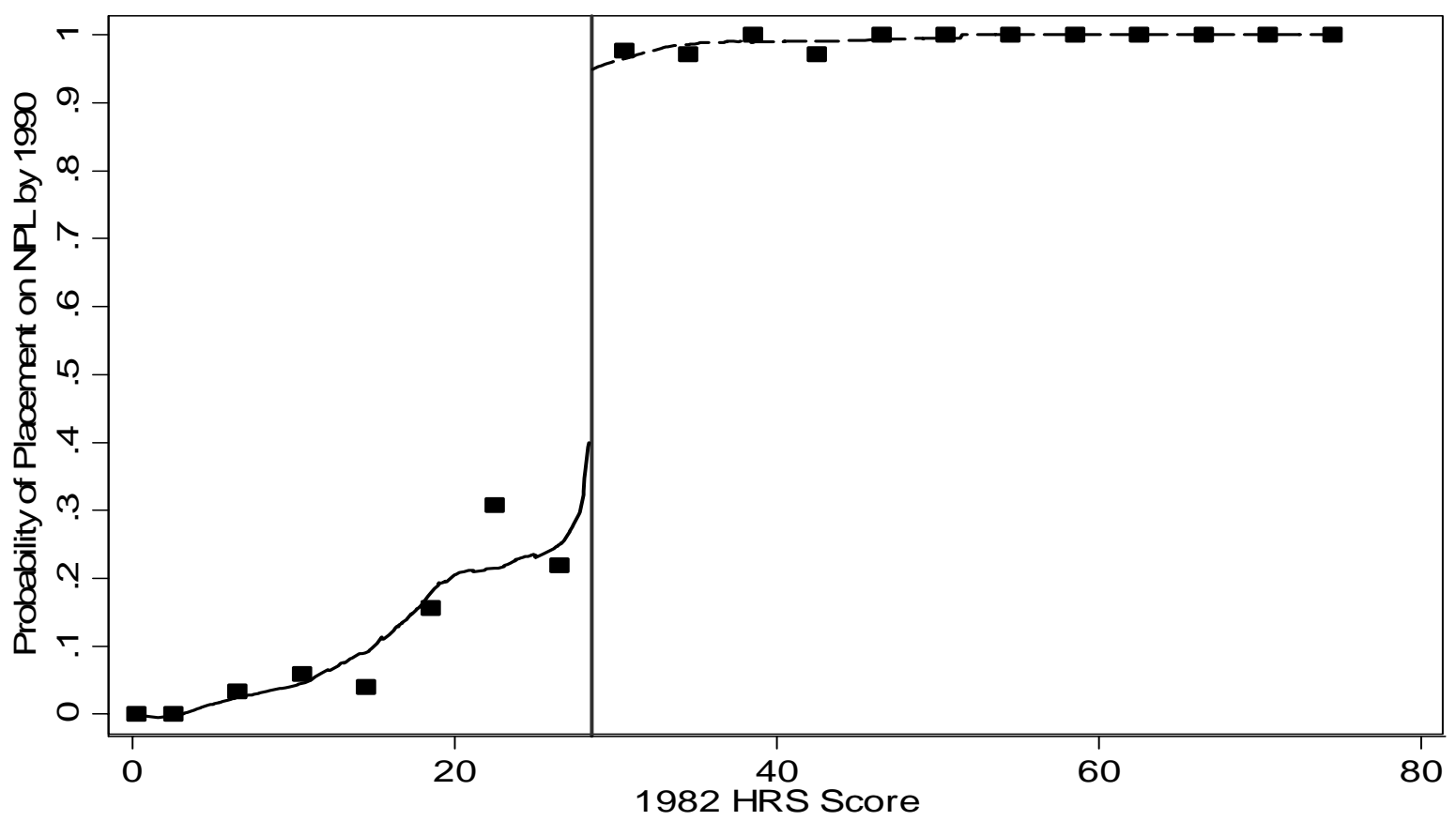

B. NPL Status by 2000

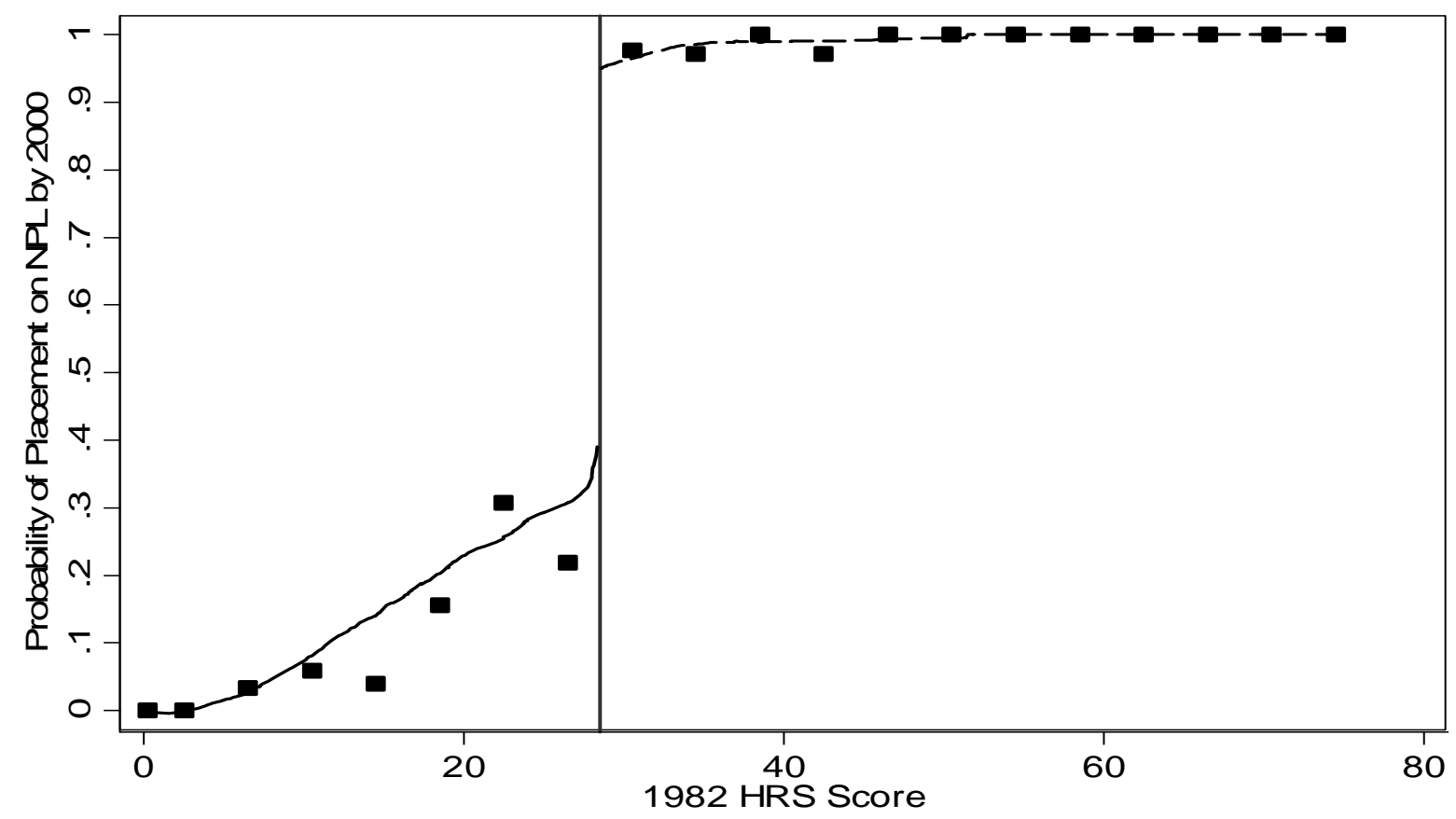

Notes: Each figure plots the bivariate relation between the probability of 1990 (Panel A) and 2000 (Panel B) NPL status and the 1982 HRS score among the 487 sites in the 1982 HRS sample. The plots are done separately for sites above (dashed line) and below (full line) the 28.5 threshold and come from the estimation of nonparametric regressions that use Cleveland's (1979) tricube weighting function and a bandwidth of 0.5 . The data points present the mean probabilities in the same 4-unit intervals of the HRS score as in Figures 3 and 4. See the text for further details. 
Figure 6: 1980 Residual House Prices After Adjustment for Column 4 Covariates

A. Full 1982 HRS Sample

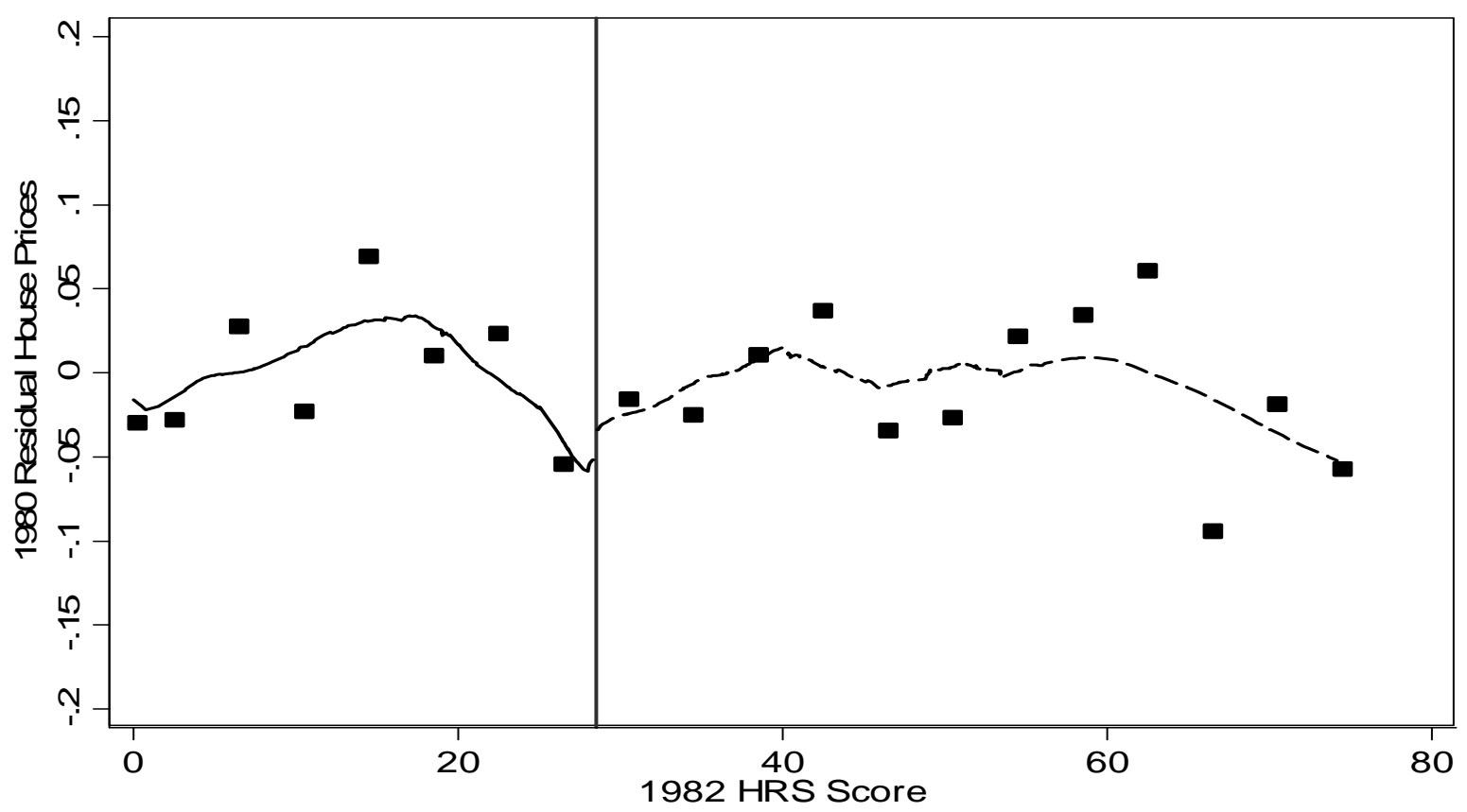

B. Regression Discontinuity Sample

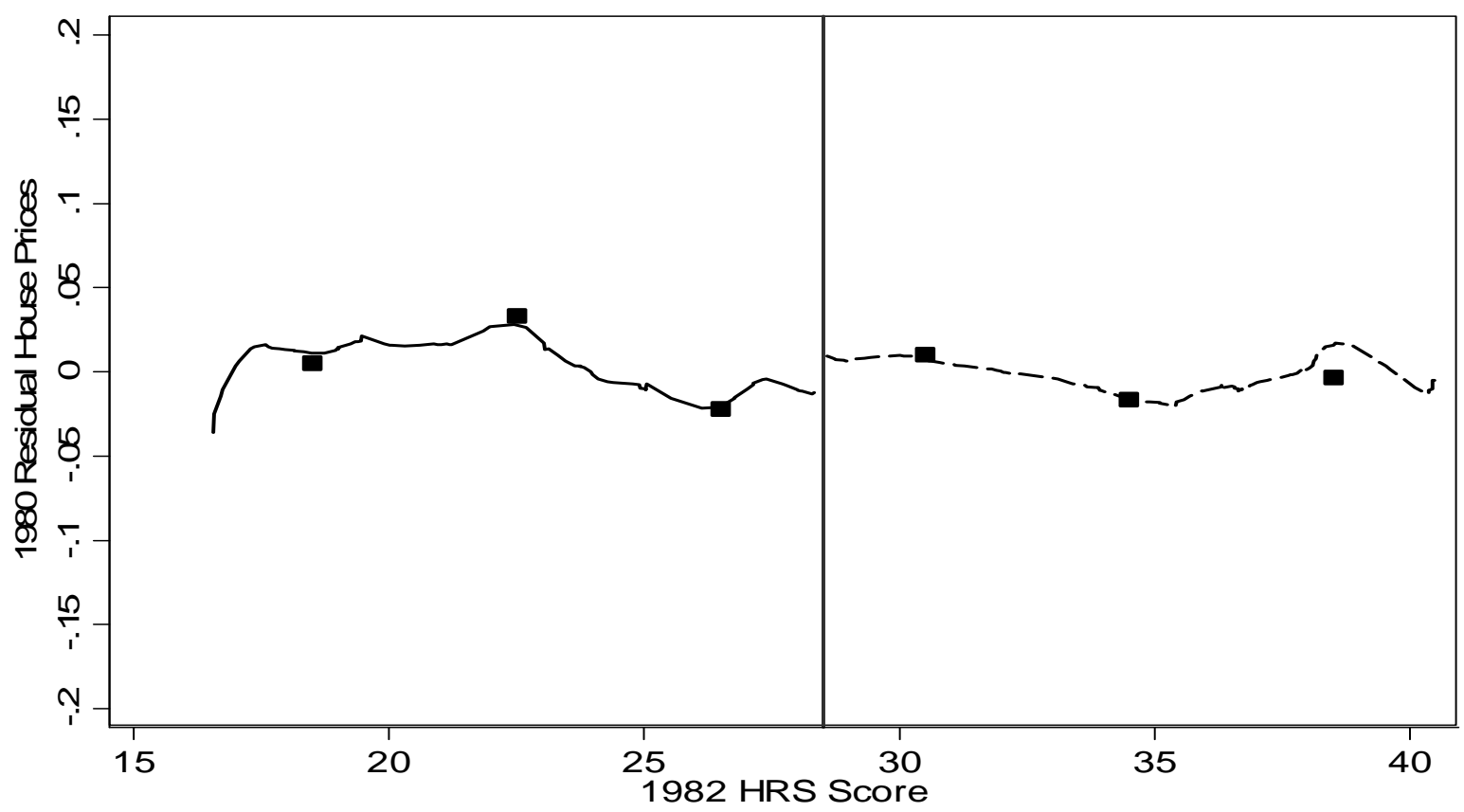

Notes: Each figure plots the results from nonparametric regressions between 1980 residual housing prices after adjustment for the covariates in the column (4) specification of Table 4 (except the indicator for a HRS score above 28.5) and the 1982 HRS scores. The nonparametric regressions use Cleveland's (1979) tricube weighting function and a bandwidth of 0.5. These plots are done separately for sites above (dashed line) and below (full line) the 28.5 threshold. The All NPL sample is used in Panel A, while Panel B uses the regression discontinuity sample. The data points present the mean probabilities in the same 4-unit intervals of the HRS score as in Figures 3 and 4 . See the text for further details. 
Figure 7: Own Tract 2000 Residual House Prices After Adjustment for Column 4 Covariates

A. Full 1982 HRS Sample

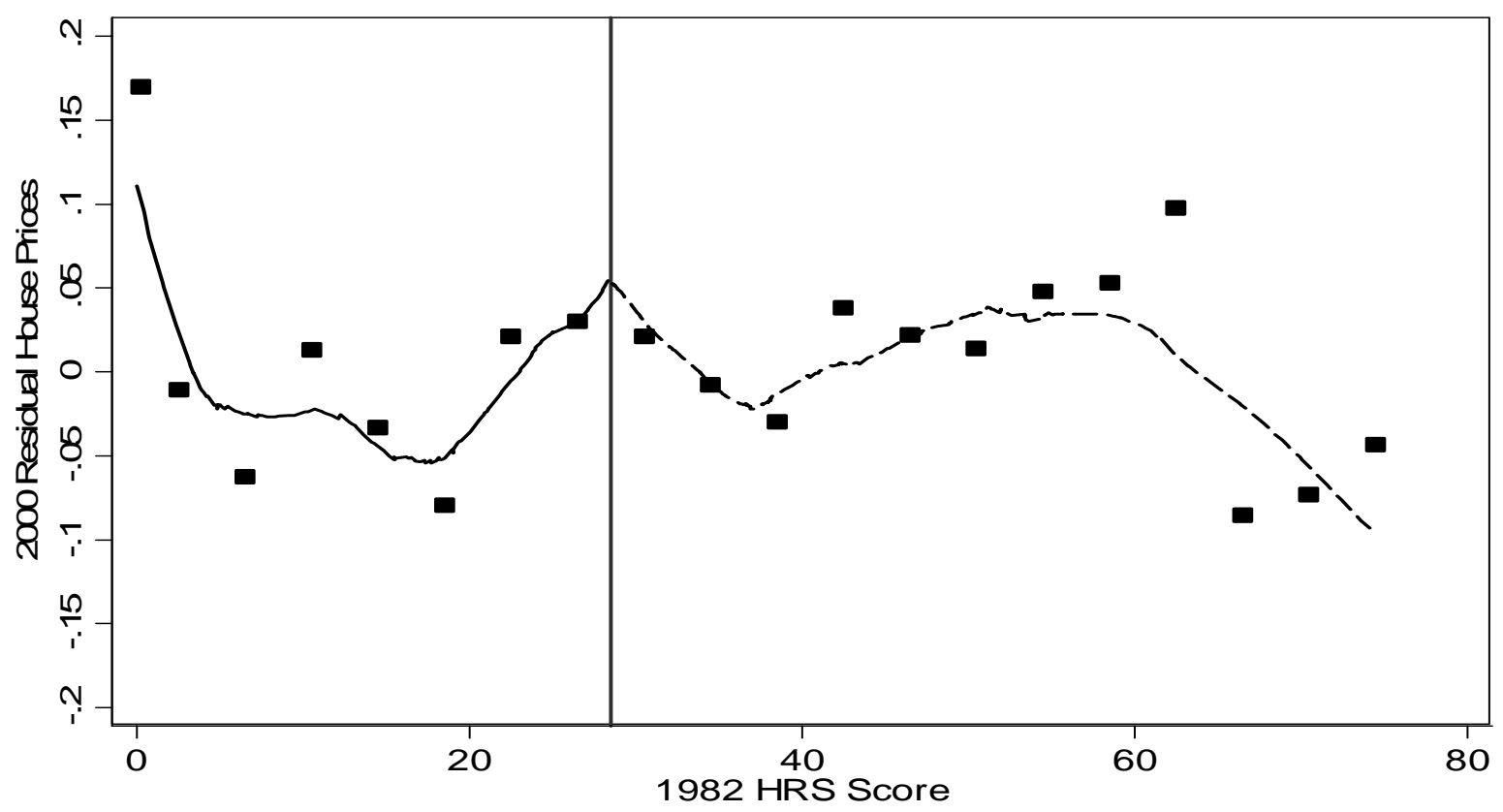

B. Regression Discontinuity Sample

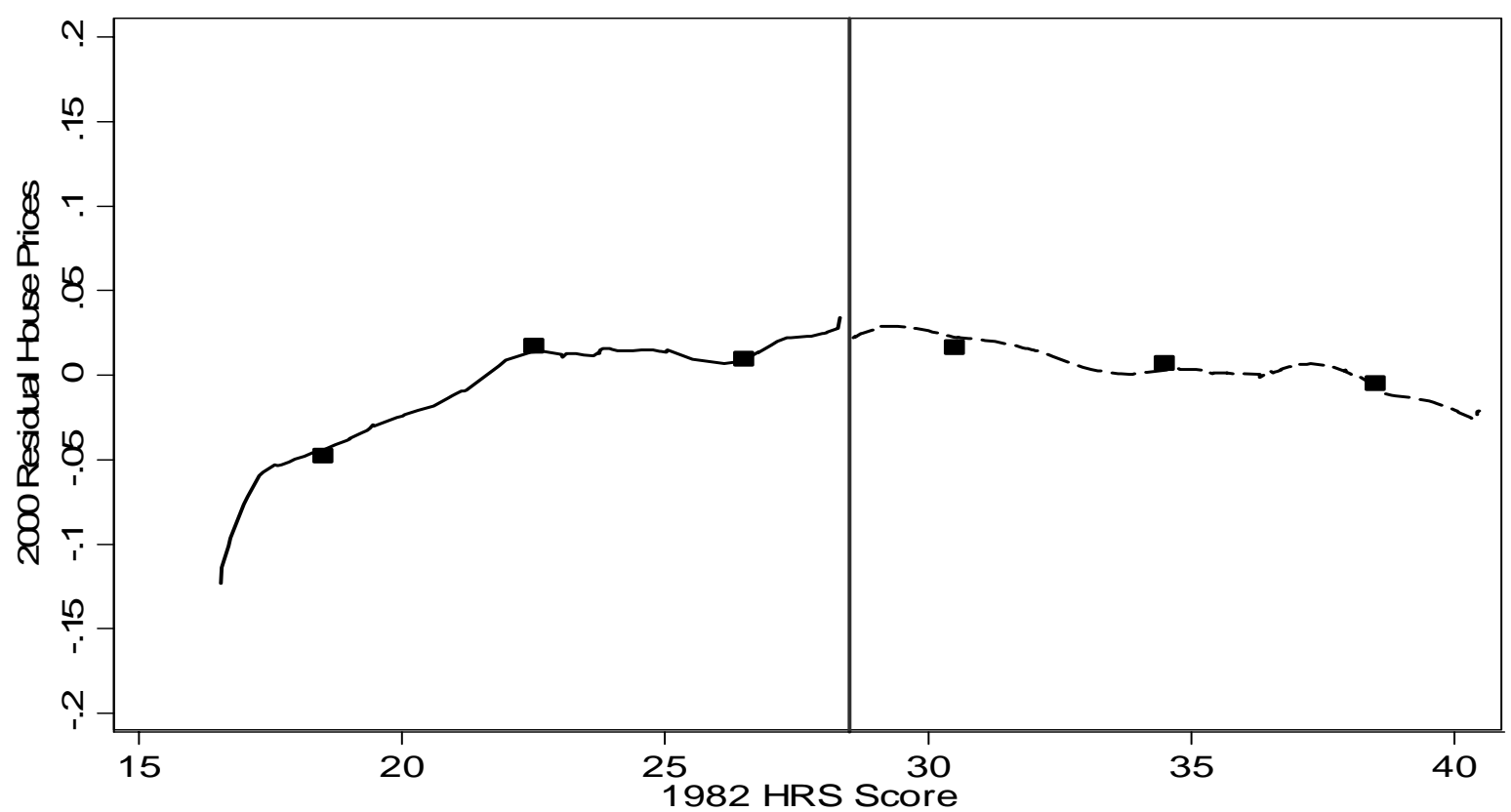

Notes: Each figure plots the results from nonparametric regressions between own tract 2000 residual housing prices after adjustment for the covariates in the column (4) specification of Table 5 (except the indicator for a HRS score above 28.5) and the 1982 HRS scores. The nonparametric regressions use Cleveland's (1979) tricube weighting function and a bandwidth of 0.5. These plots are done separately for sites above (dashed line) and below (full line) the 28.5 threshold. The All NPL sample is used in Panel A, while Panel B uses the regression discontinuity sample. The data points present the mean probabilities in the same 4-unit intervals of the HRS score as in Figures 3 and 4. See the text for further details. 
Figure 8: Adjacent Tracts 2000 Residual House Prices After Adjustment for Column 4 Covariates

A. Full 1982 HRS Sample

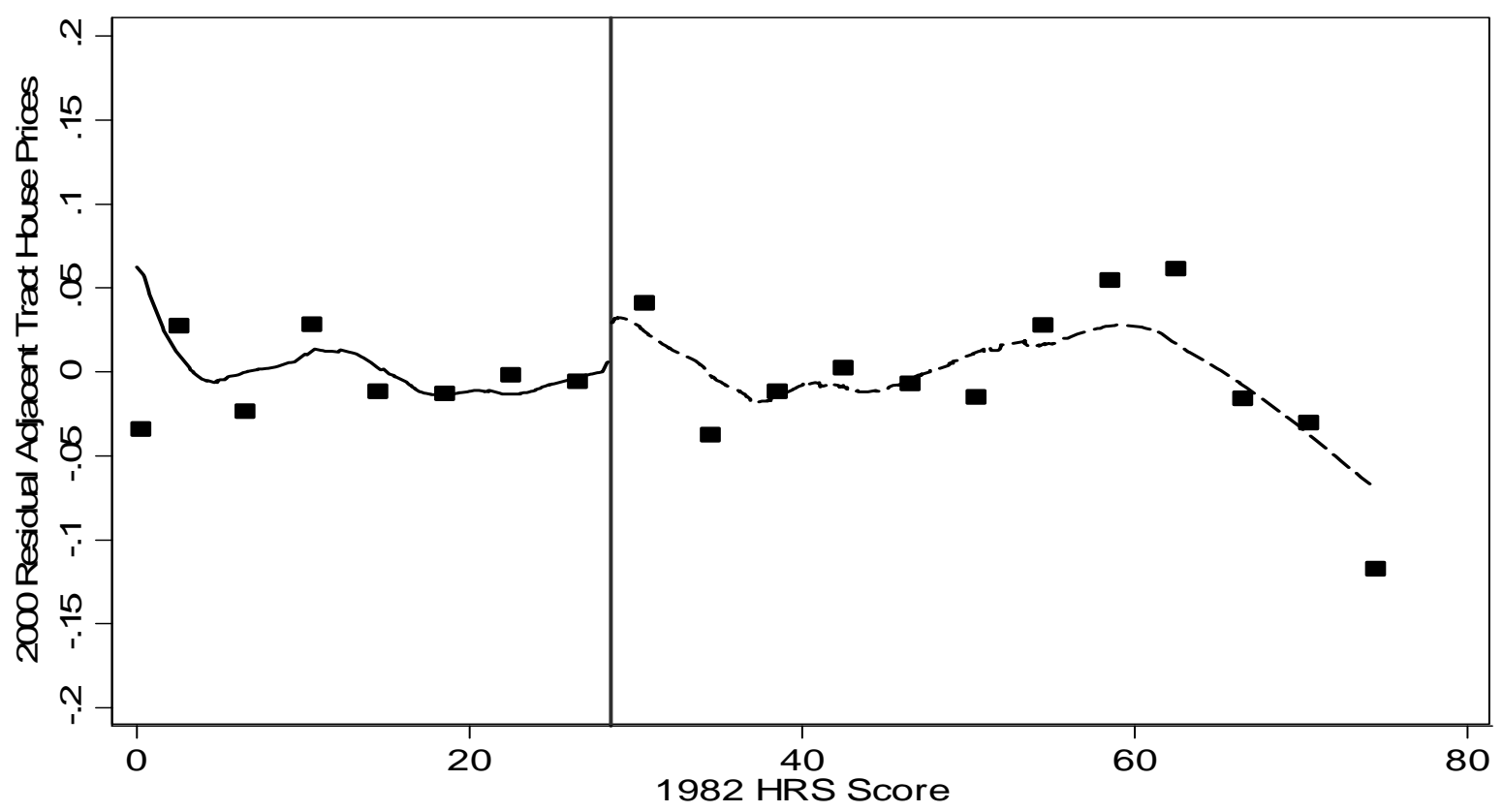

B. Regression Discontinuity Sample

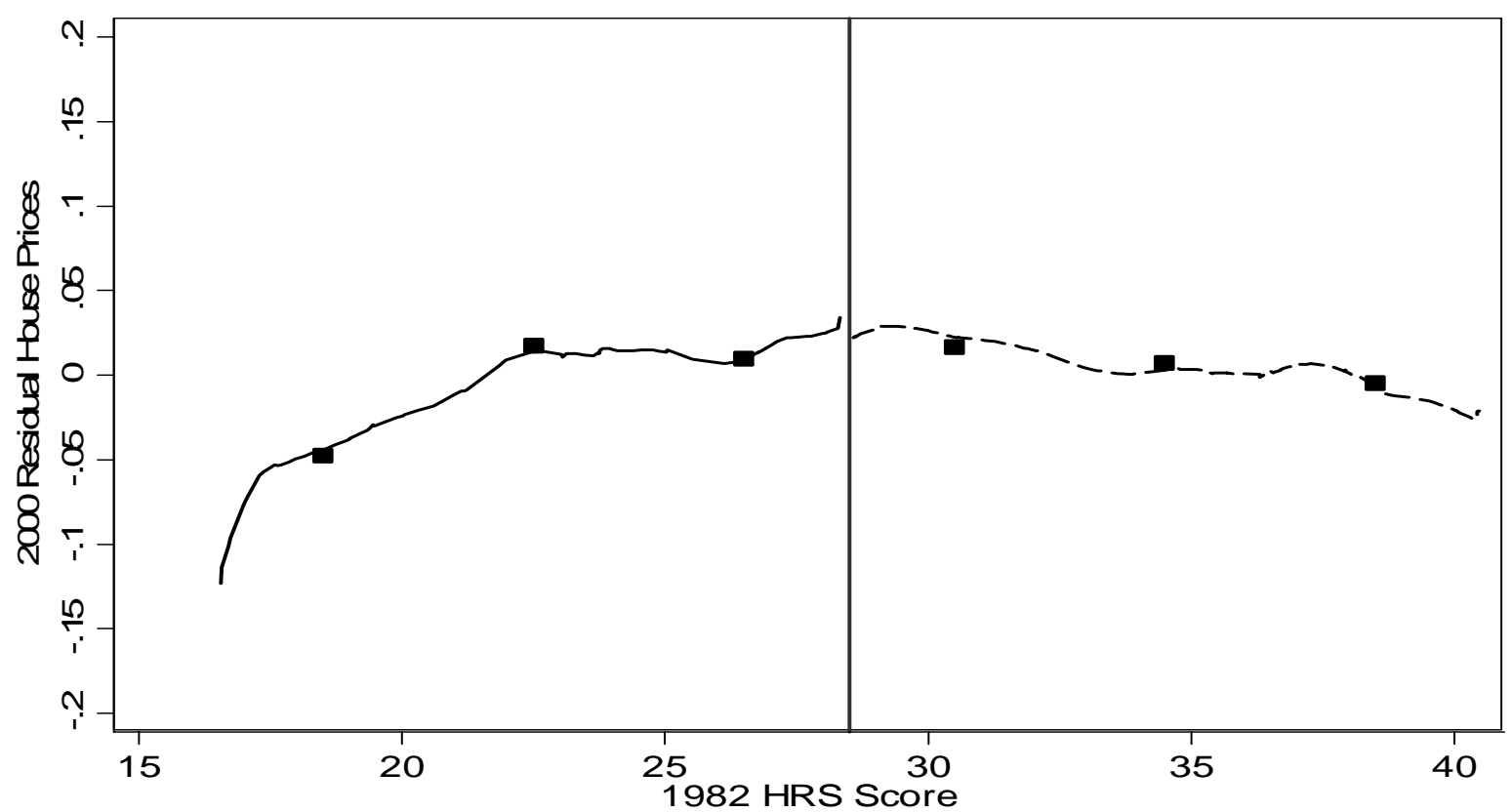

Notes: Each figure plots the results from nonparametric regressions between adjacent tract 2000 residual housing prices after adjustment for the covariates in the column (4) specification of Table 5 (except the indicator for a HRS score above 28.5) and the 1982 HRS scores. The nonparametric regressions use Cleveland's (1979) tricube weighting function and a bandwidth of 0.5. These plots are done separately for sites above (dashed line) and below (full line) the 28.5 threshold. The All NPL sample is used in Panel A, while Panel B uses the regression discontinuity sample. The data points present the mean probabilities in the same 4-unit intervals of the HRS score as in Figures 3 and 4. See the text for further details. 
Figure 9: 2000 Residual Own Tract Population After Adjustment for Column 2 Covariates

A. Full 1982 HRS Sample

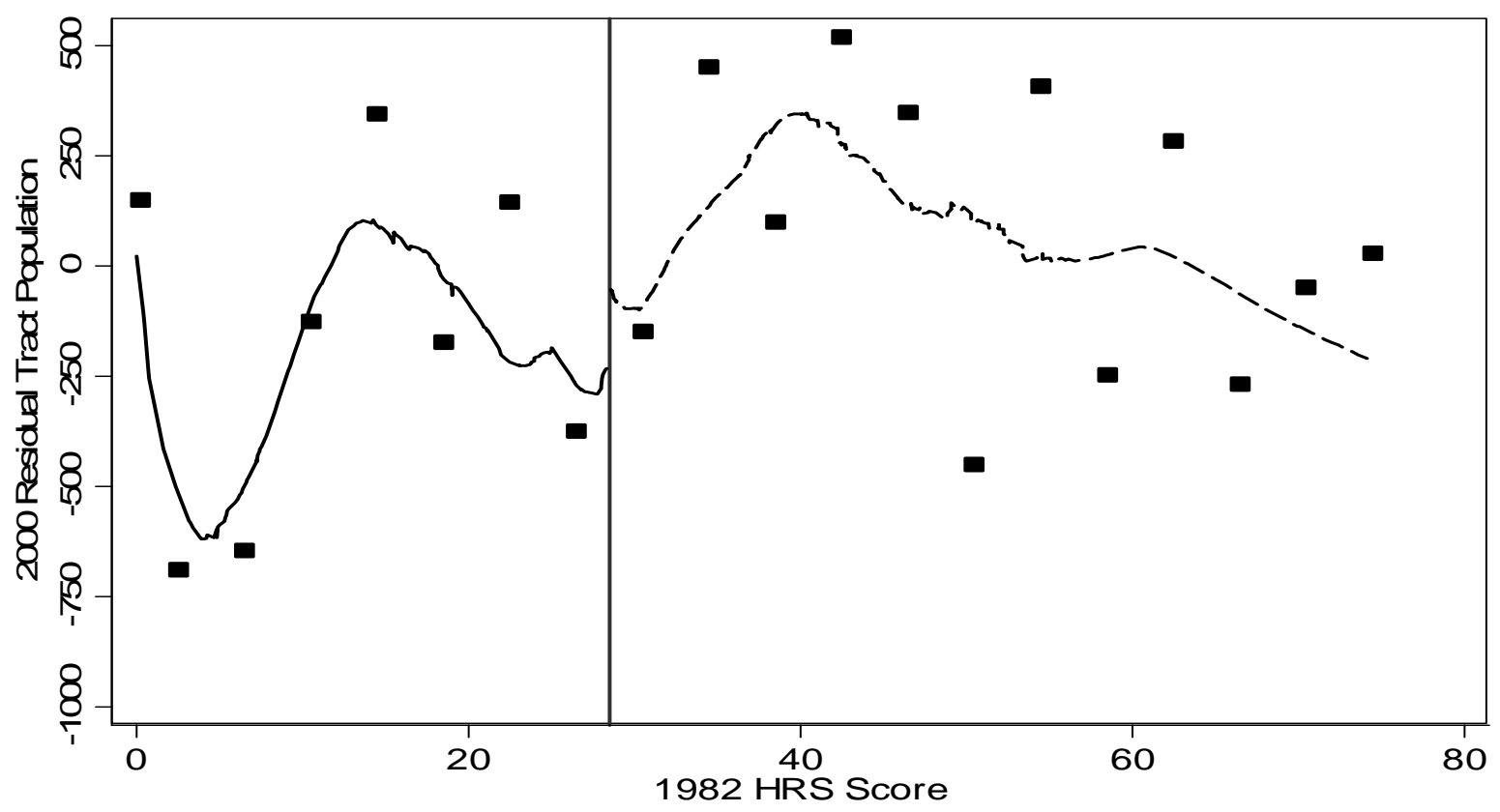

B. Regression Discontinuity Sample

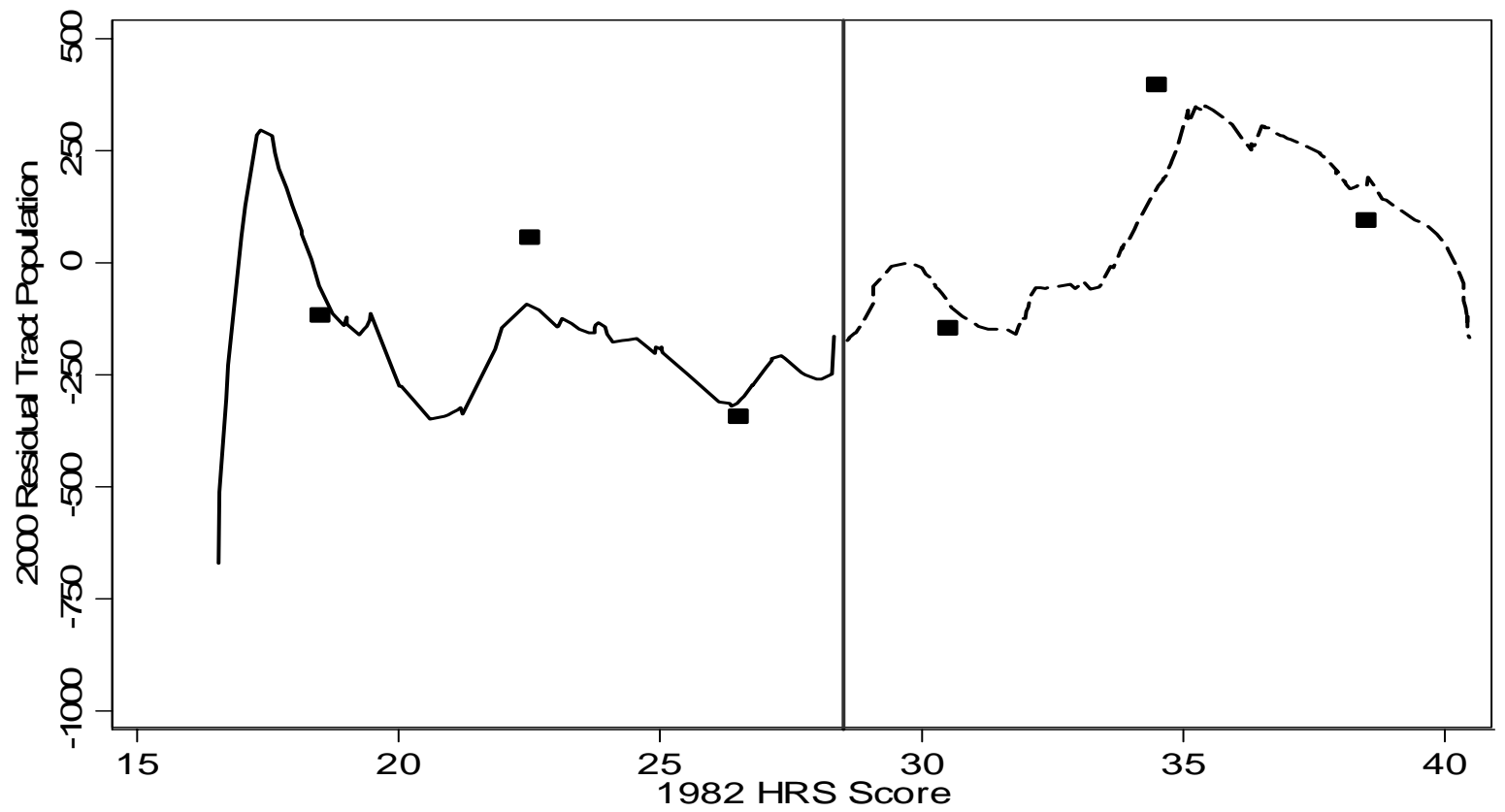

Notes: Each figure plots the results from nonparametric regressions between 2000 residual own tract population after adjustment for the covariates in the column (4) specification of Table 8 (except the indicator for a HRS score above 28.5) and the 1982 HRS scores. The nonparametric regressions use Cleveland's (1979) tricube weighting function and a bandwidth of 0.5. These plots are done separately for sites above (dashed line) and below (full line) the 28.5 threshold. The All NPL sample is used in Panel A, while Panel B uses the regression discontinuity sample. The data points present the mean probabilities in the same 4-unit intervals of the HRS score as in Figures 3 and 4. See the text for further details. 